\title{
Die Makrofauna und ihre Verteilung im Nordost- Felswatt von Helgoland
}

\author{
Klaus Janke \\ Zoologisches Institut der Universität Kiel; \\ Olshausenstr. 40-60, D-2300 Kiel 1 \\ und \\ Biologische Anstalt Helgoland (Meeresstation); \\ D-2192 Helgoland, Bundesrepublik Deutschland
}

\begin{abstract}
Macrofauna and its distribution in the northeastern rocky intertidal zone of the island of Helgoland. The macrofauna and its distribution in the sheltered, rocky intertidal zone of Helgoland (North Sea) was studied at 9 vertically and/or morphologically different stations from March to September in 1984. Seasonal variations in the communities were described based on each species' "conspicuousness". A total of 172 species was found. The macrofauna shows a zoned pattern, but also the different substrata, for example, affect its distribution. The number of species increases from the upper intertidal to the upper sublittoral zone from 23 to 133 species. The upper intertidal is characterized by Littorina saxatilis, Chaetogammarus marinus and Hyale nilssonii. Typical and abundant species of the middle and lower intertidal are Flustrellidra hispida, Littorina mariae/obtusata, Littorina littorea, Mytilus edulis and Spirorbis spirorbis. The upper sublittoral zone is characterized by Gibbula cineraria and increasing species numbers of Bryozoa, Nemertini and Opisthobranchia. Only few species (e.g. Dynamena pumila, Laomedea flexuosa, Polydora ciliata, Fabricia sabella, Jaera albifrons, Carcinus maenas) occur in the entire intertidal zone. In comparison to other very sheltered shores in Great Britain, which are also dominated by Fucaceae, the macrofauna in the Helgoland intertidal zone lacks several littoral species, such as Patella spp., Monodonta lineata, Gibbula umbilicalis, Littorina neritoides, Chthamalus spp., whereas Littorina littorea and Gibbula cineraria are highly abundant.
\end{abstract}

\section{EINLEITUNG}

Artenspektrum und Verteilung der Makrofauna im Gezeitenbereich borealer Felsküsten sind bereits häufig untersucht worden (z. B. Colman, 1933; Crisp \& Southward, 1958; Evans, 1947a, 1947b, 1949, 1957; Lewis, 1964; Moyse \& Nelson-Smith, 1963; Southward, 1958; Stephenson \& Stephenson, 1949, 1972). Beschrieben wurden ausgeprägte vertikale Verteilungsmuster der Makrofauna und Algen in Abhängigkeit von periodisch steigenden und fallenden Wasserständen und der Exposition durch Wellenschlag. Ballantine (1961), Crisp \& Southward (1958) und Moyse \& Nelson-Smith (1963) ordneten für Freilandbeobachtungen den ökologisch wichtigen Arten eigene Indizes zur Abschätzung der Häufigkeit zu. Ballantine (1961), Dalby et al. (1978) und Lewis (1964) stellten zudem einen direkten Zusammenhang zwischen der Besiedlungsstruktur und der Exposition her. Newell (1979) faßte wichtige Ergebnisse zur physiologischen Anpassung einzelner Arten an ihren Lebensraum zusammen. Neuere Untersuchungen 
erbrachten Erkenntnisse zur Dynamik und Entwicklung litoraler Lebensgemeinschaften (z. B. Connell, 1961, 1972; Hawkins \& Hartnoll, 1983; Jackson 1977a, 1977b; Lubchenco, 1980, 1982; Lubchenco \& Menge, 1978; Menge 1976, 1978a, 1978b; Osman, 1977; Paine, 1974). Luther (1976a, 1976b, 1977) beobachtete den Bewuchs und die Neubesiedlung verschiedener natürlicher und künstlicher Substrate im Gezeitenbereich. Von großer methodischer Bedeutung waren ebenfalls die Untersuchungen von Reise $(1977,1978)$, Lein $(1980,1984)$ und Cubit (1984). Eine zusammenfassende Darstellung neuerer Untersuchungsmethoden legten Price et al. (1980) vor.

Die vorliegende Arbeit behandelt das Artenspektrum und die Verteilung der Makrofauna im Helgoländer Eulitoral. Folgende Fragen standen im Mittelpunkt: (a) Welche Makrofauna-Arten leben im Helgoländer Eulitoral, und wie sind sie in ihrem Lebensraum verteilt? (b) Existiert für die Makrofauna eine vertikale Zonierung, wie sie z.B. von Lewis (1964) und Stephenson \& Stephenson (1972) für vergleichbare felsige Meeresküsten beschrieben worden ist? (c) Läßt sich anhand der Besiedlungsstrukturen der Expositionsgrad nach Ballantine (1961) abschätzen, und welche Unterschiede weist die Helgoländer Besiedlung gegenüber Gemeinschaften an vergleichbaren britischen Küsten auf?

Auch auf Helgoland wurde schon vor der Jahrhundertwende damit begonnen, die Besiedlung der die Insel umgebenden Hartböden zu untersuchen. So wurden nach der umfassenden Bearbeitung durch Dalla-Torre (1889) einzelne taxonomische Gruppen von Attems (1896), Ehrenbaum (1896), Hartlaub (1896), Hartmeyer (1908), Heincke (1894a, 1894b, 1896), Lauterborn (1894), Skolowsky (1900), Timm (1894) und Weltner (1896) für die Helgoländer Region beschrieben. Erst sehr viel später folgten weitere Untersuchungen von Dörjes (1968) und Ziegelmeier (1957, 1966). Hagmeier (1930) beschrieb das Eulitoral und dessen Morphologie. Seine Absicht, diese Arbeit durch eine Untersuchung zur Makrofauna zu vervollständigen, konnte er nicht mehr verwirklichen. Caspers (1938) legte eine zusammenfassende Darstellung zur Bodenfauna der "Tiefen Rinne" vor und ergänzte sie durch Arbeiten zur Besiedlung der Helgoländer Austernbänke (Caspers, 1950) und Seetonnen (Caspers, 1952). Anger (1978) und Harms \& Anger (1983) untersuchten die Entwicklung sublitoraler Lebensgemeinschaften bei Helgoland. Auch die Algenbesiedlung rund um die Insel ist ausführlich beschrieben worden (z. B. Kornmann \& Sahling, 1977; Lüning, 1970; Markham \& Munda, 1980; Munda \& Markham, 1982; Nienburg, 1930). In der Gezeitenzone sind in neuerer Zeit nur die Polychaeta (Gillandt, 1979a, 1979b) ausführlich bearbeitet worden. Eine zusammenfassende Untersuchung zur Makrofauna im Helgoländer Felswatt zwischen der mittleren Tidenhochwasserbinie (MTHWL) und der mittleren Tidenniedrigwasserlinie (MTNWL) fehlt jedoch. Die vorliegende Arbeit stellt einen ersten Versuch dar, diese Lücke zu schließen.

\section{DAS UNTERSUCHUNGSGEBIET}

\section{Lage, Entstehung und Gliederung}

Helgoland ist die einzige Felseninsel in der südlichen Nordsee. Die Entstehung, die Abfolge der Gesteinsschichten und die Einflüsse durch Witterung, Gezeiten und durch den Menschen sind u. a. von Hillmer et al. (1979), Krumbein (1975, 1977), Pratje (1948), Schmidt-Thomé (1937) und Wurster (1962) ausführlich beschrieben worden. Im Norden, 
Westen und Süden ist die heutige Hauptinsel von einer Abrasionsterrasse umgeben, deren obere Schichten von der See abgetragen worden sind. Ein Teil dieses Sockels fällt in Abhängigkeit von den Gezeiten periodisch trocken. Dieser wird auf Helgoland als "Felswatt" bezeichnet (Hagmeier, 1930; Krumbein, 1975). In den Jahren 1903 bis 1942 wurde entlang der Westseite eine ca. $6 \mathrm{~m}$ hohe Schutzmauer errichtet, die in ihrer letzten Bauphase bis weit über die Nordspitze verlängert wurde (Krumbein, 1975). Sie teilt die Abrasionsterrasse in das Westwatt und das Nordostwatt. In die gleiche Zeit fallen auch künstlich angespülte Landgewinne an der Ostseite der Insel und der Bau eines Hafens im Süden. Nur die Nordostseite gibt heute noch einen annähernd authentischen Eindruck der ursprünglichen Verhältnisse am Felsfuß wieder. Sie befindet sich im Wellenschatten der Nordwestmole.

Für die vorliegende Untersuchung wurde das Nordostwatt gewählt. Es wird nach Norden durch die offene See und nach Süden von dem steil aufragenden Buntsandsteinfels der Hauptinsel begrenzt. Den Abschluß nach Nordwesten bildet die o.g. Schutzmauer. Im Südosten schließt sich der Nordstrand an. Das Nordostwatt ist die einzige

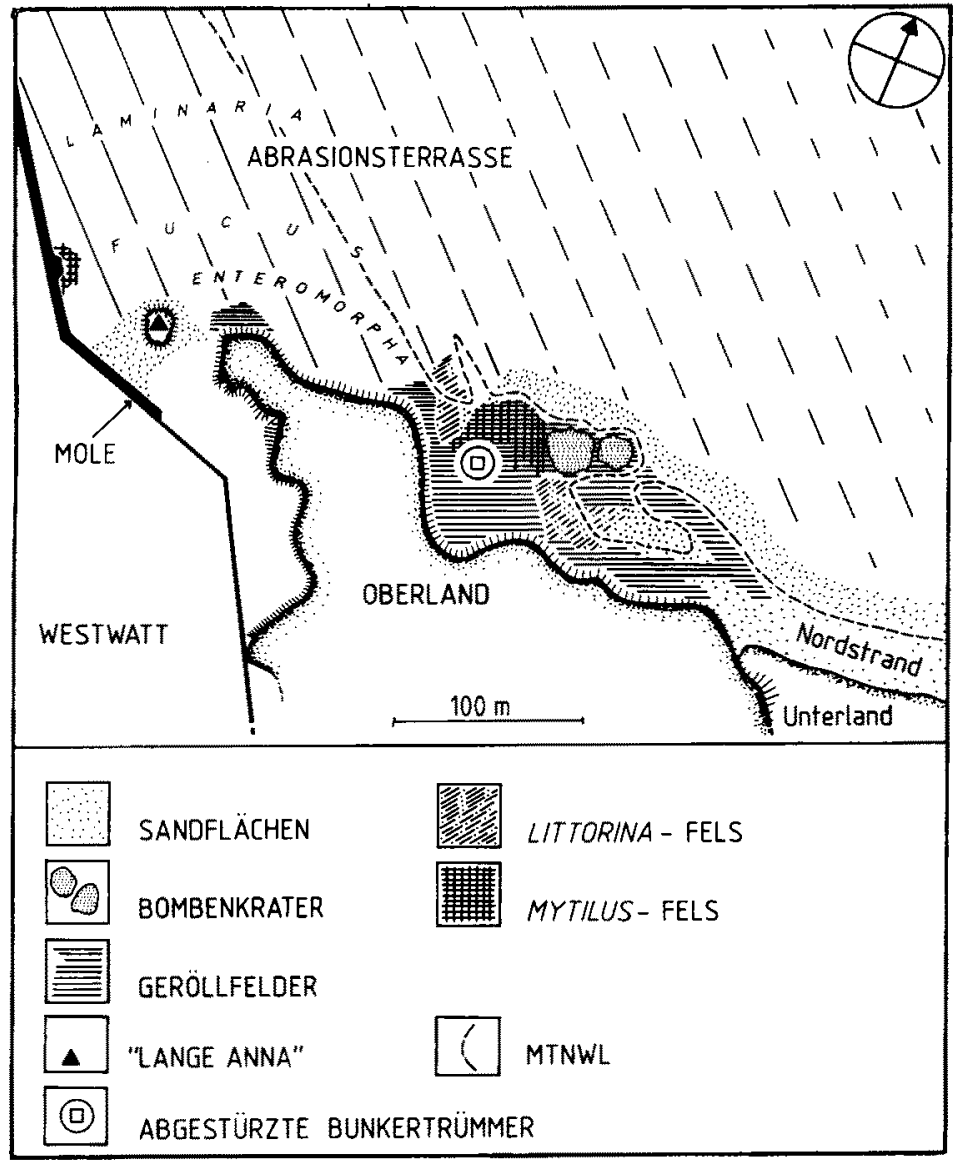

Abb. 1. Untersuchungsgebiet im Nordosten von Helgoland 
Stelle, an der auf breiter Front die Abbruchkante der Insel und die Abrasionsterrasse nahtlos ineinander übergehen. Dieser Bereich kann im Gegensatz zum Westwatt auch noch bei Nipptiden regelmäßig begangen werden, so daß eine kontinuierliche Probenahme möglich ist.

Das Nordostwatt läßt sich in zwei große Bereiche einteilen (Abb. 1). Der erste umfaßt das von herabgestürzten Bunkerbauten, Beton- und Buntsandsteinblöcken charakterisierte Trümmer- und Schuttfeld am südöstlichen Felsfuß bis zum Nordstrand. Der zweite Bereich besteht aus der eigentlichen Abrasionsterrasse, die durch ihre besondere Morphologie gekennzeichnet ist (vgl. Abb. 10). Innerhalb dieser Bereiche lassen sich verschiedene Habitate unterscheiden. Für das Trümmer- und Schuttfeld sind dies: die Sandflächen, die Geröllfelder, der Mytilus-Fels und der Littorina-Fels.

Die Abrasionsterrasse läßt sich nach ihrer Algenbesiedlung unterteilen in: die Enteromorpha-Zone, die Fucus-Zone, die Priele und die Laminaria-Zone. Schließlich ist auch die Nordostseite der Nordwestmole als ein eigenes Habitat anzusehen.

Im Untersuchungsgebiet beträgt die mittlere Tidedauer $12,4 \mathrm{~h}$ bei einem durchschnittlichen Tidenhub von 2,2 m. Bei Hochwasser reicht der Wasserstand bis an die steile Klippenwand und überspült gerade noch die dort siedelnden Grünalgenbestände. Bei Niedrigwasser fällt ein großer Teil der Abrasionsterrasse bis zu $300 \mathrm{~m}$ seewärts frei.

Man kann in Anlehnung an Lewis (1964) und Stephenson \& Stephenson $(1949,1972)$ den Lebensraum in drei vertikale Zonen unterteilen: (1) Das Su pral i t or al (Spritzwasserzone) wird nur bei extremen Springtiden und Sturmfluten überspült. Diese Zone bildet den Übergang zum terrestrischen Lebensraum. (2) Das E ulitoral (Gezeitenzone im engeren Sinne) liegt zwischen der MTNWL und der MTHWL. Hier entwickelt sich im Gegensatz zum Supralitoral eine reichhaltige Algenbesiedlung, die sich zumeist in horizontalen Säumen anordnet. Lewis (1964) unterteilt diese Zone in ein oberes, mittleres und unteres Eulitoral. Die typische Algenbesiedlung im oberen Eulitoral besteht aus Enteromorpha spp., Blidingia spp., Porphyra spp. und Pelvetia canaliculata. Pelvetia fehlt auf Helgoland. Im mittleren und unteren Eulitoral wachsen als Leitformen Fucus spp. und Ascophyllum nodosum. Auch Ascophyllum fehlt auf Helgoland als bestandsbildende Art (Kornmann \& Sahling, 1977). Diese Braunalge besiedelt jedoch einige geschützt gelegene Molenabschnitte. (3) Das Sublitor a l (Dauerflutzone) ist der Bereich unterhalb der MTNWL. Nur der oberste Saum fällt bei extremen Springtiden trocken. Die typische Algenbesiedlung wird durch Laminaria-Arten repräsentiert. Die vorliegende Untersuchung beschränkt sich auf das Eulitoral und den obersten Bereich des Sublitorals.

\section{Salzgehalt und Temperaturen}

In Abbildung 2 sind der Salzgehalt sowie Wasser- und Lufttemperaturen im Gezeitenbereich während des Untersuchungszeitraumes dargestellt. Es fehlen solche Extremwerte, die kurzfristig durch Niederschläge, Verdunstung und durch starke Aufheizung des Bodens infolge intensiver Sonneneinstrahlung entstehen können. Im Hochsommer steigen die Lufttemperaturen im Felswatt kaum über $25^{\circ} \mathrm{C}$ an. Im Mittel schwanken sie im Laufe des Jahres zwischen 4 und $17^{\circ} \mathrm{C}$. Winterliche Frosttage sind auf Helgoland selten. In den Gezeitentümpeln treten aufgrund des kurzfristigen Trockenfalls keine bedeutenden Schwankungen des Salzgehaltes auf. So erhöhte sich innerhalb des Untersuchungs- 


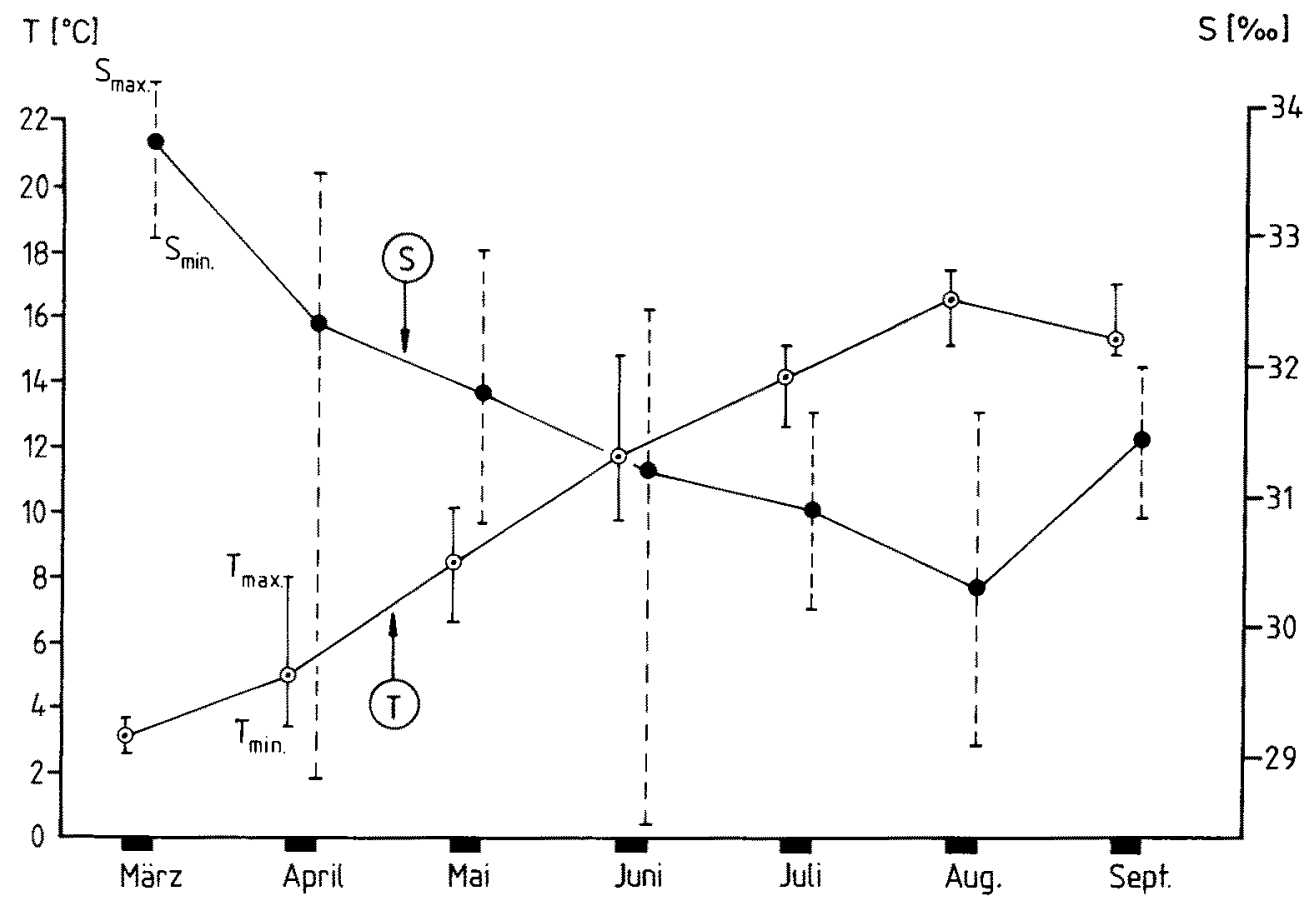

Abb. 2. Schwankungen von Temperatur (T) und Salinität (S) des Meerwassers auf Helgoland Reede (nach Angaben der BAH)

zeitraumes die Salinität auch an sehr warmen und sonnigen Tagen nur um etwa 0,5\%. Die Wassertemperatur konnte dagegen kurzfristig um ca. $7^{\circ} \mathrm{C}$ auf bis zu $24^{\circ} \mathrm{C}$ ansteigen.

\section{MATERIAL UND METHODE}

Von März bis September 1984 wurde eine monatliche Bestandsaufnahme der Makrofauna durchgeführt und die typische Besiedlung durch makroskopische Algen festgehalten. Die Tiere wurden im Lebendzustand bestimmt. Nematoda, Halacarida, Ostracoda, parasitische Formen sowie Vögel und Fische blieben im Rahmen dieser Untersuchung unberücksichtigt.

\section{Entnahme und Bearbeitung der Proben}

Monatliche Proben wurden im Bereich der 9 Habitate entnommen. Die großen Unterschiede der jeweiligen Lebensraumstrukturen erforderten verschiedene Sammelmethoden. Sie werden im folgenden vorgestellt.

Uber die Oberflächen der Sandflächen wurde ein Kescher (1000 $\mu \mathrm{m}$ Gaze) hinweggezogen und so die Besiedler der obersten Schichten eingefangen. Die untersuchte Fläche betrug ca. $3 \mathrm{~m}^{2}$. An zufällig ausgesuchten Stellen wurden die Sandflächen abgegraben und mit einer $300 \mu \mathrm{m}$ Gaze ausgesiebt. Die Rückstände wurden im Labor 
auf tierische Organismen hin untersucht. Oxische und anoxische Sedimente wurden getrennt behandelt. Die umgegrabene Gesamtfläche betrug bei einer mittleren Grabtiefe von ca. $30 \mathrm{~cm}$ etwa $1 \mathrm{~m}^{2}$.

Von den Schillfeldern und Sedimentflächen der Gezeitentümpel, Priele und Schichtflächen wurde jeweils ca. 11 in ein Probengefäß geschaufelt und im Labor unter dem Binokular untersucht.

Die Oberflächen von Bunkern, Betonquadern, Molenwänden, Metallpfeilern, Muschelschalen sowie von Buntsandsteintrümmern und hochgebrochenen -schollen wurden im Freiland mit einer Lupe $(10 \times)$ auf ihre Besiedlung hin untersucht und teilweise abgekratzt. Einzelne kleinere Proben wurden im Labor in untergetauchtem Zustand unter dem Binokular betrachtet. Neben einer Untersuchung der Oberflächen wurden von den Holzpfählen kleinere Teile abgebrochen und im Labor aufgeschält.

Zur Ermittlung der Besiedlungsdichte von Littorina littorea auf dem Littorina-Fels wurden monatlich 15 zufällig ausgesuchte Flächen von je $0,25 \mathrm{~m}^{2}$ ausgezählt.

Freischwimmende Formen in den Prielen und Gezeitentümpeln wurden mit einem Kescher (1000 $\mu \mathrm{m}$ Gaze) gefangen.

Verschiedene Algenarten wurden vorsichtig vom Grund abgerissen, in Probengefäße überführt, im Labor zweimal in warmem Meerwasser (ca. $20^{\circ} \mathrm{C}$ ) ausgewaschen und mit einer $300 \mu \mathrm{m}$ Gaze gesiebt. Anschließend wurden die Thalli nach festsitzenden Organismen unter dem Binokular abgesucht. Der Umfang der Algenproben betrug für jede Art pro Habitat 1 , für die großen Braunalgen der Gattungen Fucus und Laminaria je zwischen 10 und 151 .

15 Laminaria-Rhizoide von zufällig ausgewählten Standorten wurden entweder vorsichtig vom Boden getrennt oder zusammen mit dem Untergrund in ein warmes Meerwasserbad (ca. $20^{\circ} \mathrm{C}$ ) überführt und 2 Tage ohne Wasserwechsel darin belassen. Alle $12 \mathrm{~h}$ wurden die aus den Rhizoiden ausgetriebenen Organismen mit einer $300 \mu \mathrm{m}$ Gaze gesiebt. Schließlich wurden die Rhizoide zerschnitten und unter dem Binokular nach weiteren festsitzenden Besiedlern untersucht. Auf diese Weise konnten fast alle Organismen im Lebendzustand bestimmt werden.

\section{Abschätzung der "Auffälligkeit"}

Angaben zur Häufigkeit einer Art sind im Helgoländer Felswatt aufgrund des komplex gestalteten und unregelmäßig strukturierten Lebensraumes schwierig. Die von Ballantine (1961), Crisp \& Southward (1958), Dalby et al. (1978) und Moyse \& NelsonSmith (1963) vorgeschlagenen Indizes zur Beschreibung von Häufigkeiten wichtiger Arten des Eulitorals konnten für diese Untersuchung nur einen begrenzten Wert haben. Für die meisten Formen hätten zudem neue Indizes erst definiert werden müssen. Um jedoch auch in kürzeren Untersuchungszeiträumen sinnvolle Abschätzungen zur Häufigkeit treffen zu können, bedurfte es einer abgewandelten Methode zur Betrachtung und Auswertung. $\mathrm{Zu}$ diesem Zweck wurde ein neuer Begriff eingeführt: die "Auffälligkeit" (engl. conspicuousness). Durch die "Auffälligkeit" wird keine absolute, einheitlich festgelegte und damit eindeutig meßbare Größe beschrieben. Sie soll als Begriff statt dessen lediglich helfen, (a) eine grobe Abschätzung der Besiedlungsdichte einer Art im Vergleich zu einer anderen zu treffen, (b) Anderungen in der Besiedlungsdichte und 
-struktur anzuzeigen und (c) die Wahrscheinlichkeit beschreiben, mit der eine schon einmal angetroffene Art wiedergefunden werden kann.

Mit Hilfe der "Auffälligkeit" sollen Tendenzen in der Veränderung einer untersuchten Lebensgemeinschaft festgestellt werden. Die Zuordnung zu den jeweiligen Kategorien ist im gewissen Maße subjektiv.

Im Freiland kann eine Abschätzung der "Auffälligkeit" nur für solche Arten gelten, die für das unbewaffnete Auge noch deutlich erkennbar sind. Viele Formen werden jedoch erst unter dem Binokular sichtbar, da sie in ihrer natürlichen Umgebung entweder zu stark getarnt sind, oder aber z. B. im Substrat versteckt leben. Es erscheint daher sinnvoll, 2 verschiedene Klassen einzurichten: Klasse 1 umfaßt die Tiere, die im Freiland nicht oder nur sehr schwer auffindbar sind, obwohl sie von ihrer Größe noch zur Makrofauna gezählt werden $(\geqslant 1 \mathrm{~mm})$. Sie sind meist relativ klein und zusätzlich nur schwach oder gar nicht gefärbt. Viele dieser Formen leben versteckt zwischen Algen, in Nischen und Ritzen des Bodens oder bauen unauffällige Wohnröhren. Einige bohren sich in den Untergrund ein. Klas e 2 umfaßt solche Tiere, die im Freiland mit unbewaffnetem Auge entdeckt werden können. Kleinere Formen dieser Klasse sind auffällig gefärbt und schlecht getarnt.

Um eine repräsentative Sammelprobe zu bekommen, müssen die Sammelmethoden und die Beobachtung an die besonderen Gegebenheiten des Habitats angepaßt sein. Allgemein soll gelten, daß die "Auffälligkeiten" der Arten in Klasse 1 nur im Labor mit Hilfe eines Binokulars, die der Klasse 2 dagegen bereits im Freiland abgeschätzt werden können. Zur Bewertung der "Auffälligkeit" wurden folgende Begriffe gewählt:

(1) nicht vorhanden: Wird eine Tierart während einer Freilandbegehung oder in einer Probe unter dem Binokular nicht gefunden, so gilt sie als "nicht vorhanden". Das Symbol in den Tabellen lautet - .

(2) vereinzelt: Wird eine Art einmal oder in einem Paar gefunden, so gilt sie als "vereinzelt" (o).

(3) s elte n: Wird eine Art nur in wenigen, weit voneinander entfernten Exemplaren gefunden, die für die Lebensgemeinschaft eine anscheinend untergeordnete Rolle spielen dürften, so gilt sie als "selten" $\left({ }_{\infty}\right)$.

(4) re ge l mä Bi g: Wird eine Art in kurzen Zeitabständen wiedergefunden, ohne daß große Kolonien oder große Aggregationen gebildet worden sind, so gilt sie als "regelmäßig" (ooo).

(5) a uffällig: Wird eine Art ständig und in kleinen bis mittelgroßen Kolonien wiedergefunden, so gilt sie als "auffällig" ((o)).

(6) s e hr a uf ällig: Wird eine Art schon bei jeder oberflächlichen Betrachtung entdeckt und/oder in großen plakativen Kolonien oder Aggregationen aufgefunden, so gilt sie als "sehr auffällig" ( $\circ \circ)$.

(7) d o m in a n t: Wird eine Art so häufig angetroffen, daß sie nicht nur gegenüber der Gesamtheit aller anderen Tiere überwiegend erscheint, sondern auch räumlich diese innerhalb des Lebensraumes weitgehend verdrängt, so gilt sie als "dominant" $\left(\begin{array}{c}\infty \\ \infty\end{array}\right)$. 
Klaus Janke

Tab. 1. Im Helgoländer Nordost-Felswatt nachgewiesene Makrofauna-Arten

\begin{tabular}{|c|c|}
\hline \multicolumn{2}{|c|}{ Porifera } \\
\hline Leucosolenia complicata (Montagu, 1812) & Sycon ciliatum (Fabricius, 1780) \\
\hline Leucosolenia botryoides Ellis \& Solander, 1786 & Halichondria panicea (Pallas, 1766) \\
\hline Sycon coronatum (Ellis \& Solander, 1786) & Halisarca dujardini Johnston, 1842 \\
\hline \multicolumn{2}{|c|}{ Hydrozoa } \\
\hline Clava multicornis (Forskål, 1775) & Hydrallmania falcata (Linné, 1758) \\
\hline Coryne pusilla Gärtner, 1774 & Laomedea gelatinosa (Pallas, 1766) \\
\hline Eudendrium rameum (Pallas, 1766) & Laomedea geniculata (Linné, 1758) \\
\hline Sertularia cupressina Linné, 1758 & Laomedea flexuosa Hincks, 1868 \\
\hline Dynamena pumila (Linné, 1758) & \\
\hline \multicolumn{2}{|c|}{ Scyphozoa } \\
\hline Craterolophus tethys Clark, 1863 & Aurelia aurita Linné, 1746 \\
\hline \multicolumn{2}{|c|}{ Anthozoa } \\
\hline Actinia equina (Linné, 1758) & Sagartia troglodytes (Price, 1848) \\
\hline Urticina felina (Linné, 1761) & Sagartiogeton laceratus (Dalyell, 1848) \\
\hline Metridium senile (Linné, 1761) & Sagartiogeton undatus (Müller, 1788) \\
\hline Sagartia elegans (Dalyell, 1848) & \\
\hline \multicolumn{2}{|c|}{ Bryozoa } \\
\hline Membranipora membranacea (Linné, 1767) & Schizoporella errata (Waters, 1878) \\
\hline Conopeum reticulum (Linné, 1767) & Celleporella hyalina (Linné, 1767) \\
\hline Electra pilosa (Linné, 1767) & Alcyonidium polyoum (Hassall, 1841) \\
\hline Callopora lineata (Linné, 1767) & Flustrellidra hispida (Fabricius, 1780) \\
\hline Cibrilina punctata (Hassall, 1841) & Bowerbankia imbricata (Adams, 1800) \\
\hline Cryptosula pallasiana (Moll, 1803) & Bowerbankia pustulosa (Ellis \& Solander, 1786) \\
\hline Escharella immersa (Flemming, 1828) & Bowerbankia gracilis (Linné, 1767) \\
\hline Escharella variolosa (Johnston, 1838) & Walkeria uva (Linné, 1767) \\
\hline \multicolumn{2}{|c|}{ Sipunculida } \\
\hline \multirow{2}{*}{\multicolumn{2}{|c|}{ Goltingia minuta (Keterstein, 1862) }} \\
\hline & \\
\hline Cephalothrix rurifrons (Johnston, 1837) & Amphiporus lactifloreus (Johnston, 1827-28) \\
\hline Procephalochrix filiformis (Johnston, 1828-29) & Emplectonema gracile (Johnston, 1837) \\
\hline Lineus bilineatus (Renier, 1804) & Oerstedia dorsalis (Abildgaard, 1806) \\
\hline Lineus ruber (Müller, 1774) & Tetrastemma candidum (Müller, 1774) \\
\hline Lineus viridis (Müller, 1774) & Tetrastemma vermiculus (Quatrefages, 1846) \\
\hline Micrura fasciolata Ehrenberg 1831 & \\
\hline \multicolumn{2}{|c|}{ Kamptozoa } \\
\hline \multicolumn{2}{|l|}{ Pedicellina cernua (Pallas, 1774) } \\
\hline \multicolumn{2}{|c|}{ Polyplacophora } \\
\hline Lepidochiton cinereus (Linné, 1758) & Lepidopleurus asellus (Spengler, 1797) \\
\hline \multicolumn{2}{|c|}{ Prosobranchia } \\
\hline Acmaea virginea (Müller, 1776) & Lacuna divaricata (Fabricius, 1780) \\
\hline Gibbula cineraria (Linné, 1758) & Lacuna pallidula (Da Costa, 1879) \\
\hline Calliostoma ziziphinum (Linné, 1758) & Littorina mariae Sacchi \& Rastelli, 1966 \\
\hline Rissoa parva (Da Costa, 1779) & Littorina obtusata (Linné, 1767) \\
\hline Rissoa inconspicua (Alder, 1874) & Littorina littorea (Linné, 1767) \\
\hline Onoba aculeus (Gould, 1841) & Littorina saxatilis (Olivi, 1792) \\
\hline Hydrobia ulvae (Pennant, 1777) & Nucella lapillus (Linné, 1758) \\
\hline Skeneopsis planorbis (Fabricius, 1780) & Buccinum undatum (Linné, 1761) \\
\hline
\end{tabular}


Tab. 1 (Fortsetzung). Im Helgoländer Nordost-Felswatt nachgewiesene Makrofauna-Arten

\begin{tabular}{|c|c|}
\hline \multicolumn{2}{|c|}{ Opisthobranchia } \\
\hline Retusa truncatula (Bruguiére, 1792) & Archidoris pseudoargus (Rapp, 1827) \\
\hline Dendronotus frondosus (Ascanius, 1774) & Coryphella pedata (Montagu, 1815) \\
\hline Doto coronata (Gmelin, 1791) & Coryphella verrucosa rufibranchialis (M. Sars, \\
\hline Acanthodoris pilosa (Müller, 1789) & 1829) \\
\hline Onchidoris muricata (Müller, 1776) & Facelina auriculata (Müller, 1776) \\
\hline Polycera quadrilineata (Müller, 1776) & Aeolidia papillosa (Linné, 1761) \\
\hline \multicolumn{2}{|c|}{ Bivalvia } \\
\hline Mytilus edulis (Linné, 1758) & Hiatella arctica (Linné, 1767) \\
\hline Anomia ephippium (Linné, 1758) & Hiatella rugosa (Pennant, 1777) \\
\hline Venerupis pullastra (Montagu, 1803) & Teredo navalis Linné, 1758 \\
\hline \multicolumn{2}{|c|}{ Polychaeta } \\
\hline Lepidonotus squamatus (Linné, 1767) & Polydora ciliata (Johnston, 1838) \\
\hline Harmothoe impar (Johnston, 1839) & Scolelepis squamata (Müller, 1789) \\
\hline Harmothoe imbricata (Linné, 1767) & Malacoceros fuliginosus (Claparéde, 1868) \\
\hline Gattyana cirrosa (Pallas, 1766) & Tharyx multibranchiis (Grube, 1863) \\
\hline Sthenelais boa (Johnston, 1839) & Amphitrite figulus (Dalyell, 1853) \\
\hline Anaitides maculata (Linné, 1767) & Capitella capitata (Fabricius, 1780) \\
\hline Eumida sanguinea (Oerstedt, 1843) & Capitomastus giardi (Mesnil, 1897) \\
\hline Eulalia viridis (Linné, 1767) & Arenicola marina (Linné, 1758) \\
\hline Microphthalmus sczelkowii (Mecznikow, 1865) & Lanice conchilega (Pallas, 1766) \\
\hline Typosyllis armillaris (O. F. Müller, 1776) & Sabellaria spinulosa Leuckart, 1849 \\
\hline Syllides articulocirratus Gillandt, 1979 & Fabricia sabella (Ehrenberg, 1836) \\
\hline Autolytus prolifer (O. F. Müller, 1776) & Pomatoceros triqueter (Linné, 1758) \\
\hline Nereis pelagica Linné, 1761 & Janua pagenstecheri (Quatrefages, 1865) \\
\hline Nereis diversicolor O. F. Müller, 1776 & Circeis spirillum (Linné, 1758) \\
\hline Nereis virens Sars, 1839 & Spirorbis tridentatus (Levinsen, 1883) \\
\hline Ophryotrocha gracilis Huth, 1934 & Spirorbis spirorbis (Linné, 1758) \\
\hline \multicolumn{2}{|c|}{ Oligochaeta } \\
\hline \multicolumn{2}{|l|}{ Paranais litoralis (O. F. Müller, 1774) } \\
\hline \multicolumn{2}{|c|}{ Pantopoda } \\
\hline Nymphon rubrum Hodge, 1865 & Anoplodactylus angulatus (Dohrn, 1881) \\
\hline Achelia hispida Hodge, 1864 & Pycnogonum littorale (Ström, 1762) \\
\hline Phoxichilidium femoratum (Rathke, 1799) & \\
\hline \multicolumn{2}{|c|}{ Cirripedia } \\
\hline Balanus crenatus Bruguiére, 1789 & Elminius modestus Darwin, 1854 \\
\hline Balanus balanus Linné, 1758 & Verruca stroemia (Müller, 1776) \\
\hline Semibalanus balanoides (Linné, 1767) & \\
\hline \multicolumn{2}{|c|}{ Amphipoda } \\
\hline Chaetogammarus marinus (Leach, 1815) & Dexamine spinosa (Montagu, 1813) \\
\hline Gammarellus homari (Fabricius, 1779) & Dexamine thea Boeck, 1861 \\
\hline Cheirocratus sundevalli (Rathke, 1843) & Hyale nilssonii (Rathke, 1843) \\
\hline Melita palmata (Montagu, 1804) & Corophium insidiosum Crawford, 1937 \\
\hline Calliopius laeviusculus (Kröyer, 1838) & Jassa falcata (Montagu, 1808) \\
\hline Apherusa jurenei (Milne Edwards, 1830) & Caprella linearis (Linné, 1767) \\
\hline Apherusa bispinosa (Bate, 1857) & \\
\hline
\end{tabular}


Tab. 1 (Fortsetzung). Im Helgoländer Nordost-Felswatt nachgewiesene Makrofauna-Arten

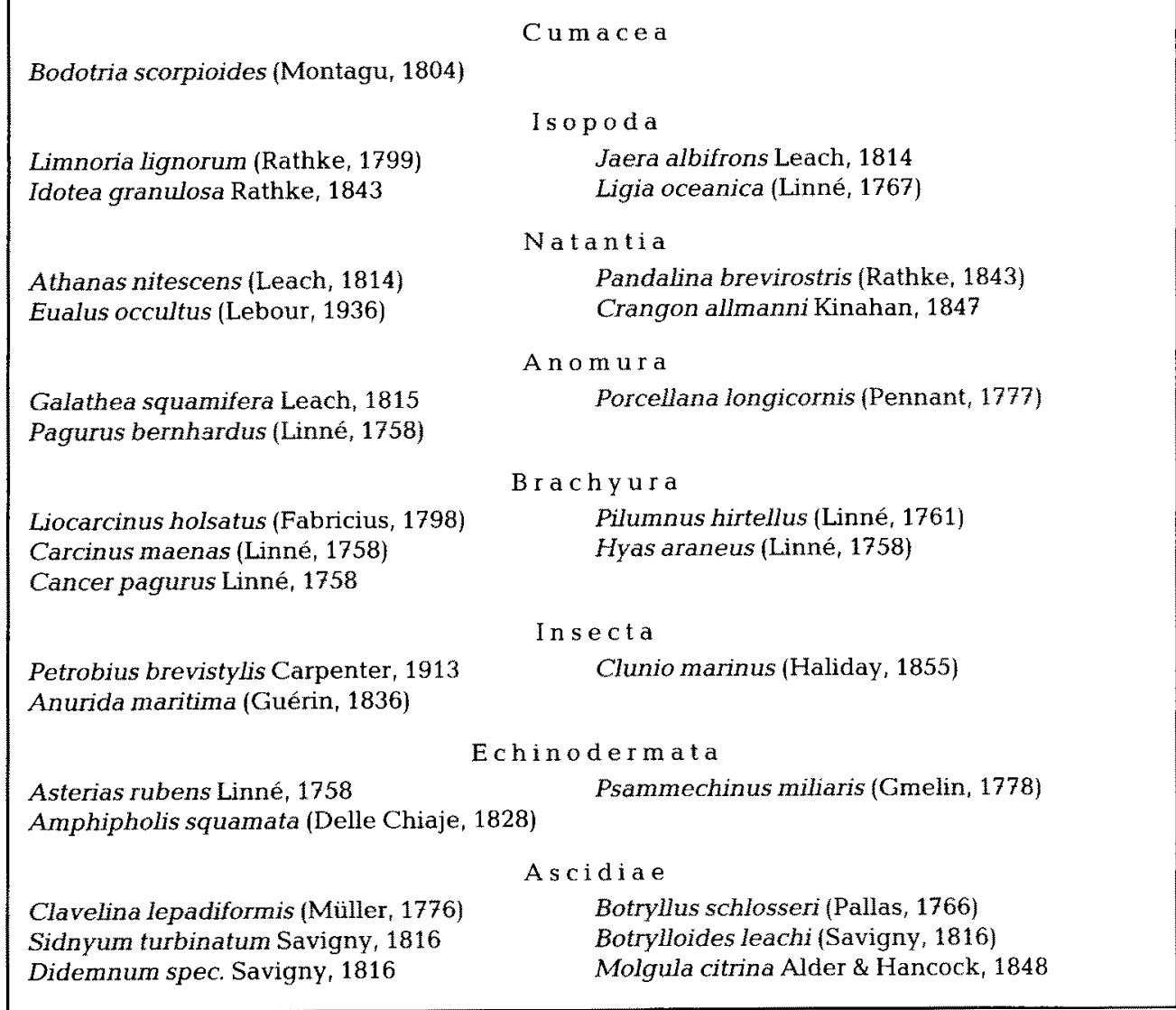

\section{ERGEBNISSE}

\section{Artenspektrum}

Innerhalb des Untersuchungszeitraumes wurden im Nordostwatt von Helgoland 172 Makrofauna-Arten gefunden (Littorina mariae und L. obtusata wurden nicht unterschieden und vielmehr als eine Art geführt). Sie gehören 25 übergeordneten taxonomischen Gruppen an (vgl. Tab. 1). Zu einigen Arten bedarf es kurzer Anmerkungen.

Littorina mariae/obtusata. Die Taxonomie der Littorinen hat sich in den letzten Jahren ständig geändert (Raffaelli, 1982). L. mariae ist als eigene Art erst sehr spät beschrieben worden (Sacchi \& Rastelli, 1966). Auch auf Helgoland wurde sie in jüngster Zeit nachgewiesen (Gallardo \& Götting, 1985). In allen vorausgegangenen Publikationen, so z. B. auch bei Ziegelmeier (1966), wurde L. mariae auf Helgoland als die nahe verwandte Art $L$. obtusata beschrieben, da sich die beiden Formen schalenmorphologisch kaum unterscheiden. Im Helgoländer Felswatt überwiegt L. mariae (Gallardo \& 
Götting, 1985). Von 96 untersuchten Männchen fanden sie nur ein Exemplar von $L$ obtusata. Ihr Befund wird gestützt durch die hohe Anzahl an nierenförmigen Gelegen sowie deren geringe Embryonenzahl und ihre ausschließliche Eiablage auf Fucus serratus. Die Flachen Strandschnecken werden im folgenden als eine Form unter dem Namen $L$. mariae/obtusata geführt. Um die Unterscheidung der beiden Arten zu erleichtern, sind in Tabelle 2 die wichtigsten Differenzierungsmerkmale zusammengefaßt. Eine deutliche Unterscheidung kann jedoch auch danach nicht durch die Betrachtung einzelner Individuen, sondern nur einer größeren Teilpopulation erfolgen.

Tab. 2. Littorina obtusata und L. mariae. Merkmale zur Differenzierung beider Arten. Zusammengestellt nach Gallardo \& Götting (1985), Goodwin \& Fish (1977), Nielsen (1980) und Raffaelli (1982)

\begin{tabular}{|c|c|c|}
\hline Merkmal & Littorina obtusata & Littorina mariae \\
\hline Größe & \multicolumn{2}{|c|}{ L. obtusata bleibt auf Helgoland kleiner als $L$. mariae } \\
\hline Geschlechtsorgane & $\begin{array}{l}\text { Ovipositor der } q 9 \text { fast immer mit } \\
\text { Pigmentierung } \\
\text { Penis der } \partial \partial^{\star} \text { kurz, mit } 2 \text { oder } 3 \\
\text { Drüsenreihen }\end{array}$ & $\begin{array}{l}\text { Ovipositor der } \$ Q \text { ohne } \\
\text { Pigmentierung } \\
\text { Penis der } \delta \partial \text { lang und schmal, mit } \\
1 \text { Drüsenreihe }\end{array}$ \\
\hline Gelege & $\begin{array}{l}2 \% \text { nierenförmig, } 10 \% \text { rund, } \\
\text { restliche langgestreckt } \\
\text { Eikapsel } \varnothing 210-255 \mu \mathrm{m} \\
250-300 \text { Eikapseln/Gelege } \\
\text { Ablage auf: Fucus spiralis, } \\
F \text {. vesiculosus, Ascophyllum } \\
\text { nodosum (auf Phylloid, Cauloid } \\
\text { und Rhizoid) }\end{array}$ & $\begin{array}{l}\text { mehr als } 20 \% \text { nierenförmig, niemals } \\
\text { rund, restliche langgestreckt } \\
\text { Eikapsel } \varnothing 195-200 \mu \mathrm{m} \\
80-120 \text { Eikapseln/Gelege } \\
\text { Ablage auf: Fucus serratus (nur auf } \\
\text { dem Phylloid) }\end{array}$ \\
\hline Vorkommen & $\begin{array}{l}\text { oberes und mittleres Eulitoral, } \\
\text { auf Fucus spiralis, F. vesiculosus, } \\
\text { Ascophyllum nodosum }\end{array}$ & unteres Eulitoral, auf Fucus serratus \\
\hline Gehäuse (adult) & & \\
\hline
\end{tabular}

Littorina saxatilis. Nach neueren Untersuchungen (z. B. Hannaford-Ellis, 1979; Heller, 1975; Smith, 1981) handelt es sich hier um einen Komplex von mindestens 4 Arten, die sich nach Fretter (1980) in einem Prozeß fortschreitender Differenzierung befindet. Die Helgoländer Population gehört nach der z. Zt. gültigen Nomenklatur (Raffaelli, 1982) der Art Littorina saxatilis an.

Onoba aculeus. Diese zu den Rissoacea gehörende Kleinschnecke wird nach Wissen des Autors an dieser Stelle zum ersten Male für Helgoland beschrieben. Möglicherweise 
ist sie in der Vergangenheit mit Cingula semicostata (= Onoba striata) verwechselt worden (vgl. Fretter \& Graham, 1978; Rasmussen, 1973).

Nucella lapillus. Diese Schnecke wird in der neueren Literatur fälschlicherweise als Thais lapillus (L.) bezeichnet. Nach der taxonomischen Nomenklatur gilt jedoch weiterhin die ältere Bezeichnung, da die Typusform der Gattung Nucella die Art N. lapillus ist. Als locus typicus wird Helgoland angegeben.

Harmothoe imbricata, Nereis diversicolor und Circeis spirillum sind von Gillandt $(1979 a, b)$ im Helgoländer Nordostwatt nicht gefunden worden. Somit erhöht sich die Artenzahl der im Untersuchungsgebiet nachgewiesenen Polychaeten auf 56.

Chaetogammarus marinus. Bei einer Nachuntersuchung im März 1985 wurde neben dieser Art auch Gammarus salinus Spooner, 1947 gefunden. G. salinus besiedelte die gleichen Habitate wie Ch. marinus. Beide Arten kamen in etwa gleicher "Auffälligkeit' nebeneinander vor. Im Untersuchungszeitraum März bis September 1984 fehlte G. salinus jedoch.

Jassa falcata. Neuere Untersuchungen an Helgoländer Jassa-Populationen (Conlan, pers. Mitteilung an Herrn Dr. Anger, Helgoland) ergaben, daß die für Helgoland bisher nicht beschriebenen Arten $J$. marmorata und $J$. pulchella vorkommen. Sie wurden im Untersuchungszeitraum zwar nicht gefunden, doch kann ein Auftreten dieser Arten im Untersuchungsgebiet (vor allem im oberen Sublitoral) nicht ausgeschlossen werden.

Jaera albifrons. Bei den untersuchten Exemplaren handelte es sich in allen Fällen um $J$. a. albifrons. Dieser Befund wird von Gruner (1965) bestätigt. Moritz (1975) sprach dagegen die von ihm untersuchten Männchen von Helgoland der Form $J$, a, syei zu.

\section{Die Habitate und ihre Besiedlung}

\section{Die Sandflächen}

Die untersuchten Sandflächen befinden sich im nordwestlichen Anschluß an den Nordstrand (Abb. 1). Sie werden seewärts durch ein wallförmiges Geröllfeld begrenzt. Das Sediment besteht in der Einteilung nach Stripp (1969) überwiegend aus Fein- und Mittelsand (siehe auch Gillandt, 1979a). Die Sedimentation des hier eingespülten Materials wird durch den Schutz des vorgelagerten Geröllfeldes begünstigt. Die Korngrößenverteilung weicht deutlich von der des Nordstrandes ab (Tab. 3). Dort überwiegt der Anteil an groben und sehr groben Sedimenten.

Die Mächtigkeit der Sedimente schwankt zwischen etwa 5 und $80 \mathrm{~cm}$. Die Sande werden unterbrochen von eingelagertem Beton- und Felsgeröll. Meist ragen nur die

Tab. 3. Korngrößenverteilung der Sedimente auf den untersuchten Sandflächen am Nordstrand

\begin{tabular}{|ccc|}
\hline Sediment & Sandflächen & Nordstrand \\
Korngröße & & \\
\hline$>1000 \mu \mathrm{m}$ & $2,2 \mathrm{~g} / 100 \mathrm{~g}$ & $34,1 \mathrm{~g} / 100 \mathrm{~g}$ \\
$500-1000 \mu \mathrm{m}$ & $2,6 \mathrm{~g} / 100 \mathrm{~g}$ & $28,6 \mathrm{~g} / 100 \mathrm{~g}$ \\
$200-500 \mu \mathrm{m}$ & $77,2 \mathrm{~g} / 100 \mathrm{~g}$ & $14,3 \mathrm{~g} / 100 \mathrm{~g}$ \\
$100-200 \mu \mathrm{m}$ & $17,4 \mathrm{~g} / 100 \mathrm{~g}$ & $19,0 \mathrm{~g} / 100 \mathrm{~g}$ \\
$<100 \mu \mathrm{m}$ & $0,6 \mathrm{~g} / 100 \mathrm{~g}$ & $4,0 \mathrm{~g} / 100 \mathrm{~g}$ \\
\hline
\end{tabular}




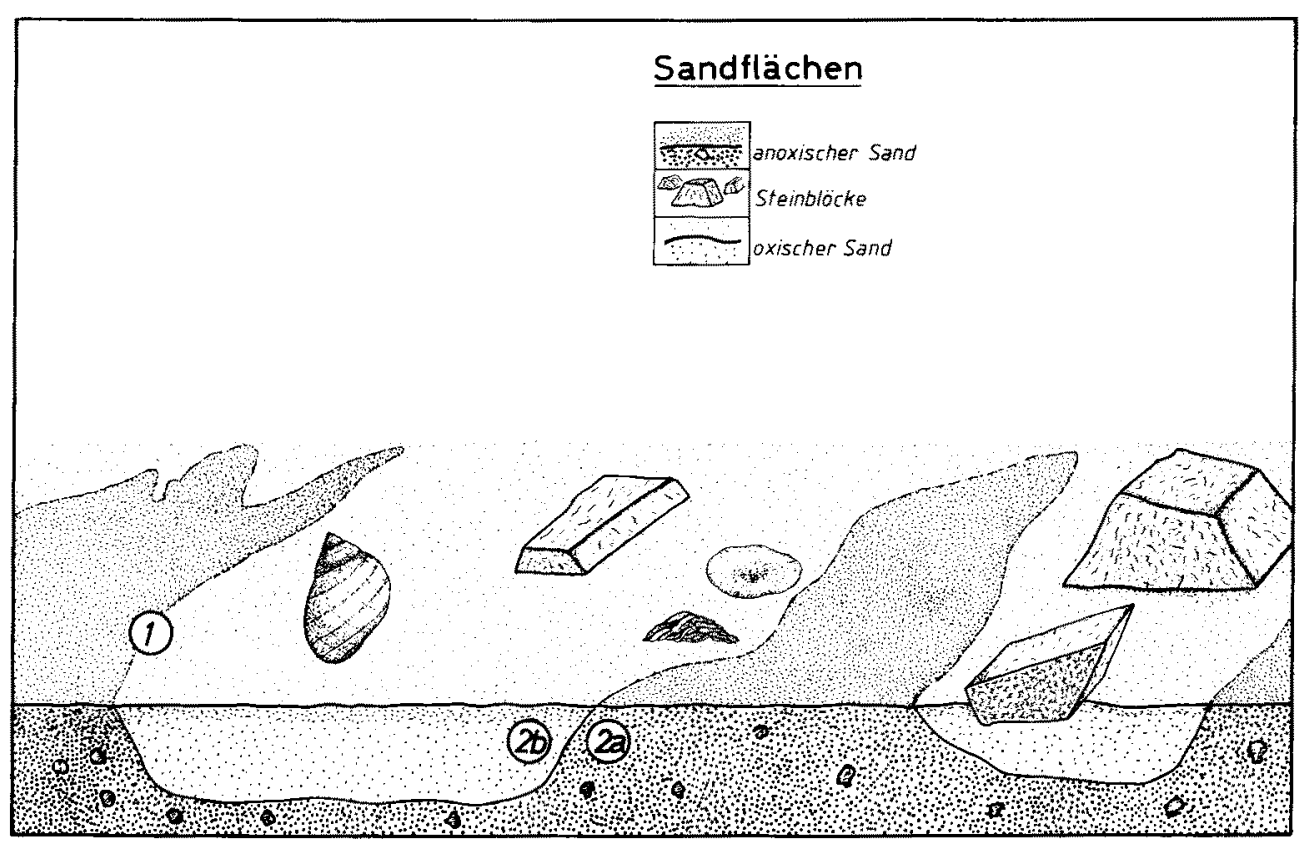

Abb 3. Die Sandflächen im Helgoländer Nordost-Felswatt (schematisch). 1 Oberflächen der Sandpartien; $2 a$ anoxisches Sediment; $2 b$ oxisches Sediment

Spitzen der Blöcke aus dem Sediment hervor. Die Oberflächen der Sande sind häufig durch eine starke Rippelung gewellt, was auf eine intensive Umwälzung der oberen Sedimentschichten hindeutet. Die Sandflächen lassen sich in zwei Abschnitte unterteilen (Abb. 3): (1) stark sulfidhaltige, anoxische Bereiche (grau bis schwarz, mit Algenresten vermischt); (2) sauerstoffreiche Bereiche (braun bis braun-gelb, maximal $5 \mathrm{~cm}$ tief).

Tab. 4. Zeitliche und räumliche Verteilung der Makrofauna im Bereich der Sandflächen. Zur Numerierung der Kleinhabitate siehe Abbildung 3

\begin{tabular}{|c|c|c|c|c|c|c|c|c|c|c|}
\hline \multirow[t]{2}{*}{ Species } & \multicolumn{7}{|c|}{ Monat (März-September) } & \multicolumn{3}{|c|}{ Kleinhabitat } \\
\hline & III & IV & $\mathrm{V}$ & VI & VII & VIII & LX & 1 & $2 \mathrm{a}$ & $2 b$ \\
\hline Littorina littorea & $\infty$ & cos & $\infty$ & $\infty$ & $\infty$ & $\infty$ & 。 & $\bullet$ & & \\
\hline Mytilus edulis & $\infty$ & $\infty$ & $\infty$ & 。 & - & - & - & $\bullet$ & & \\
\hline Venerupis pullastra & $\infty$ & $\infty$ & $\infty$ & $\infty$ & $\infty$ & $\infty$ & 。 & & & - \\
\hline Anaitides maculata & $\begin{array}{l}\infty \\
\infty\end{array}$ & $\infty$ & - & - & - & - & - & & & - \\
\hline Scolelepis squamata & & $\infty$ & - & - & - & - & - & & & $\bullet$ \\
\hline Malacoceros fuliginosus & - & - & $\infty 00$ & $\infty$ & $\infty$ & $\infty$ & 。 & & - & - \\
\hline Capitella capitata & $\infty$ & ooo & $\infty$ & $\infty$ & $\infty$ & $\infty 00$ & $\infty$ & & $\bullet$ & $\bullet$ \\
\hline Arenicola marina & 000 & $\infty$ & $\infty \infty$ & $\infty$ & 000 & $\circ$ & 80 & & $\bullet$ & $\bullet$ \\
\hline Lanice conchilega & $\infty$ & $\infty$ & $\infty$ & - & - & - & - & & & - \\
\hline Crangon allmanni & - & - & - & - & - & $\because$ & - & - & & \\
\hline Carcinus maenas & $\infty$ & - & $\infty$ & $\infty$ & - & $\infty$ & - & $\bullet$ & & \\
\hline
\end{tabular}


Für die $\mathrm{O}_{2}$-Armut großer Teile der Sandflächen dürften die nach Stürmen bis zu einem halben Meter hoch aufgetürmten Driftalgen und die darauf einsetzenden Zersetzungsprozesse ursächlich sein.

Flor a: Die Sandflächen werden nicht von festsitzenden Großalgen besiedelt, da es in diesem Bereich keine für Verankerung notwendigen Hartsubstrate gibt. Von großer ökologischer Bedeutung sind jedoch die auf dem Sediment siedelnden Diatomeen. Sie werden von Littorina littorea abgeweidet.

Fauna: Im Bereich der Sandflächen wurden 11 Makrofauna-Arten gefunden (Tab. 4). Die formenreichste Gruppe bildeten die Polychaeta (6 Arten). "Auffällige" Arten gehörten zu den Polychaeta (Anaitides maculata, Arenicola marina) und kurzweilig auch Natantia (Crangon allmanni). Die Oberflächen der Sande wurden vor allem von Littorina littorea besiedelt. An die herausragenden Geröllsteine heftete sich an einigen Stellen Mytilus edulis. Ihre Schalen waren ohne Aufwuchs. Dicht unter der Oberfläche eingegraben überdauerte Carcinus maenas die Trockenperiode. Im August konnte auch ein Schwarm von Crangon allmanni beobachtet werden. Diese Garnele ist für den Gezeitenbereich nicht typisch (Allen, 1960). Ihr Vorkommen liegt eher unterhalb von $20 \mathrm{~m}$ Tiefe.

Mehr als die Hälfte aller Arten im Bereich der Sandflächen entfielen auf endopsammale Polychaeta. Ein besonders typischer Bewohner in beiden Sandabschnitten war Arenicola marina. Die Kotsandhaufen an der Oberfläche ermöglichten eine Abschätzung der Besiedlungsdichte. Auf 25 zufällig ausgesuchten Zählflächen (je $0,25 \mathrm{~m}^{2}$ ) ergab sich im August 1984 eine mittlere Dichte von 21 Individuen $/ \mathrm{m}^{2}$. Gillandt $(1979 \mathrm{~b})$ gibt die Häufigkeit von Arenicola marina in den $\mathrm{H}_{2} \mathrm{~S}$-Sanden mit bis zu 20 Individuen/ $\mathrm{m}^{2}$ an. Nur für oxische Bereiche lag die Besiedlungsdichte im August 1984 bis 62 Individuen $/ \mathrm{m}^{2}$. Weitere Polychaeta waren Malacoceros fuliginosus und Capitella capitata. Nach Gillandt (1979a, b) kommen beide Arten besonders im $\mathrm{H}_{2} \mathrm{~S}$-Sand vor. Nach eigenen Beobachtungen traten sie in etwa gleicher Häufigkeit auch im $\mathrm{O}_{2}$-reichen Sediment auf. Im April wurde außerdem Scolelepis squamata gefunden. Diese Art bevorzugte oxische Sandpartien in direkter Nähe der Fels- und Geröllblöcke. An geschützten Stellen siedelte im Frühjahr Lanice conchilega. Auch Anaitides maculata wurde nur im Frühjahr angetroffen und besiedelte ausschließlich $\mathrm{O}_{2}$-reiche Sedimente. Die grünen Laichballen wurden von März bis Mai an der Oberfläche der Sande beobachtet.

\section{Die Geröllfelder}

Die Geröllfelder stellen ein morphologisch komplexes Habitat dar (Abb. 4). Sie sind durch große Betontrümmer und -quader charakterisiert. Diese Steine können in den Boden eingesenkt, gegeneinandergelehnt oder aufeinandergestapelt sein. In den so entstandenen kleinen Höhlen, in die wenig Licht dringt, hält sich ein feuchtes und kühles Klima. Der Boden ist von zerriebenem Buntsandsteinschutt mit Kies- und Schillanteilen bedeckt. In den Mulden sammelt sich das Wasser während der Ebbe in kleinen Gezeitentümpeln. Diese haben jedoch nur kurze Zeit Bestand, da sie nur wenig höher als die MTNWL liegen.

Die für die Gezeitentümpel sonst charakteristischen Schwankungen von Salzgehalt und Temperatur gibt es demzufolge hier kaum (siehe auch Gillandt, 1979a). Leicht zu entdecken sind auch die in den Boden eingesenkten Metallträger, die in zwei Reihen in 


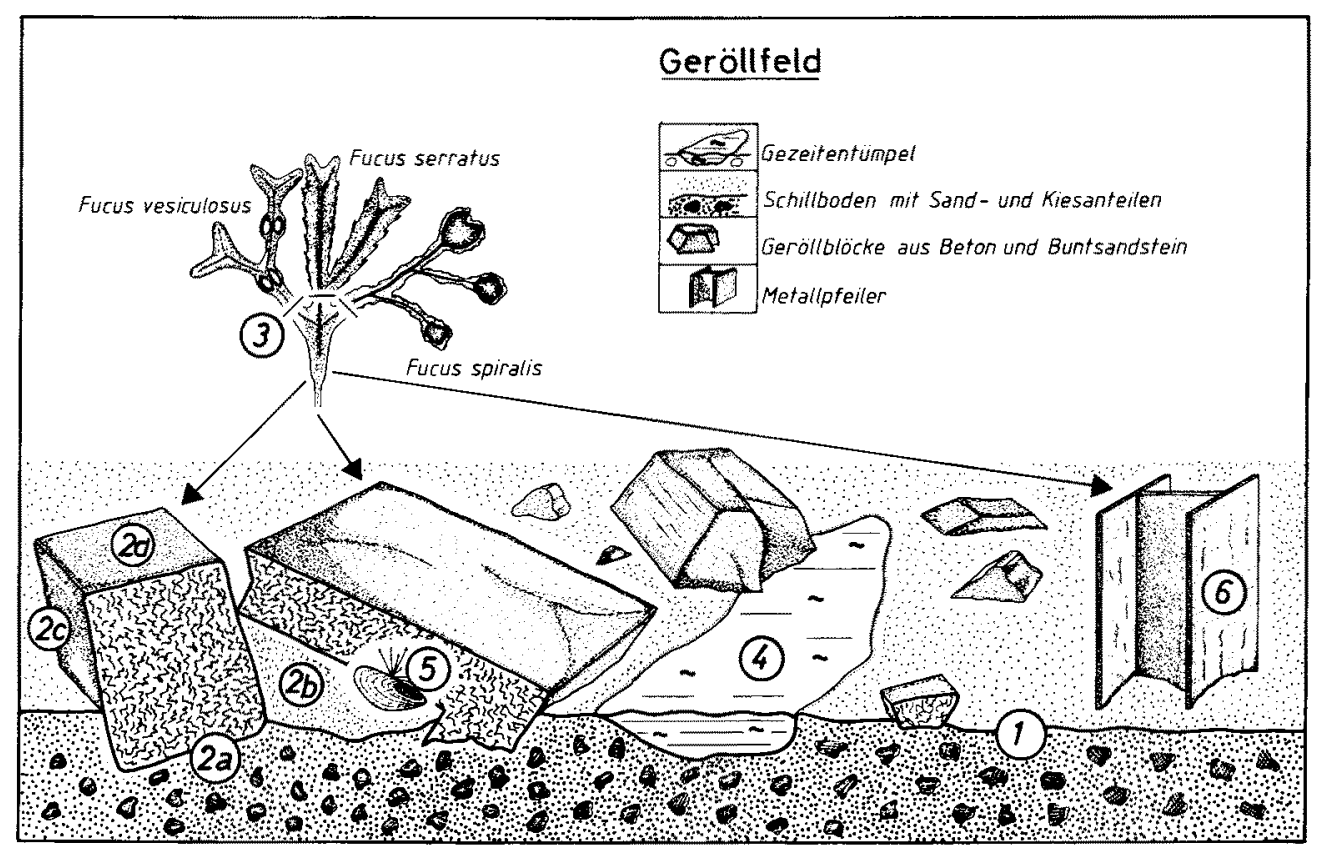

Abb. 4. Geröllfelder im Helgoländer Felswatt (schematisch). 1 Schillboden mit Sand u und Kiesanteilen; 2a Unterseite der Bunkertrümmer und Betonsteine; $2 \mathrm{~b}$ Oberflächen der Bunkertrümmer und Betonsteine in geschützt gelegenen Höhlen; $2 c$, d exponiert gelegene Oberflächen der Bunkertrümmer und Betonsteine; 3 Fucus spp; 4 Gezeitentümpel; 5 Schalen von geschützt siedelnden Mytilus-Schalen; 6 Metallpfeiler

dem wallförmigen südöstlich gelegenen Geröllfeld stehen. Sie gehören zu den Überresten einer alten Lorenbahn.

Flor a: Die Algenvegetation der Geröllfelder wird durch die 3 im Felswatt vorkommenden Fucus-Arten bestimmt: Fucus spiralis, F. vesiculosus und F. serratus. Die nach Kornmann \& Sahling (1977) und Nienburg (1930) auf der Abrasionsterrasse und an den Molen in einer vertikalen Zonierung siedelnden Algen kommen in diesem Habitat auch nebeneinander vor. Bevorzugter Standort sind die etwa waagerecht liegenden Oberflächen der Bunkertrümmer und Betonquader, doch wachsen sie auch vereinzelt auf den Metallpfeilern. Im Licht- und Wellenschatten der Fucaceen siedelt Chondrus crispus in kleineren Beständen. Die einzelnen Pflanzen bleiben gegenüber denen in tieferen Zonen kleiner. Größere Exemplare findet man zusammen mit Corallina officinalis in den Gezeitentümpeln. Neben diesen ganzjährigen Formen treten vor allem in den Sommermonaten kleine Rasen von Enteromorpha spp. und Blidingia minima auf. Beide Arten siedeln an hochgelegenen Partien der Bunkertrümmer und Betonquader. Geschützt gelegene senkrechte Betonflächen werden im Sommer von Ulva lactuca bewachsen.

Fauna: Im Bereich der Geröllfelder wurden 58 Makrofauna-Arten gefunden (Tab. 5). Die formenreichsten Gruppen waren die Polychaeta (16 Arten) und die Prosobranchia (6). "Auffällige" Arten gehörten zu den Hydrozoa, Prosobranchia, Polychaeta, 
Tab. 5. Zeitliche und räumliche Verteilung der Makrofauna im Bereich der Geröllfelder. Zur Numerierung der Kleinhabitate siehe Abbildung 4

\begin{tabular}{|c|c|c|c|c|c|c|c|c|c|c|c|c|c|c|c|c|}
\hline \multirow[t]{2}{*}{ Species } & \multicolumn{7}{|c|}{ Monat (März-September) } & \multicolumn{9}{|c|}{ Kleinhabitat } \\
\hline & III & IV & $\mathrm{V}$ & VI & & & & 1 & $2 a$ & $2 \mathrm{~b}$ & & & 3 & 4 & 5 & 6 \\
\hline Dynamena pumila & $\therefore$ & $\infty$ & $\infty$ & $\infty 00$ & $\infty 000$ & $\infty \circ 8$ & $\infty 00^{\circ}$ & & - & - & $\bullet$ & & & & & - \\
\hline Laomedea flexuosa & 000 & $\infty$ & $\infty$ & 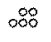 & 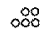 & 008 & 000 & & - & - & & - & & - & - & - \\
\hline Actinia equina & $\infty$ & $\infty$ & $\infty 00$ & $\infty$ & $\infty$ & $\infty$ & $\infty$ & & & - & & - & & & - & \\
\hline Metridium senile & - & - & $\circ$ & $\infty$ & $\infty 00$ & $\infty \infty$ & $\infty$ & & & - & & & & $\bullet$ & & \\
\hline Cryptosula pallasiana & $\circ$ & - & - & $\infty$ & $\infty$ & $\infty 00$ & $\infty$ & & $\bullet$ & - & & & & & & \\
\hline Lepidochiton cinereus & $\infty$ & $\infty$ & $\infty$ & $\infty$ & $\infty$ & $\infty$ & $\infty$ & & & & & - & & - & & \\
\hline Lacuna divaricata (juv.) & - & - & - & - & 000 & 000 & $\infty \infty$ & & & & & & - & & & \\
\hline Lacuna pallidula (juv.) & - & - & - & - & - & $\infty \infty$ & $\infty \infty$ & & & & & & - & & & \\
\hline Littorina mariae/ob & $\infty$ & $\infty \infty$ & $\infty 00$ & $\infty \infty$ & $\infty$ & $\infty 0^{2}$ & $\infty$ & - & & & - & & - & - & & - \\
\hline Littorina littorea & 008 & 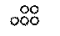 & $\infty 00$ & $\therefore$ & $\infty 0$ & $\cong$ & ○ & - & & & & & - & - & & - \\
\hline Littorinas & 0,0 & $\infty$ & $\infty 00$ & 000 & 000 & $\infty \infty 0$ & $\infty$ & - & & & & - & & & & - \\
\hline Mytilus edulis & 000 & $\infty 0^{\circ}$ & $\infty 0^{\circ}$ & $\infty 0^{\circ}-(-1)-(-1)$ & $\infty 0^{\circ}-(-3)-(-1)$ & $\infty 0^{8}$ & $\infty 0^{\circ}$ & - & & & & & & $\bullet$ & & - \\
\hline Polydora ciliata & 000 & $\infty \circ$ & $000^{\circ}$ & 0,8 & 000 & 000 & $\infty$ & & & - & - & - & & - & - & \\
\hline Solelepis squamata & $\infty$ & 000 & $\infty$ & $\infty$ & $\infty$ & $\infty$ & $\infty$ & - & - & & & & & - & & \\
\hline Malacoceros fuliginosus & - & - & - & $\infty$ & $\infty$ & 。 & 。 & • & & & & & & & & \\
\hline Lanice con & $\infty \infty$ & $\infty$ & $\infty 0^{\circ}$ & $\infty \infty$ & $\infty 00$ & $\infty 00$ & $\infty$ & - & - & & & & & - & & \\
\hline Fabricia sabella & $\infty 0^{\circ}$ & $\infty 0^{\circ}$ & $\infty$ & $\infty 00$ & $\infty \infty$ & $\infty 00$ & $\infty$ & & & - & & - & & & & - \\
\hline Janua pagenstecheri & $\infty$ & 0,0 & $\infty 0^{2}$ & 000 & $\infty 0^{\circ}$ & $\infty \infty$ & $\infty$ & & - & & & - & & & - & \\
\hline Spirorbis tridentatus & 008 & 0,0 & $\infty$ & 000 & $\infty$ & $\infty 00$ & oo & & - & - & & - & & & - & \\
\hline Balanus crenatus & $\infty$ & $\infty \infty$ & $\infty \infty$ & $\infty 00$ & $\infty \infty$ & $\infty$ & ০oo & & - & & & & & & - & - \\
\hline Semibalc & $\infty 0^{\circ}$ & $\infty 0^{\circ}$ & $\infty$ & 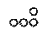 & $\infty 0^{\circ}$ & $000^{\circ}$ & $\infty \infty^{\circ}$ & & & & & - & & - & - & - \\
\hline Elminius modestus & $\infty$ & $\infty 0^{\circ}$ & $\infty 0^{\circ}$ & $\infty 08$ & $\infty 0^{\circ}$ & $\infty$ & $\infty$ & & & - & - & & - & - & - & - \\
\hline Chaetogammarus marinus & $\infty \infty^{\circ}$ & $\infty \circ$ & - & - & - & - & $000^{\circ}-(-3)-(-3)$ & - & - & & & & & & & \\
\hline Hyale nilssonii & oo & $\infty 00$ & $\infty$ & 008 & $\infty$ & $\infty \infty 0$ & $\infty$ & & & & & & & & - & - \\
\hline Jassa falcata & $\infty \infty$ & $\infty$ & $\circ$ & $\infty$ & $\infty \infty 0$ & $\infty$ & $\infty$ & & & & & & & $\bullet$ & - & \\
\hline Idotea granulosa & - & $\infty$ & $\infty$ & & $\infty$ & $\infty$ & $\infty$ & & & & & & - & & & \\
\hline Jaera albifrons & $\infty$ & & $\infty$ & $\infty$ & $\infty$ & $\infty$ & $\infty 00$ & & & & & & & - & - & - \\
\hline Carcinus maenas & $\infty$ & 000 & $\infty \circ$ & $\infty 00$ & $000^{\circ}$ & $\infty 00$ & & & & & - & & - & - & - & - \\
\hline Amphipholis squamata & - & - & & & & $\infty$ & $\infty$ & & & - & & & & & - & \\
\hline \multirow{6}{*}{\multicolumn{17}{|c|}{ 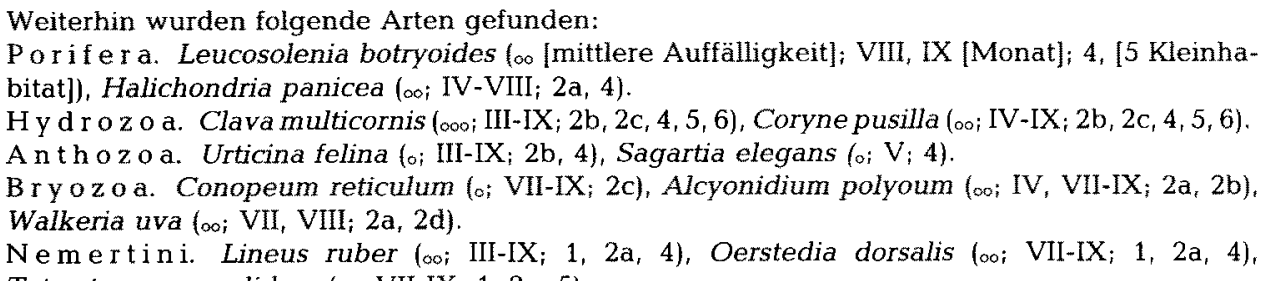 }} \\
\hline & & & & & & & & & & & & & & & & \\
\hline & & & & & & & & & & & & & & & & \\
\hline & & & & & & & & & & & & & & & & \\
\hline & & & & & & & & & & & & & & & & \\
\hline & & & & & & & & & & & & & & & & \\
\hline \multicolumn{17}{|c|}{ Tetrastemma candidum (oo; VII-IX; $1,2 \mathrm{a}, 5)$} \\
\hline \multicolumn{17}{|c|}{$\begin{array}{l}\text { Poly placoph or a. Lepidopleurus asellus (oo; III-V; } 4) \\
\text { Prosobranchia. Gibbula cineraria (o; III-IX; } 1,2 \mathrm{~d} \text { ). }\end{array}$} \\
\hline \multirow{2}{*}{\multicolumn{17}{|c|}{ 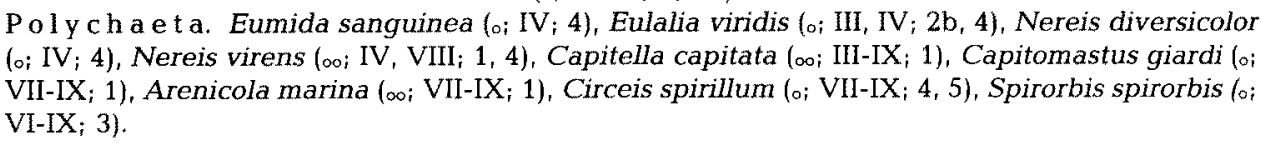 }} \\
\hline & & & & & & & & & & & & & & & & \\
\hline \multicolumn{17}{|c|}{ Oligoch a eta. Paranais litoralis $\left(_{000}\right.$ IV-IX; $\left.1,2 \mathrm{a}, 4\right)$} \\
\hline \multirow{2}{*}{\multicolumn{17}{|c|}{$\begin{array}{l}\text { Pantopoda. Anoplodactylus angulatus (o; III, V, VIII; 5). } \\
\text { Ins e cta. Clunio marinus (o; VIII; 3). }\end{array}$}} \\
\hline \multirow{2}{*}{\multicolumn{17}{|c|}{$\begin{array}{l}\text { In sect a. Clunio marinus (o; vill; } 3 \text { ). } \\
\text { Echinodermata. Asterias rubens }\end{array}$}} \\
\hline & & & & & & & & & & & & & & & & \\
\hline & & & & & & & & & & & & & & & & \\
\hline
\end{tabular}


Cirripedia, Amphipoda, Isopoda und Brachyura (Tab. 5). Typische Substratspezialisten waren Lacuna divaricata und L. pallidula (beide auf Fucus). Auf fast allen Untergründen konnte man dagegen Laomedea flexuosa, Littorina littorea, Fabricia sabella, Elminius modestus, Jaera albifrons und Carcinus maenas antreffen. Saisonal bzw. neu auftretende Formen waren Conopeum reticulum, Walkeria uva, Asterias rubens und Amphipholis squamata (Spätfrühling und Sommer). Die saisonale Zunahme von Elminius modestus (Juli/August) und Semibalanus balanoides (Februar/März) ist bereits von Harms \& Anger (1983) beschrieben worden. Die Neubesiedlungsphase der letztgenannten Art konnte innerhalb des Untersuchungszeitraumes allerdings nicht beobachtet werden.

\section{Der Mytilus-Fels}

Der Mytilus-Fels (Abb, 5) ragt als der am höchsten gelegene Bereich des Trümmerund Schuttfeldes noch länger als 2 Stunden nach Einsetzen der Flut deutlich über den Meeresspiegel hinaus. Der aus Schill, Kies und zerriebenem Buntsandstein bestehende Untergrund wird fast vollständig von Mytilus edulis bedeckt. Eingestreut in diese Flächen liegen mittlere und kleine Beton- und Basaltsteine. Während der Zeit des Trockenfallens bilden sich in kleinen Mulden bis zu $30 \mathrm{~cm}$ tiefe Gezeitentümpel. Ihr Untergrund unterscheidet sich nicht von dem der Umgebung. Auf der östlichen Seite liegen große Quader aus Beton (ca. 1 bis $3,5 \mathrm{~m}^{3}$ ), die aufeinandergestapelt, gegeneinandergelehnt und teilweise auch im Boden versenkt liegen. Durch ihre Anordnung entstehen auch hier die für die Geröllfelder schon beschriebenen Höhlen. Auf dem

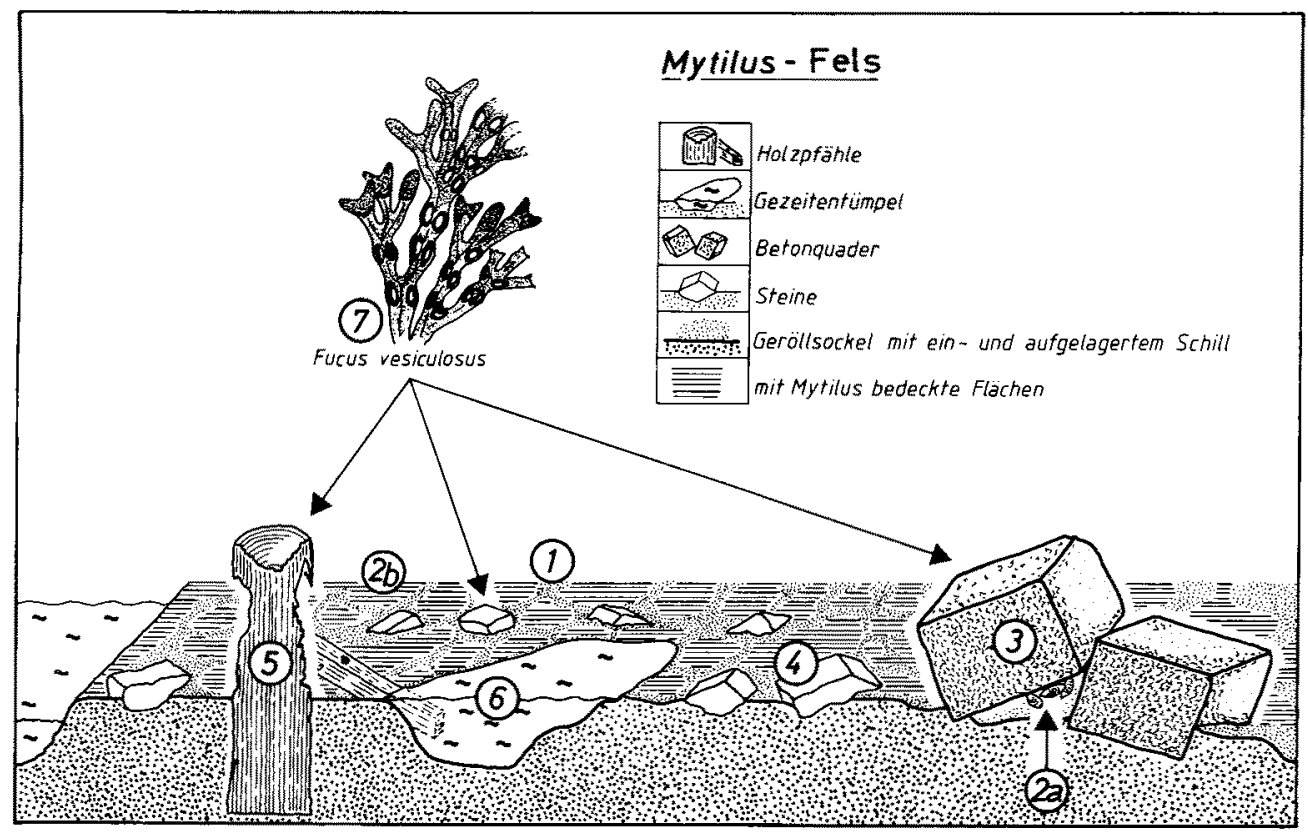

Abb. 5. Der Mytilus-Fels im Helgoländer Felswatt (schematisch). 1 Schillboden mit zerriebenen Buntsandstein- und Kiesanteilen; 2a Schalen von geschützt siedelnden Mytilus-Beständen; $2 \mathrm{~b}$ Von Mytilus edulis besiedelte Flächen; 3 Oberflächen der großen Betonquader; 4 Oberflächen der kleineren Geröllsteine; 5 Holzpfähle; 6 Gezeitentümpel; 7 Fucus vesiculosus 
Mytilus-Fels stehen zudem in zwei parallelen Reihen senkrecht in den Untergrund eingelassene Holzpfähle von bis zu $50 \mathrm{cra}$ Höhe und ca. $30 \mathrm{~cm}$ Durchmesser. Weitere Holzbohlen liegen im Schillsand und unter den Mytilus-Beständen. Sie reichen z. T. bis in die Gezeitentümpel hinein.

Flor a: Die Algenvegetation wird von Fucus vesiculosus bestimmt. Bevorzugte Siedlungsflächen sind die Oberflächen der Beton- und Basaltsteine. Geschlossene, flächendeckende Bestände sind nicht ausgeprägt. Auf den höher gelegenen Partien der Quader wachsen zudem Fucus spiralis und F. serratus. In ihrem Licht- und Windschatten siedelt Chondrus crispus. Die Holzpfähle werden von Fucus vesiculosus und krustenbildenen Rotalgen bewachsen. Bevorzugte Standorte sind die Pfahlkuppen. Eine reichhaltige Algenbesiedlung weisen die Gezeitentümpel auf. Hier findet man während des gesamten Jahres Cladophora rupestris, Chondrus crispus, Corallina officinalis und krustenbildende Rotalgen. Die typische saisonale Frühlingsform ist Dumontia incrassata. Zum Sommer folgen Ulva lactuca, Cladophora sericea und Chaetomorpha tortuosa.

F a u n : Im Bereich des Mytilus-Felsens wurden 59 Makrofauna-Arten gefunden (Tab. 6). Die formenreichsten Gruppen waren die Polychaeta (13 Arten), Prosobranchia (9) und Amphipoda (8). "Auffällige" Arten gehörten zu den Hydrozoa, Prosobranchia, Bivalvia, Cirripedia, Amphipoda, Isopoda, Anomura und Brachyura. Eng an die Gezeitentümpel (Kleinhabitat 6 in Tab. 6) gebunden blieben einige Anthozoa, Prosobranchia und Pantopoda. Dagegen fanden einige Hydrozoa (Dynamena pumila, Laomedea flexuosa), Prosobranchia (Littorina littorea, L. saxatilis), Polychaeta (Polydora ciliata, Lanice conchilega, Janua pagenstecheri, Spirorbis tridentatus), Cirripedia (Semibalanus balanoides, Elminius modestus) und Brachyura (Carcinus maenas) eine weitere Verbreitung innerhalb des Habitats.

Der saisonale Aspekt wurde am Beispiel von Lacuna spp. deutlich. Die den Winter überdauernden Populationen laichten im Frühjahr (März/April) ab. Danach starben die adulten Schnecken zum größten Teil. Zu dieser Zeit waren die Laichgelege auf Fucus serratus und Laminaria spp. sehr häufig. Zum Juli erschienen die neuen juvenilen Schneckengenerationen. Besonders deutlich war dieses Phänomen auch in der Fucus serratus-Zone der Abrasionsterrasse zu beobachten. Einen besonderen Lebensraum für das gesamte Felswatt boten die Holzpfähle (Kleinhabitat 5 in Tab. 6). Hier lebten 2 holzbohrende Arten: Teredo navalis und Limnoria lignorum. Der häufig mit Limnoria vergesellschaftet vorkommende Amphipode Chelura terebrans konnte nicht nachgewiesen werden. Der Oberflächenbewuchs der Holzpfähle ähnelte dem der benachbarten Hartsubstrate. Neben den Cirripedia waren besonders Hydrozoa, und sedentäre Polychaeta die typischen Besiedler. Zwischen den auf den Kuppen wachsenden Fucus vesiculosus-Beständen lebten Littorina mariae/obtusata und Hyale nilssonii.

\section{Der Littorina-Fels}

Der Littorina-Fels ist benannt nach der hier "sehr auffällig" vorkommenden Schnecke Littorina littorea. Die Oberfläche dieses Habitats ist durch die einheitlich gegliederten und zur See flach abfallenden Buntsandsteinflächen gekennzeichnet. Diese sind nur gelegentlich von wenigen kleineren Geröllsteinen unterbrochen. An einigen Stellen ragen sehr flache Buntsandsteinplatten hervor, die leicht hochgebrochen werden können.

Flor a: Die Flora des Littorina-Felsens ist saisonal unterschiedlich zusammenge- 
Tab. 6. Zeitliche und räumliche Verteilung der Makrofauna auf dem Mytilus-Fels. Zur Numerierung der Kleinhabitate siehe Abbildung 5

\begin{tabular}{|c|c|c|c|c|c|c|c|c|c|c|c|c|c|c|c|}
\hline \multirow{2}{*}{ Species } & \multicolumn{7}{|c|}{ Monat (März-September) } & \multicolumn{8}{|c|}{ Kleinhabitat } \\
\hline & III & IV & $\mathrm{v}$ & VI & VII & VIII & IX & 1 & $2 a$ & $2 \mathrm{~b}$ & 3 & 4 & 5 & 6 & 7 \\
\hline Dynamena pumila & $\infty \infty$ & $\infty \infty$ & $\infty$ & $\infty$ & $\infty$ & $\infty \infty^{\circ}$ & $\infty$ & & - & & - & & - & - & \\
\hline Laomedea flexuosa & $\infty$ & $\infty$ & $\infty$ & $\infty 0^{\circ}$ & $\infty 0^{\circ}$ & $\infty \infty^{\circ}$ & $\infty$ & & - & & & - & - & & - \\
\hline Metridium senile & - & - & $\infty$ & $\infty \infty$ & $\infty$ & $\infty \infty$ & $\infty$ & & - & & - & & & & \\
\hline Lepidochiton cinereus & - & - & - & $\infty$ & $\infty$ & $\infty$ & $\infty$ & & & & & & & - & \\
\hline Lepidopleurus asellus & $\infty \infty \infty$ & 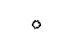 & $\infty$ & $\infty$ & $\circ$ & 。 & 。 & & & & & & & - & \\
\hline Lacuna divaricata $(\mathrm{x}=$ juv. $)$ & $\infty$ & . & - & - & $\mathrm{xxx}$ & $\mathrm{xxx}$ & $x x^{x}$ & & & & & & & & - \\
\hline Lacuna pallidula ( $\mathrm{x}=$ juv.) & $\infty$ & $\circ$ & - & - & $\mathrm{xxx}$ & $\operatorname{xox}$ & $\operatorname{xxx}$ & & & & & & & & - \\
\hline tusata & . & $\infty$ & $\infty$ & $\infty$ & $\infty \infty$ & $\infty \infty$ & $\infty$ & - & & & - & & - & & - \\
\hline Littorina littorea & $\infty \infty^{\circ}$ & $\infty$ & $\cong$ & $\infty$ & $\cong$ & $\infty$ & $\infty$ & - & - & - & - & - & - & - & - \\
\hline Litto & $\infty \infty$ & $\infty 0^{\circ}$ & $\infty \circ$ & $\infty 0^{\circ}$ & 000 & $\infty 00$ & $\infty$ & - & - & - & - & & & & \\
\hline Is edulis & $\begin{array}{l}\infty \infty \\
\infty \infty \infty\end{array}$ & $\infty \infty \infty 00$ & $\stackrel{\infty}{\infty \infty 0}$ & $\infty$ & $\infty$ & $\stackrel{\infty}{\infty}$ & 이 & • & & & - & & & & \\
\hline is & $\infty$ & $\infty$ & $\infty$ & - & - & - & - & & & & & & - & & \\
\hline liata & $\infty$ & $\infty$ & $\infty$ & $\infty 0^{\circ}$ & $\infty 00$ & $\infty$ & 0 & & & & - & & - & - & \\
\hline Scolelepis squamata & - & 。 & $\infty$ & $\infty$ & $\infty$ & $\infty$ & - & & & & & & & - & \\
\hline Lanice conchilega & $\infty$ & $\infty$ & $\infty$ & 000 & $\infty 0^{\circ}$ & $\infty \infty 0$ & 000 & - & & & & & & - & \\
\hline Fabric & $\infty$ & $\infty$ & 000 & $\infty \infty^{\circ}$ & $\infty$ & $\infty \infty$ & $\infty$ & & - & & - & & - & - & \\
\hline$r i$ & $\infty 0^{\circ}$ & $\infty$ & $\infty$ & $\infty 0^{\circ}$ & $\infty$ & $\infty \infty \infty$ & $\infty 00$ & & & & & & - & - & \\
\hline Spiro & $\infty$ & $\infty 0^{\circ}$ & $\infty 0^{\circ}$ & $\infty 0^{\circ}$ & $\infty$ & $\infty$ & $\infty \infty \infty$ & & - & & - & & & - & \\
\hline Semibalanus balanol & $\infty$ & $\infty 0^{\circ}$ & $\infty \infty^{\circ}$ & $\infty 0^{\circ}$ & $\infty \infty^{\circ}$ & $\infty \infty^{\circ}$ & $\infty 0^{\circ}$ & & - & - & - & & - & - & \\
\hline Elminius modestus & $\infty$ & $\infty \infty$ & 000 & $\infty \infty^{\circ}$ & $\infty \infty^{\circ}$ & $\infty$ & $\infty$ & & - & - & & & - & - & \\
\hline sonii & & $\infty \infty$ & $\infty 0^{\circ}$ & $\infty 0^{\circ}$ & $\infty \infty$ & $\infty$ & $\infty$ & & & & & & & & - \\
\hline ia lignorum & $\infty$ & $\infty \circ$ & $\infty \infty^{\circ}$ & $\infty 0^{\circ}$ & $\infty \infty^{\circ}$ & $\infty \infty^{\circ}$ & 008 & & & & & & - & & \\
\hline nulosa & $\infty$ & $\infty$ & $\infty \infty$ & $\infty \infty$ & $\infty \infty 00$ & 000 & $\infty \infty$ & & & & & & & & \\
\hline Jaera albifrons & - & 0,0 & $\infty \circ$ & $\infty$ & $\infty$ & $\infty$ & $\infty \infty$ & - & - & & & & & - & \\
\hline Pagurus bernhardus & - & - & $\infty$ & $\infty \infty$ & 000 & 000 & 000 & & & & & & & - & \\
\hline Carcinus maenas & & $\infty \infty$ & & $\infty 00$ & $\infty \infty^{\circ}$ & $\infty$ & $\infty$ & - & & & & & - & & - \\
\hline \multicolumn{16}{|c|}{ 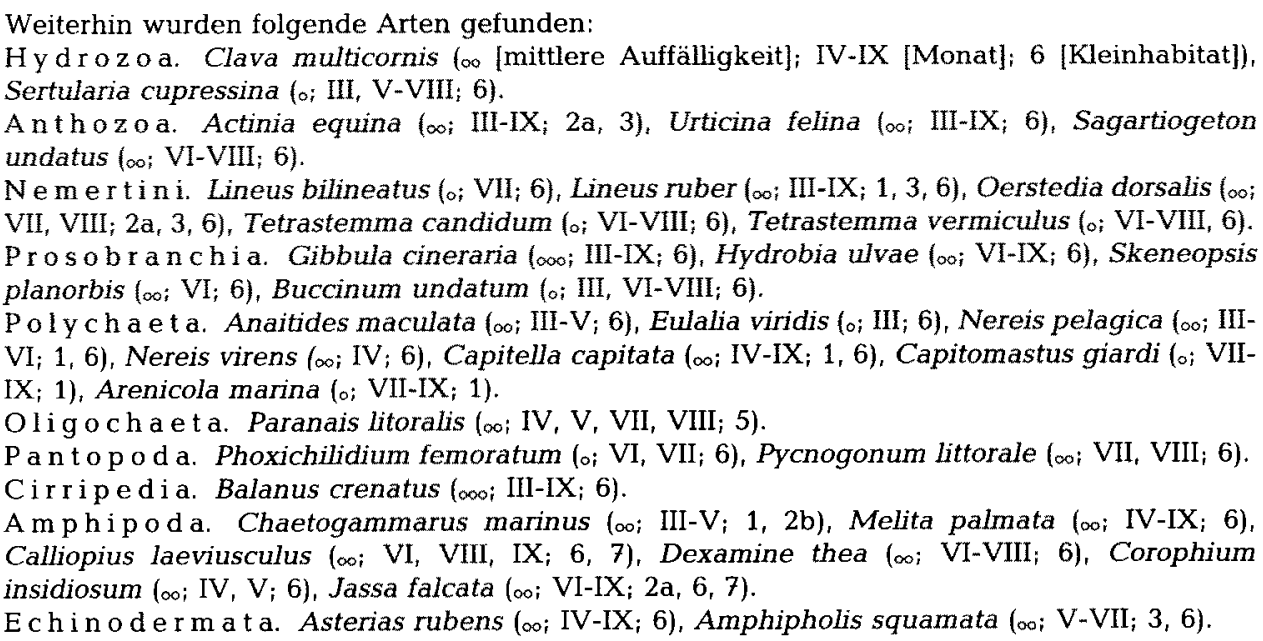 } \\
\hline
\end{tabular}


Tab. 7. Zeitliche und räumliche Verteilung der Makrofauna auf dem Littorina-Fels. Zur Numerierung der Kleinhabitate siehe Abbildung 6

\begin{tabular}{|c|c|c|c|c|c|c|c|c|c|c|c|}
\hline \multirow[t]{2}{*}{ Species } & \multicolumn{7}{|c|}{ Monat (März-September) } & \multicolumn{4}{|c|}{ Kleinhabitat } \\
\hline & III & IV & V & VI & VII & VIII & IX & 1 & 2 & 3 & 4 \\
\hline Cryptosula pallasiana & - & - & - & - & $\infty$ & $\infty$ & $\infty$ & & & - & \\
\hline Littorina littorea & $\infty$ & $\infty$ & 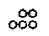 & $\infty$ & $\infty$ & $\infty$ & $\infty$ & - & - & & \\
\hline Polydora ciliata & - & - & - & 。 & $\infty$ & $\infty$ & $\infty$ & & & - & \\
\hline Fabricia sabella & - & - & - & - & $\infty$ & $\infty$ & - & & & - & \\
\hline Paranais litoralis & - & - & - & - & - & $\infty 0^{\circ}$ & $\infty$ & & & - & \\
\hline Carcinus maenas & - & - & - & - & - & $\infty$ & $\infty$ & $\circ$ & & & \\
\hline \multicolumn{12}{|c|}{ 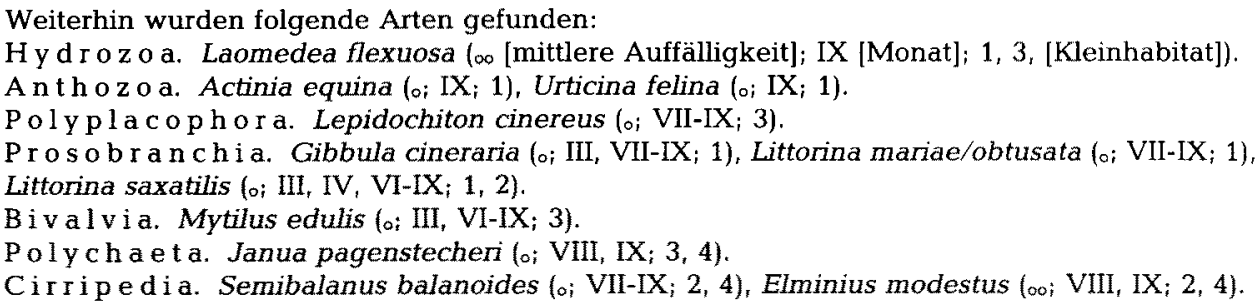 } \\
\hline
\end{tabular}

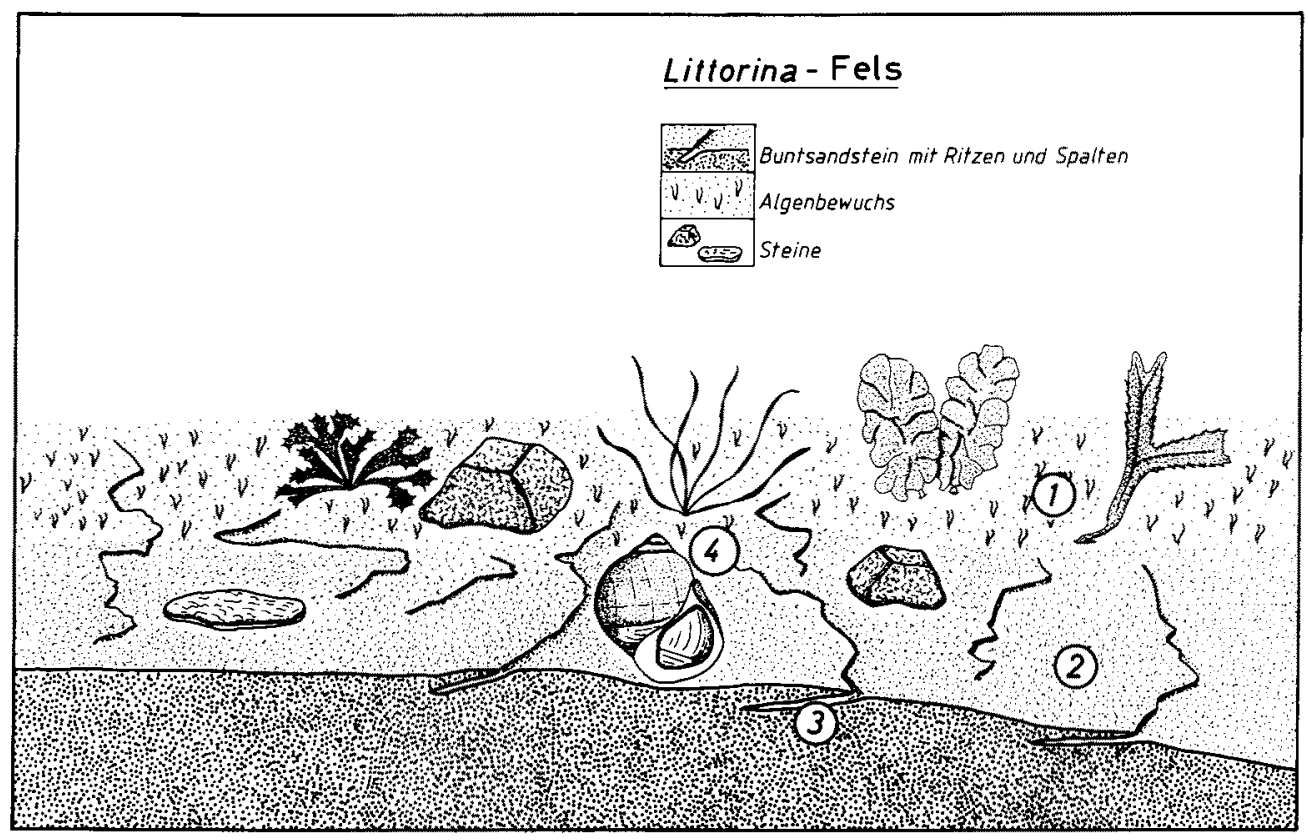

Abb. 6. Der Littorina-Fels im Helgoländer Felswatt (schematisch). 1 Buntsandsteinflächen mit Algenbewuchs; 2 Buntsandsteinflächen ohne Algenbewuchs; 3 Nischen und Ritzen im Buntsandstein; 4 Oberflächen von Littorina-Gehäusen 
setzt. Die auf der gesamten Fläche ganzjährig vorherrschende Art ist Chondrus crispus. In wenigen Exemplaren findet man Fucus serratus und $F$. vesiculosus. Der Frühjahrsaspekt wird ergänzt durch Dumontia incrassata. Diese Rotalge bildet dann zusammen mit Chondrus crispus flächendeckende Teppiche. Zum Hochsommer folgen Cladophora sericea, Ulva lactuca und Chaetomorpha tortuosa. In den Spätsommermonaten verschwinden die saisonal auftretenden Formen wieder und der im Frühling angetroffene Aspekt wird erneut bestimmend. Ein großer Teil der Flächen bleibt während der gesamten Zeit ohne Bewuchs durch benthische Algen. Die Littorina-Population weidet den Diatomeenrasen ab und verhindert möglicherweise gleichzeitig die Ansiedlung von größeren benthischen Formen.

F a u n a Im Bereich des Littorina-Felsens wurden 17 Makrofauna-Arten gefunden (Tab. 7). die artenreichsten Gruppen bildeten die Prosobranchia (4 Arten) und die Polychaeta (3). "Auffällige" Formen gehörten zu den Prosobranchia (Littorina littorea), Polychaeta (Polydora ciliata) und den Oligochaeta (Paranais litoralis). Substratspezifische oder räumlich eng begrenzte Verbreitung fanden Cryptosula pallasiana (Buntsandstein), Littorina mariae/obtusata (auf Fucus) und Paranais litoralis (Ritzen im Buntsandstein). Auch die Gehäuseoberflächen von Littorina littorea wurden besiedelt. Sie waren bevorzugter Standort von sedentären Polychaeta und Cirripedia. Die Artenzahl der

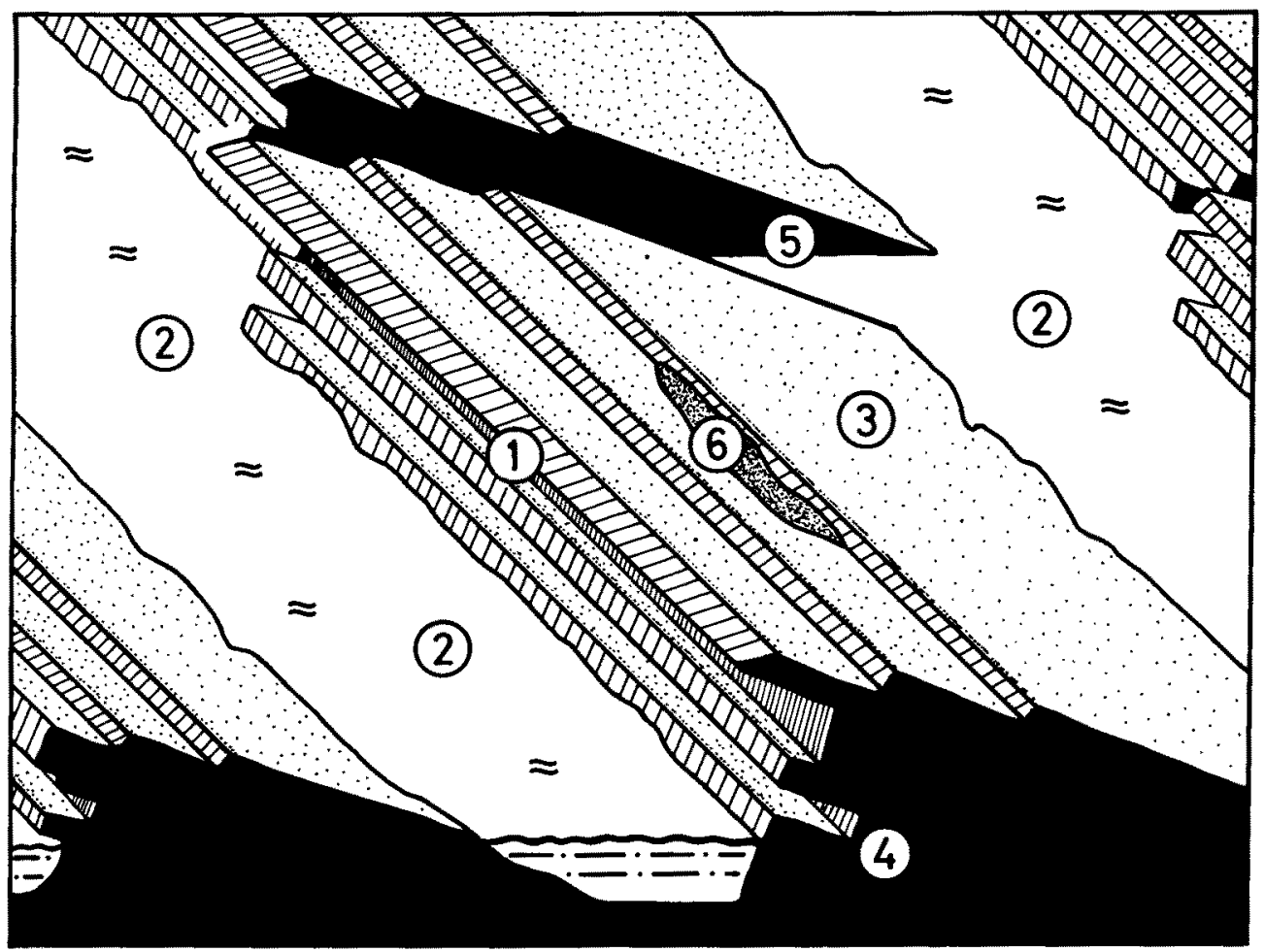

Abb. 7. Schematische Darstellung der Oberflächenstruktur im Helgoländer Felswatt. 1 Schichtkopf; 2 Priel; 3 Schichtfläche; 4 Schichthöhle; 5 Verwerfung; 6 Schillablagerung (verändert nach Hagmeier, 1930) 
Makrofauna stieg zwischen März und September von 4 auf 16 Arten an. Einzig Fabricia sabella wurde im September nicht mehr aufgefunden. Die Littorina-Besiedlungsdichte lag in den Monaten April bis August zwischen 156 und 172 Individuen $/ \mathrm{m}^{2}$. Im März und September lagen die Werte deutlich darunter ( $77 \mathrm{bzw} .132$ Individuen $/ \mathrm{m}^{2}$ ). Eine Dispersionsanalyse ergab, daß die Schnecken nicht gleichmäßig oder zufällig, sondern haufenartig verteilt waren.

\section{Die Abrasionsterrasse}

Die Abrasionsterrasse (Abb. 7) bildet den Hauptteil des Felswatts. In Anlehnung an Hagmeier (1930) lassen sich folgende morphologische Strukturen unterscheiden: (1) Schichtköpfe, (2) Priele, (3) Schichtflächen, (4) Schichthöhlen, (5) Verwerfungen und (6) Schillablagerungen.

Diese Strukturen (Abb. 7) reichen im Nordostwatt bis an den steil aufragenden Felsen und fallen bei extremen Springtiden bis zu $300 \mathrm{~m}$ seewärts trocken. Die in einem Winkel von $15-20^{\circ} \mathrm{C}$ anstehenden Feinschichten des Buntsandsteins werden von der See ausgeräumt und hinterlassen zwischen den härteren Schichten Priele zurück, die in Richtung NW auf die offene See hinausführen. Die Verwerfungsritzen verlaufen zu den Prielen in einem Winkel von etwa $80-110^{\circ} \mathrm{C}$. Die Abrasionsterrasse (Abb. 8) läßt sich aufgrund ihrer vertikal zonierten Algenbesiedlung zunächst in drei Bereiche einteilen: die Enteromorpha-Zone im oberen Eulitoral, die Fucus-Zone im mittleren und unteren Eulitoral (wobei im mittleren Bereich F. spiralis und $F$. vesiculosus, im unteren und bedeutend weiter ausgedehnten Bereich $F$. serratus überwiegen) und die LaminariaZone im oberen Sublitoral; sie wird von $L$. saccharina und L. digitata gebildet.

Da die Exposition des Nordostwatts in allen Bereichen in etwa gleich groß ist und die Morphologie auf der Abrasionsterrasse überall ähnliche Strukturen und den gleichen Untergrund aufweist, kann das periodische Trockenfallen als ein entscheidender Faktor für die Zonierung der Algen angesehen werden. Bei einer Probennahme, die sich am Litoralgradienten orientieren soll, ist die Algenbesiedlung daher als ein Anhaltspunkt zur Abschätzung des Wasserstandsniveaus gut geeignet. Eine Sonderstellung nehmen die Priele ein (Abb. 13), da viele von ihnen auch bei extremen Springtiden nicht trockenfallen. Die heterogen gestalteten Prielbetten sind in ihrer Morphologie nicht mit den Hauptbesiedlungsflächen der Großalgen, den Schichtflächen, vergleichbar. Für die Probennahme auf der Abrasionsterrasse wurden deshalb folgende Habitate unterschieden: (1) die Enteromorpha-Zone; (2) die Fucus serratus-Zone; (3) die Priele; (4) die Laminaria-Zone.

\section{Die Enteromorpha-Zone}

Die Enteromorpha-Zone (Abb. 10) liegt im oberen Bereich der Abrasionsterrasse. Sie reicht bis an den steil aufragenden Felsen des Oberlandes. Der flach zur See abfallende Buntsandsteingrund ist an einigen Stellen von kleinen Schillfeldern bedeckt. Hier liegen außerdem abgestürzte Buntsandsteinblöcke, die mit Chrysokoll ausgekleidete Vertiefungen ("Drusen") aufweisen können. Diese werden häufig von Littorina saxatilis als Schlupfwinkel aufgesucht. In flachen Mulden sammelt sich während der Ebbe das Wasser am Boden zu kleinen Gezeitentümpeln. Da dieser Bereich tagsüber lange im Lichtschatten der Felswand liegt, treten in diesen hochgelegenen Wasserlachen keine durch Sonneneinstrahlung bedingten extremen Salinitäts- und Temperatur- 


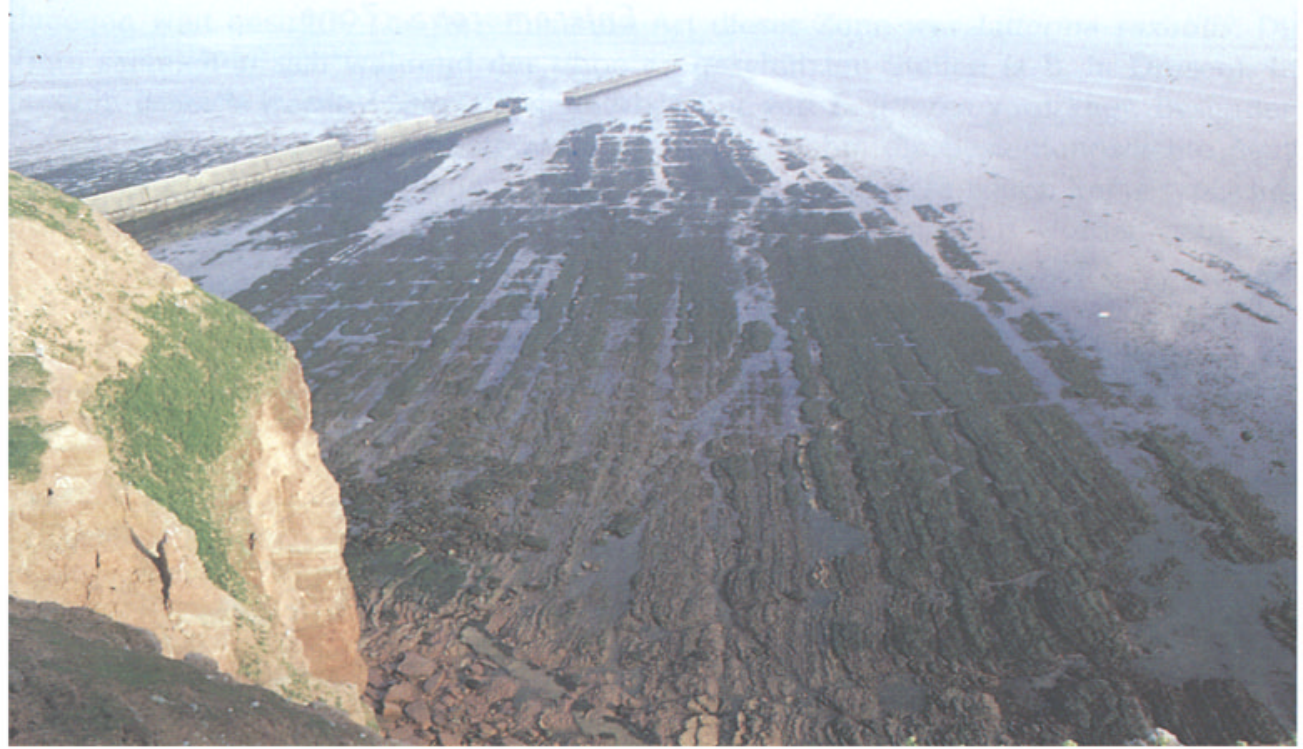

Abb. 8. Abrasionsterrasse im Helgoländer Nordost-Felswatt bei extremem Niedrigwasser. Blickrichtung N/NW. Links die verlängerte NW-Mole (Juni 1984)

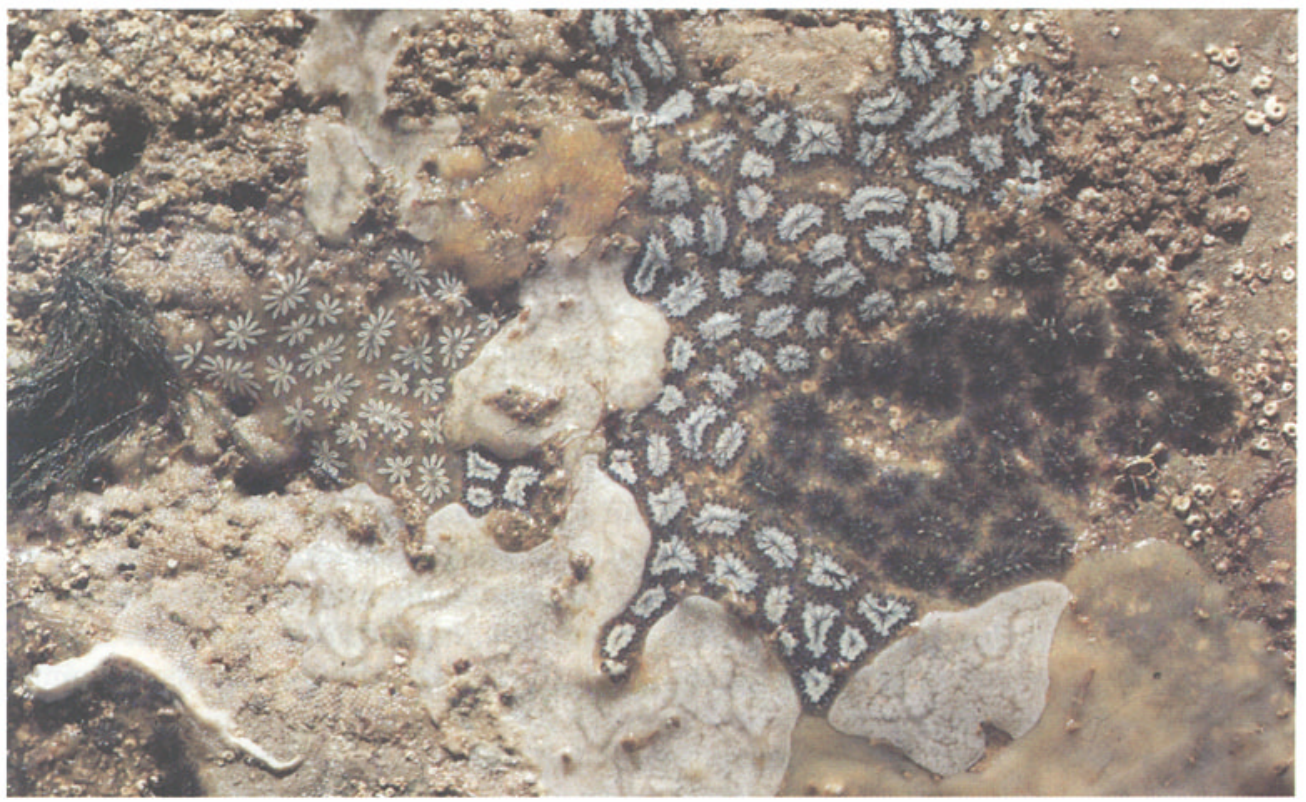

Abb. 9. Priel im Helgoländer Felswatt. Besiedlung der Unterseite einer Buntsandsteinscholle (Kleinhabitat 3b in Abb. 13, Tab. 10). Halisarca dujardini (unten rechts), Cryptosula pallasiana (unten links), Fabricia sabella-Polster (oben links und rechts), Pomatoceros triqueter (unten links), Spirorbidae (oben links und rechts), Sidnyum turbinatum (oben Mitte), Botryllus schlosseri (3 Klone, Mitte links und rechts), Didemnum sp. (zentrale und untere Mitte; Juli 1984) 


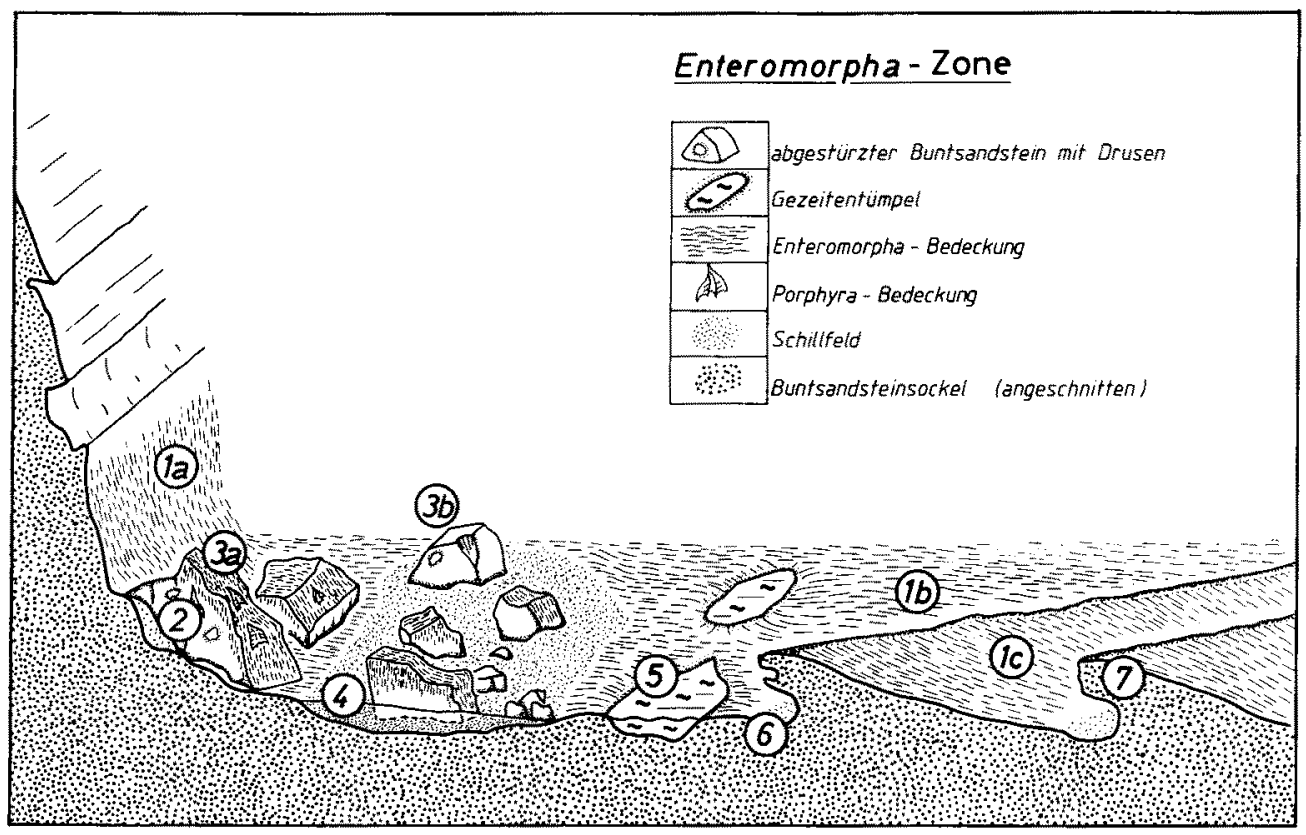

Abb. 10. Enteromorpha-Zone im Helgoländer Felswatt (schematisch). 1a Enteromorpha-Rasen am steil aufragenden Fels; $1 \mathrm{~b}$ E.-Rasen auf annähernd waagerechten Flächen; 1c E.-Rasen auf den Schichtflächen; 2 Höhle unter abgestürzten Felsblöcken; 3a Bewachsene Oberflächen der Felsblöcke; 3b Nackte Oberflächen der Felsblöcke; 4 Sand- und Schillfeld; 5 Gezeitentümpel; 6 Fußregion des Schichtkopfes (= Minipriel); 7 Schichtkopf

schwankungen auf. Die für die Abrasionsterrasse typischen geomorphologischen Strukturen sind nur schwach ausgebildet.

Flor a: Die Enteromorpha-Zone ist nach ihrer Hauptbesiedlungsform benannt. Sie bildet flache und fädige Rasen, die große Partien der oberen Abrasionsterrasse fast vollständig bedecken. An einigen Stellen wird zusammen mit Blidingia spp. auch der untere Fuß der Steilwand besiedelt. Enteromorpha spp. wächst sowohl auf dem Buntsandstein als auch auf den Betontrümmern, nicht aber auf Schillfeldern. Von der Steilwand herabgestürzte Geröllsteine werden binnen weniger Tage besiedelt. Die Besiedlung durch Enteromorpha spp. begann im Untersuchungszeitraum etwa Mitte März und dauerte bis Ende September. Danach riß der bis dahin dichte Rasen auf. Ab Mitte Oktober war er völlig verschwunden. An einigen Buntsandsteinfelsen siedelte zusätzlich ab Ende Juni bis Ende September Porphyra umbilicalis in kleineren Beständen. Blidingia spp. konnte dagegen während des gesamten Untersuchungszeitraumes angetroffen werden.

$\mathrm{F}$ a u n a: Im Bereich der Enteromorpha-Zone wurden 23 Makrofauna-Arten gefunden (Tab. 8). "Auffällige" Arten gehörten zu den Hydrozoa (Laomedea flexuosa), Prosobranchia (Littorina saxatilis), Amphipoda (Chaetogammarus marinus) und Brachyura (Carcinus maenas). Relativ artenreich vertreten war die Gruppe der Insecta ( 3 Arten). Petrobius brevistylis lebte versteckt in Nischen und Ritzen des Supralitorals und wanderte während der Ebbe in dieses Habitat ein (siehe auch Larink, 1968). 
Typische Kleinhabitatspezialisten waren die Polychaeta. Die Prosobranchia waren dagegen weit gestreut. Die bestimmende Art dieser Zone war Littorina saxatilis. Die Tiere sammelten sich während der Ebbe an geschützten Stellen (z. B. in Drusen). Im unteren Bereich wurde $L$. saxatilis immer stärker von $L$. littorea verdrängt. Besonders unterhalb der scharf abgegrenzten Grünalgenzone nahm die Besiedlungsdichte deutlich und sprunghaft zu. Gibbula cineraria und Idotea granulosa waren keine typischen Besiedler dieses Habitats. Sie dürften durch die Flut eingespült worden sein. Die

Tab. 8. Zeitliche und räumliche Verteilung der Makrofauna in der Enteromorpha-Zone. Zur Numerierung der Kleinhabitate siehe Abbildung 10

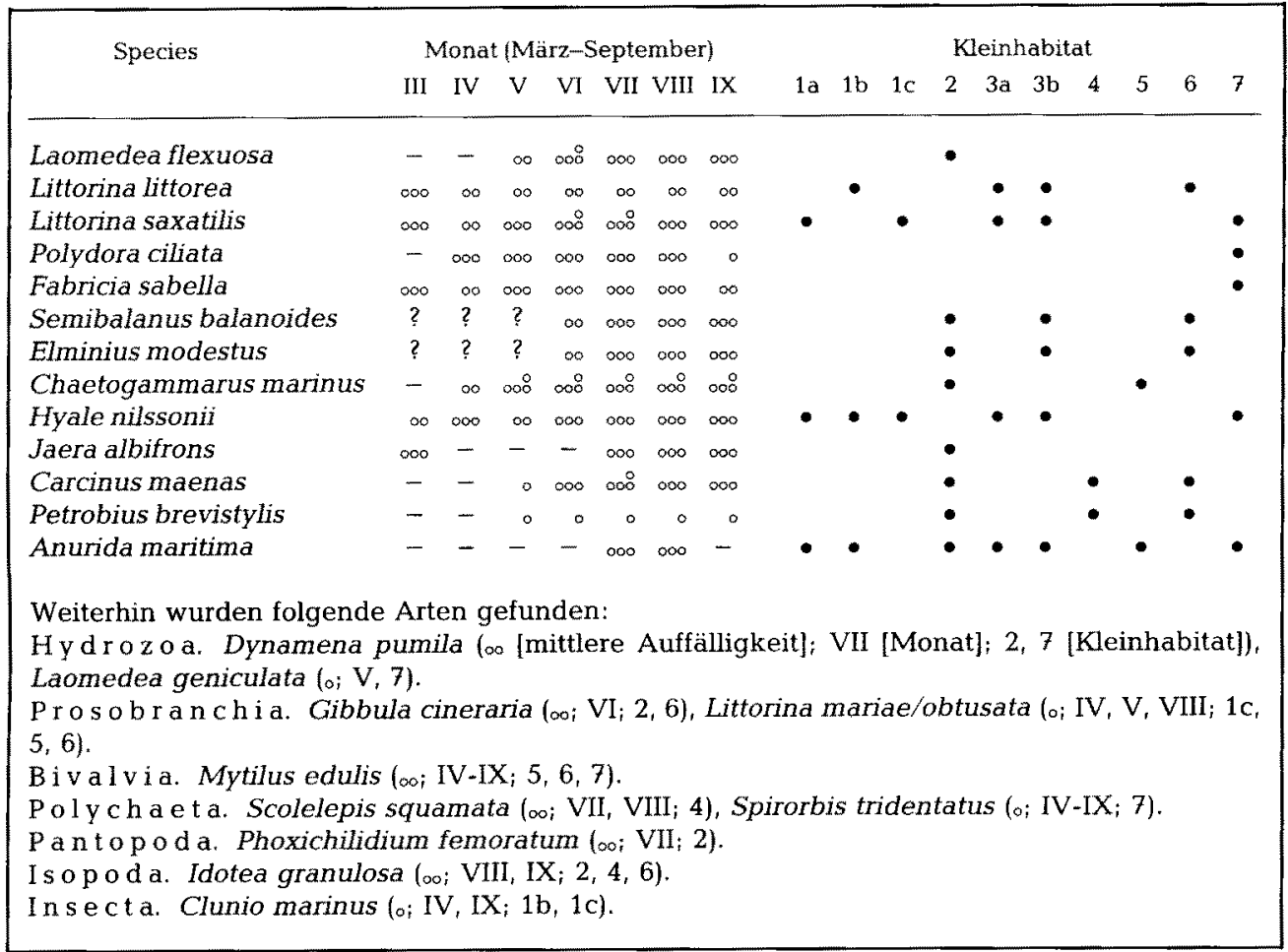

Enteromorpha-Zone wurde zur Ebbezeit auch von terrestrischen Arten besucht. Außer Petrobius brevistylis wanderten Aranae, Acari (z. B. Molgus litoralis) und Oniscidae in diesen Bereich ein. Sie blieben bei dieser Untersuchung jedoch unberücksichtigt.

Saisonale Veränderungen in der Zusammensetzung der Makrofauna wurden nur innerhalb weniger Gruppen beobachtet. Amphipoda und Prosobranchia waren während des gesamten Untersuchungszeitraumes "auffällig" oder "regelmäßig" vertreten. Die ab Juni festgestellten adulten Cirripedia wurden während der vorausgegangenen Probennahmen offensichtlich übersehen. Semibalanus balanoides und Elminius modestus kamen in der Enteromorpha-Zone also ganzjährig, aber nicht "auffällig" vor. 


\section{Die Fucus serratus-Zone}

Die Fucus-Zone (Abb. 11) bildet den mittleren und unteren Bereich des Eulitorals. In diesem Habitat sind die geomorphologischen Strukturen der Abrasionsterrasse deutlich ausgeprägt. Außerdem fallen die Buntsandsteinschollen in den flachen Prielen (Kleinhabitat $5 \mathrm{a} / \mathrm{b}$ in Abb. 11) und die Gezeitentümpel auf den Schichtflächen (Kleinhabitat $3 \mathrm{~b}$ in Abb. 11) auf. Letztere messen bei einer Tiefe von etwa $30 \mathrm{~cm}$ nicht mehr als $1,5 \mathrm{~m}$ im Durchmesser. Die Priele in der Fucus serratus-Zone fallen während der Ebbe regelmäßig trocken. Nur an einigen Stellen bleiben flache Pfützen zurück. Die Sohlen der Priele sind häufig mit Sand- und Schillfeldern bedeckt. Auch auf den Schichtflächen sammelt sich dieses Material in Ritzen und an geschützt gelegenen Stellen an.

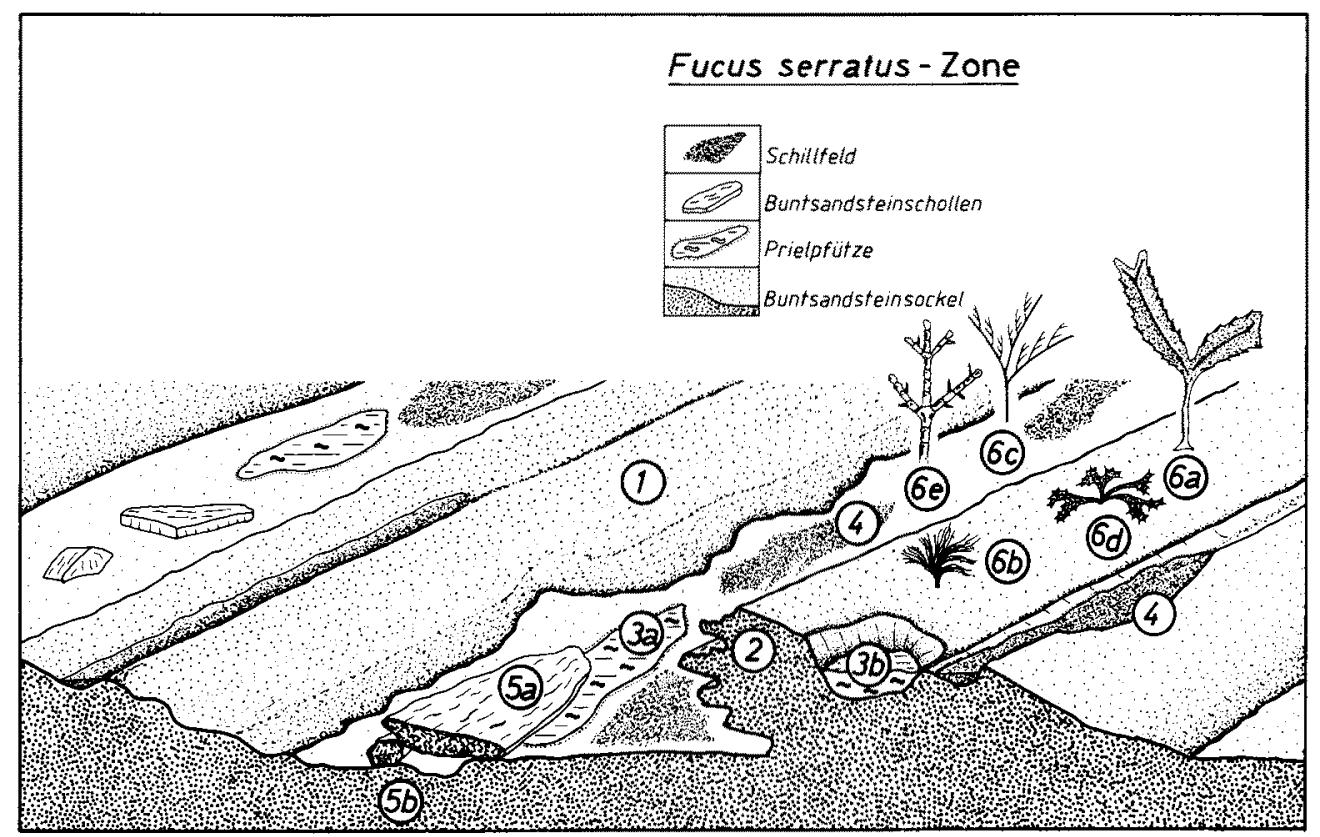

Abb. 11. Fucus serratus-Zone im Helgoländer Felswatt (schematisch). 1 Schichtfläche; 2 Schichtkopf; 3a Prielpfütze; 3b Gezeitentümpel; 4 Schillfeld; 5a Buntsandsteinscholle (Aufseite); 5b Buntsandsteinscholle (Unterseite); 6a Fucus serratus; 6b Cladophora rupestris; 6c Cladophora sericea; 6d Chondrus crispus; $6 \mathrm{e}$ Corallina officinalis

Flora: Die Fucus serratus-Zone ist nach ihrer Hauptbesiedlungsform benannt. Diese Großalge wächst flächendeckend vor allem auf den Schichtflächen. An den Schichtköpfen hängen bei Ebbe die Thalli soweit herunter, daß diese verdeckt und vor dem Sonnenlicht geschützt bleiben. In den Prielen ist der Fucus serratus-Bewuchs geringer, so daß sich vor allem hier, aber auch auf den Schichtflächen, andere Algen ansiedeln. Die wichtigsten Arten sind Cladophora rupestris, Chondrus crispus und krustenbildende Rotalgen. In den Prielpfützen und Gezeitentümpeln überwiegt Corallina officinalis. Häufige saisonale Frühlingsformen sind Rhodomela converfoides (nur in Prielen und Gezeitentümpeln) und Dumontia incrassata. Im Frühsommer folgen Cladophora sericea, Chaetomorpha tortuosa und Ceramium rubrum (auf Fucus). In den oberen 
Tab. 9. Zeitliche und räumliche Verteilung der Makrofauna in der Fucus serratus-Zone. Zur Numerierung der Kleinhabitate siehe Abbildung 11

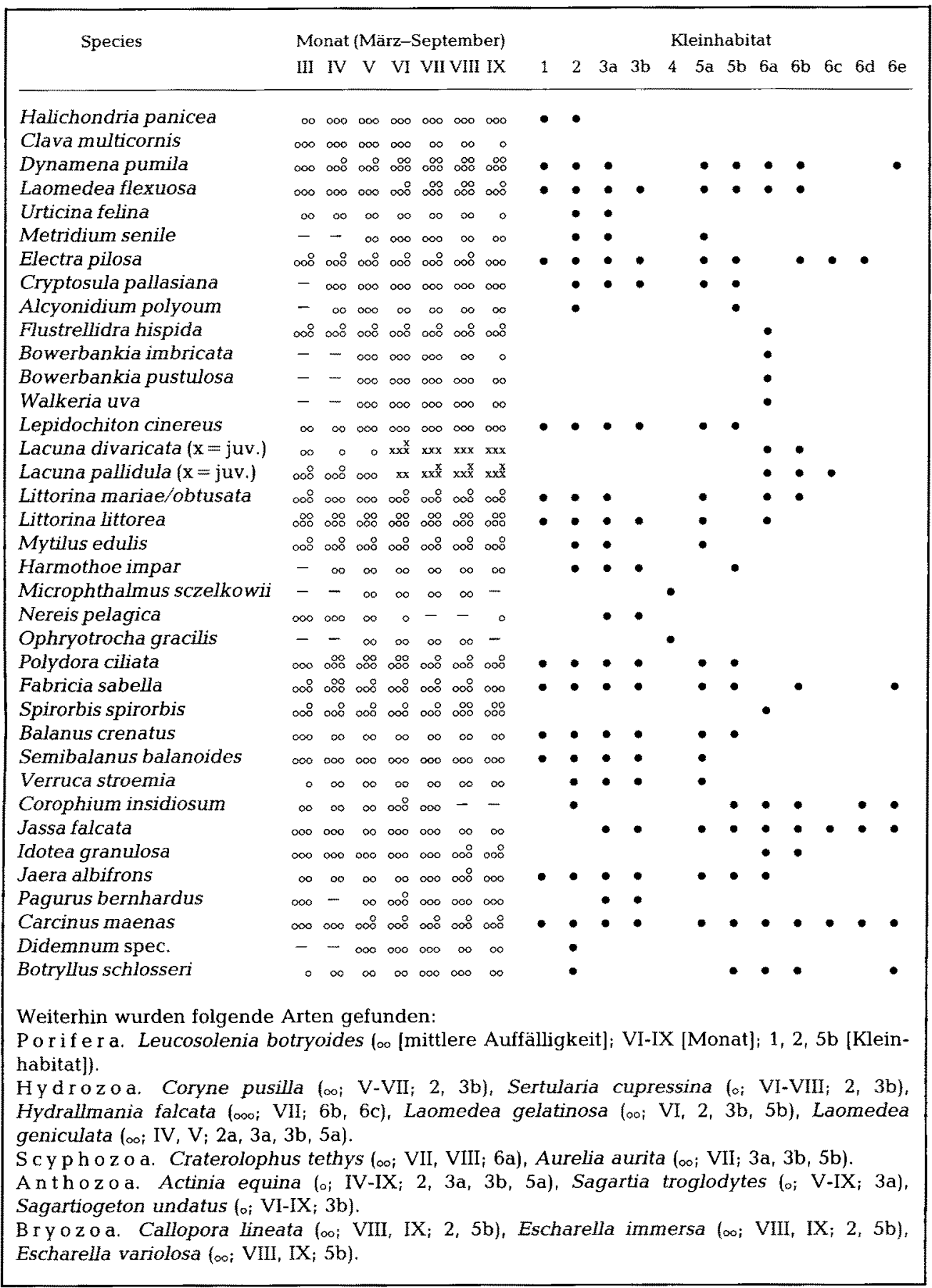


Tab. 9 (Fortsetzung). Verteilung der Makrofauna in der Fucus-serratus-Zone

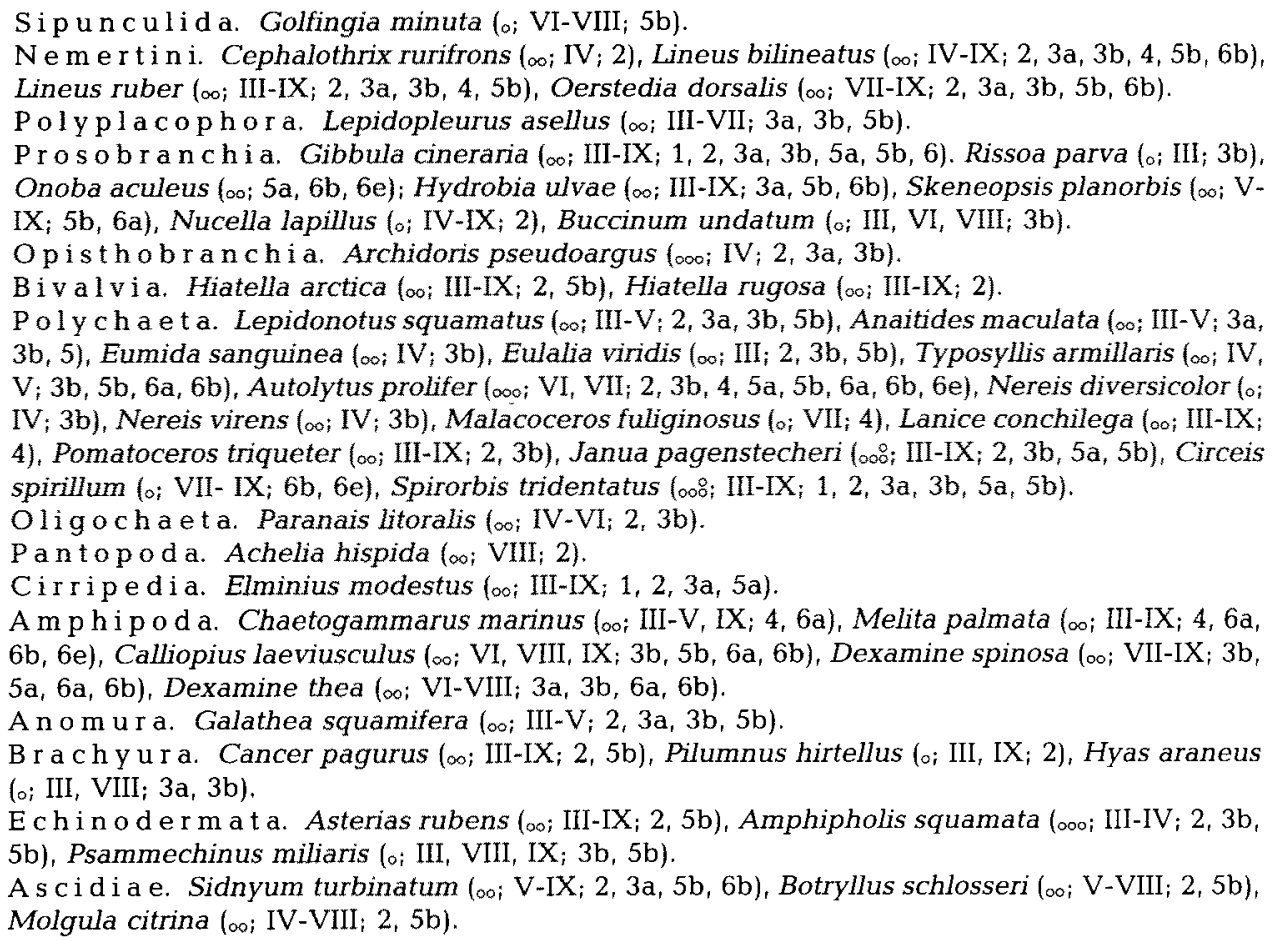

Bereichen dieser Zone treten auch Fucus spiralis und F. vesiculosus auf. Beide Arten kommen jedoch nicht in flächendeckenden Beständen vor. Gelegentlich wachsen Laminaria digitata und $L$. saccharina in den unteren Bereichen der Priele. Sie lösen dort Fucus serratus als Leitform ab. Die Laminaria-Bestände reichen so fingerförmig in die $F$. serratus-Zone hinein. Bei der Probennahme innerhalb der Fucus-Zone wurden sie nicht berücksichtigt.

Fauna: In der Fucus serratus-Zone wurden 99 Makrofauna-Arten gefunden (Tab. 9). Die artenreichsten Gruppen waren die Polychaeta (21 Arten), Prosobranchia (11) und Bryozoa (10). "Auffällige" Arten gehörten zu den Hydrozoa, Bryozoa, Prosobranchia, Bivalvia, Polychaeta, Amphipoda, Isopoda, Anomura und Brachyura.

Die Porifera waren in der Fucus serratus-Zone mit 2 Arten vertreten. "Regelmäßig" anzutreffen war Halichondria panicea. Von den 8 Hydrozoa-Arten waren nur Dynamena pumila und Laomedea flexuosa "auffällig" vertreten. Die Scyphozoa waren nur im Juli und August im Felswatt präsent. Die kleinen Polypen von Aurelia aurita siedelten auf dem Buntsandsteinboden. Craterolophus tethys dagegen haftete nur auf Großalgen. Anthozoa waren zwar weit verbreitet, doch kamen sie nur in geringer Individuendichte vor. Lediglich Metridium senile war während des Untersuchungszeitraumes "regelmäBig" anzutreffen. Sagartia troglodytes und Sagartiogeton undatus benötigten einen ständig überspülten Standort. 
Eine charakteristische Gruppe, die in höher gelegenen Bereichen nur spärlich vorkam, bildeten die Bryozoa. Zu den Substratspezialisten innerhalb dieser Gruppe gehörten Callopora lineata, Cryptosula pallasiana, Escharella immersa, E. variolosa und Alcyonidium polyoum (alle auf Buntsandstein). Bowerbankia imbricata, B. pustulosa und Walkeria uva siedelten fast ausschließlich auf Cladophora rupestris. Flustrellidra hispida wurde dagegen nur auf Fucus serratus gefunden. Electra pilosa konnte auf mehreren Substraten angetroffen werden. Diese "auffällige" Art besiedelte sowohl den Hartboden als auch Algenthalli.

Typische Besiedler der Fucus serratus-Zone waren auch die Polyplacophora. Die sublitorale Form Lepidopleurus asellus wurde mit abnehmender "Auffälligkeit" bis in den Juli hinein beobachtet. Sie kam im Gegensatz zu Lepidochiton cinereus ausschließlich in ständig überspülten Kleinhabitaten vor. Die Prosobranchia bildeten bei einer Freilandbegehung die "auffälligste" Gruppe. Das galt insbesondere für Littorina littorea, die unterhalb der Enteromorpha-Zone bis in die mittlere Fucus serratus-Zone ihre höchste Besiedlungsdichte hatte. Sie weidete bevorzugt auf steinigem Untergrund, konnte aber auch häufig auf Schillsubstrat und auf den Algenthalli beobachtet werden. Ein typischer Besiedler auf Fucus serratus war Littorina mariae/obtusata. Ausschließlich auf Algen anzutreffen waren auch Lacuna divaricata, Lacuna pallidula und Skeneopsis planorbis. Juvenilstadien dieser Arten bevorzugten als Substrat Cladophora rupestris. Die Adultformen von Lacuna divaricata und $L$. pallidula wurden besonders häufig auf Fucus serratus beobachtet. Bei einem gleichzeitigen Angebot von Laminaria spp. bevorzugte Lacuna divaricata jedoch diese Braunalge. Obwohl die beiden Lacuna-Arten auch nebeneinander vorkamen, wiesen sie geringfügige Unterschiede in ihrer Substratwahl auf. Einen Hinweis boten hierzu auch die Gehäusefärbung und die Verteilung der Laichgelege. Lacuna divaricata war immer einheitlich rot bis rotbraun gefärbt und legte ihren Laich bevorzugt auf Laminaria spp. ab. L. pallidula hatte dagegen eine olivgrüne Gehäusefarbe. Ihre Gelege fand man fast ausschließlich auf Fucus serratus. Auch Gibbula cineraria fand in der Fucus serratus-Zone "regelmäßige" Verbreitung. Die Besiedlungsdichte wuchs mit Dauer der Wasserbedeckung. Nucella lapillus kam nur in sehr kleinen Beständen (ca. 2-4 Individuen) an wenigen Standorten vor. Als besiedlungshemmender Faktor für Cirripedia und Mytilus edulis hatte diese kleine Population keine Bedeutung. Buccinum undatum wurde nur "vereinzelt" ins Felswatt verdriftet und überdauerte die Zeit des Trockenfallens in den Gezeitentümpeln. Mytilus edulis war im oberen Bereich "sehr auffällig" vertreten und konnte hier sogar den Großalgenbewuchs verdrängen. Zum unteren Eulitoral hin wurden die Bestände kleiner. Hiatella arctica und $H$. rugosa kamen räumlich streng getrennt vor. Während $H$. arctica in den Schichtköpfen zwischen den Feinschichten festgeheftet lebte, bohrte sich $H$. rugosa aktiv eine Höhle in den Buntsandstein. Nach außen waren nur die beiden Siphonenöffnungen sichtbar.

Die Polychaeta waren zwar formenreich vertreten, doch nur wenige Arten waren fester Bestandteil der Fauna und "regelmäßig" oder "auffällig" vertreten. Diese lebten überwiegend (hemi-)sessil. Während Polydora ciliata im Buntsandstein bohrte, baute Fabricia sabella Wohnröhren auf der Oberfläche. Viele dieser kleinen Behausungen bildeten die Fabricia-"Sande" oder -"Polster". Janua pagenstecheri, Spirorbis tridentatus und Pomatoceros triqueter verankerten ihre Kalkröhren direkt am Hartboden. Circeis spirillum siedelte dagegen auf Corallina officinalis und Cladophora rupestris. 
Ein echter Substratspezialist auf Fucus serratus war Spirorbis spirorbis. Ausschließlich im Schillsubstrat wurden Ophryotrocha gracilis und Microphthalmus sczelkowii beobachtet. Auch Lanice conchilega blieb in diesem Bereich auf die Schillfelder beschränkt.

Die Cirripedia traten in einer deutlichen Vertikalzonierung auf. Im oberen Bereich dominierten in etwa gleicher Besiedlungsdichte Semibalanus balanoides und Elminius modestus. Zum unteren Eulitoral nahm ihre "Auffälligkeit" deutlich ab. Statt dessen traten hier zusätzlich in kleineren Beständen Balanus crenatus und Verruca stroemia auf. Die für den Südhafen nachgewiesene Art Balanus improvisus (Harms \& Anger, 1983) wurde nicht gefunden.

Amphipoda waren im Bereich der Fucus serratus-Zone zwar eine artenreiche, nicht aber eine "auffällige" Gruppe. Sie besiedelten hauptsächlich die Algen. Typische Vertreter waren Corophium insidiosum und Jassa falcata. Beide Arten kamen auch häufig nebeneinander in großer Dichte vor. Allerdings fehlte C. insidiosum im August und September. Dexamine spinosa, $D$. thea und Calliopius laeviusculus erschienen nur in den Sommermonaten. Lediglich Jassa falcata und Melita palmata wurden während des gesamten Untersuchungszeitraumes angetroffen.

Die vorkommenden Isopoda-Arten waren räumlich streng voneinander getrennt. Während Idotea granulosa bevorzugt auf Fucus serratus und Cladophora rupestris lebte, siedelte Jaera albifrons zumeist auf den Hartböden in Nischen, Ritzen und unter Steinen. Die beiden Anomura-Arten haben ihre Hauptverbreitung eigentlich im Sublitoral. Sie konnten deshalb auch nur an ständig überspülten Stellen in der Gezeitenzone angetroffen werden. Galathea squamifera lebte versteckt in den Höhlen an den unteren Schichtköpfen, Pagurus bernhardus besiedelte vornehmlich die Gezeitentümpel und Pfützen. Die Brachyura kamen mit 4 Arten vor. "Auffällig" vertreten war nur Carcinus maenas. Juvenile Stadien besiedelten vor allem fädige Grünalgen und Chondrus crispus. Cancer pagurus lebte versteckt in den unteren Höhlen der Schichtköpfe und unter Buntsandsteinschollen. Pilumnus hirtellus wurde in dieser Zone nur in den Schichtköpfen gefunden. Juvenile Exemplare von Hyas araneus kamen "vereinzelt" in Pfützen und Gezeitentümpeln vor.

Von den nachgewiesenen Echinodermata kam nur Amphipholis squamata "regelmäßig" vor. Asterias rubens und Psammechinus miliaris blieben "vereinzelt" oder "selten". Ihr Hauptvorkommen lag in den Sommermonaten. Bevorzugte Standorte waren die Unterseiten von überspülten Buntsandsteinschollen und die Schichtköpfe.

Botryllus schlosseri war die am weitesten verbreitete Ascidie in der Fucus serratusZone. Sie besiedelte neben den Schichtköpfen, den Buntsandsteinschollen und Fucus serratus auch Cladophora rupestris und Corrallina officinalis. Didemnum sp., Botrylloides leachi und Molgula citrina blieben dagegen auf die Schichtköpfe und die Unterseiten der Buntsandsteinschollen beschränkt. Sidnyum turbinatum trat zudem in den Prielpfützen und neben Botryllus schlosseri auch auf Cladophora rupestris auf. Die Kolonien blieben jedoch klein.

Ein besonderes Substrat in diesem Bereich bot die Großalge Fucus serratus (Abb. 12). Die Helgoländer Bestände waren gegenüber denen von u. a. Colman (1940), Hagerman (1966), Boaden et al. (1975), Seed \& Boaden (1977), Wood \& Seed (1980) und Seed et al. (1981) an anderen Untersuchungsstandorten bearbeiteten Fucus- "Wäldern' ärmer besiedelt. Porifera, Anthozoa und Cirripedia wurden überhaupt nicht auf Fucus serratus gefunden. Bryozoa und Ascidiae kamen jeweils nur mit einer Art vor. Formen- 


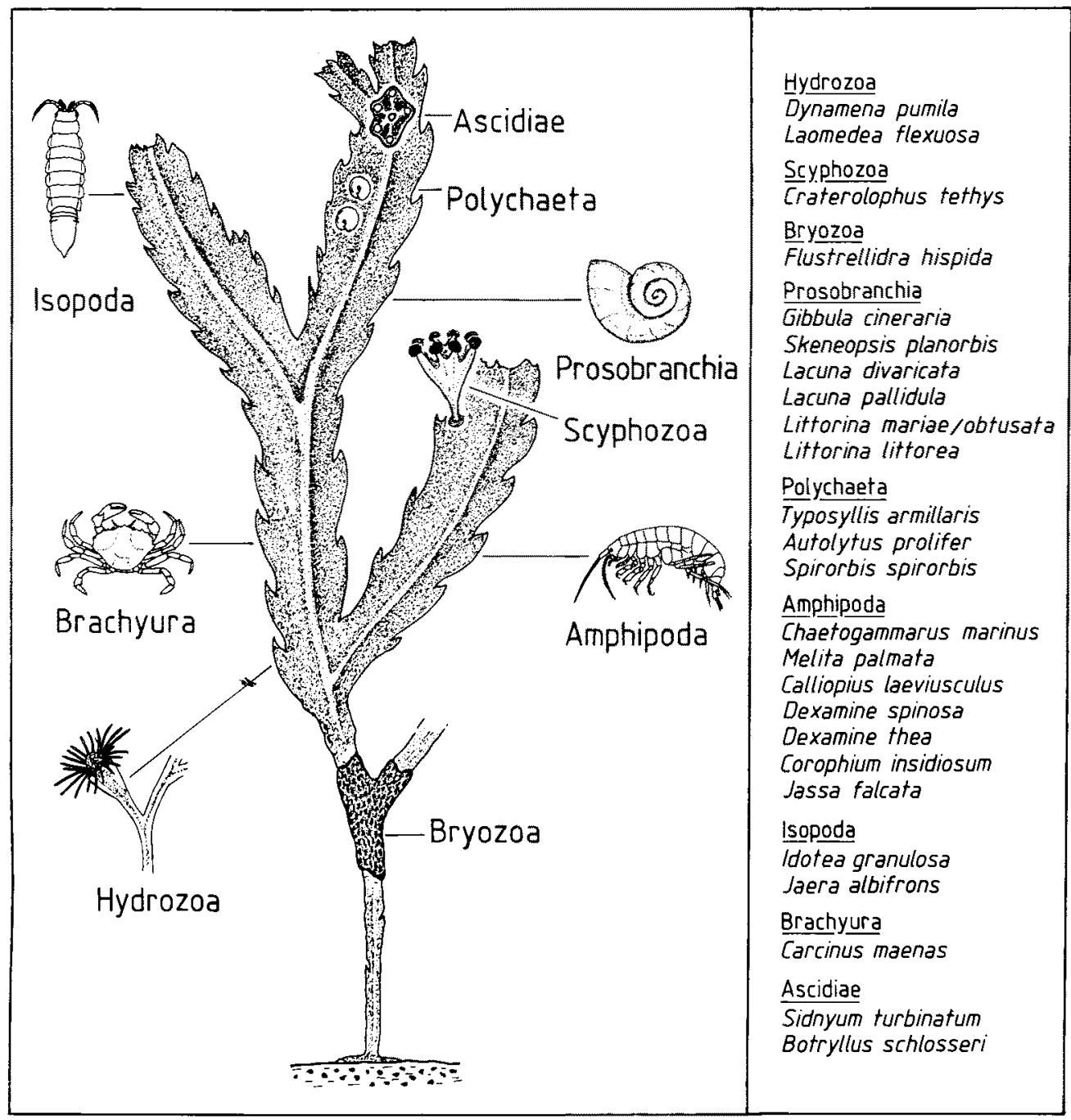

Abb. 12. Die Makrofauna auf Fucus serratus im Helgoländer Felswatt (schematisch). Nähere Erläuterungen siehe Text

arm waren auch die erranten Gruppen wie z. B. Opisthobranchia, Polychaeta und Isopoda vertreten. Vergleichsweise artenreich kamen dagegen die Prosobranchia und Amphipoda vor.

\section{Die Priele}

Die Priele auf der Abrasionsterrasse sind flache, aus dem Buntsandstein ausgewaschene, Rinnen. Sie führen in nordwestlicher Richtung in die offene See. Auf ihrer westlichen Seite werden sie durch die flach ansteigenden Schichtflächen begrenzt, an ihrer Ostseite ragt ein steiler Schichtkopf auf (Abb. 13). Im Gegensatz zu den Prielen in 


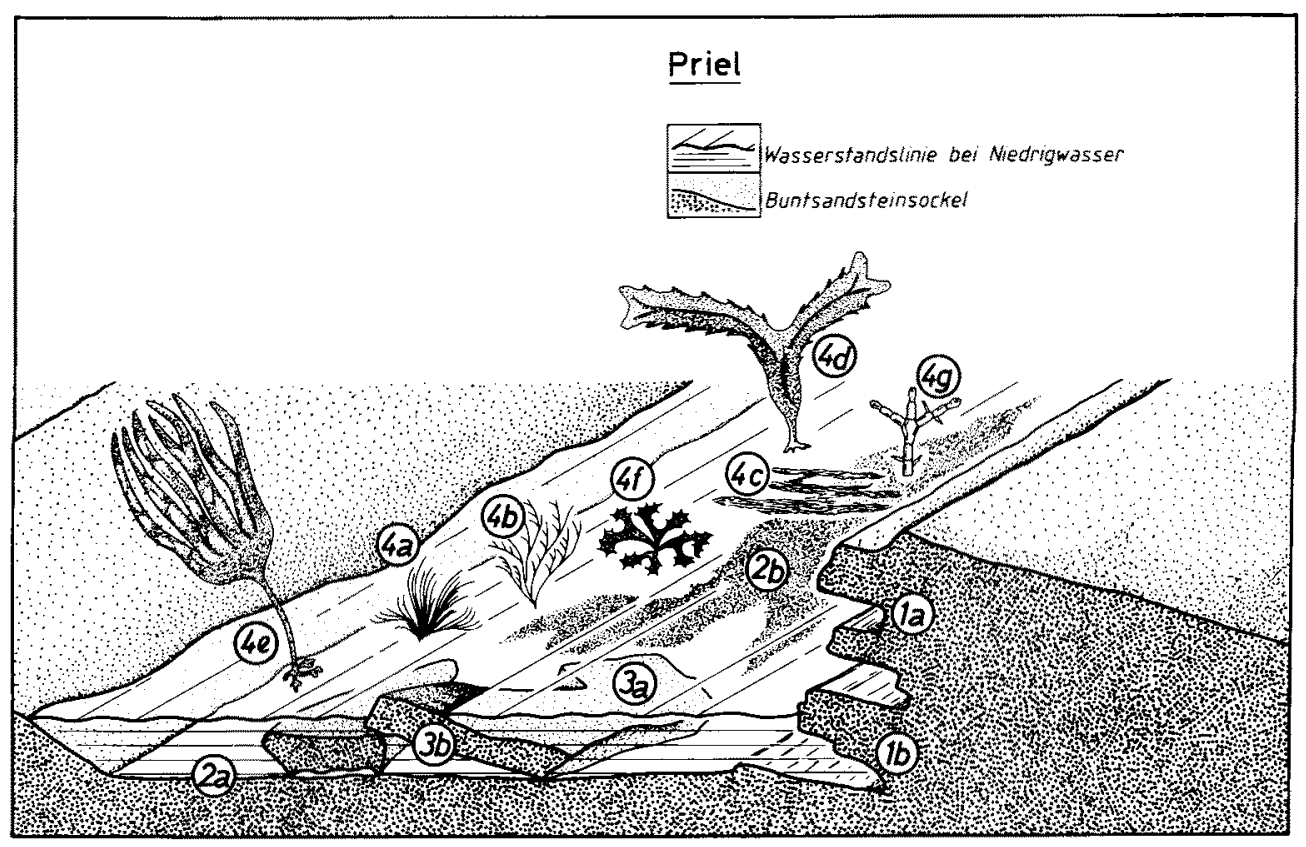

Abb. 13. Priel im Helgoländer Felswatt (schematisch), 1a Obere Partie des Schichtkopfes (bei Ebbe freifallend); $1 \mathrm{~b}$ Untere Partie des Schichtkopfes (ständig überspült); $2 \mathrm{a}$ Prielsohle; $2 \mathrm{~b}$ Schillfeld auf der Prielsohle; $3 a$ Buntsandsteinscholle (Aufseite); 3b Buntsandsteinscholle (Unterseite); 4a Cladophora rupestris; $4 \mathrm{~b}$ Cladophora sericea; $4 \mathrm{c}$ Chaetomorpha tortuosa; $4 \mathrm{~d}$ Fucus serratus; $4 \mathrm{e}$ Laminaria spp.; $4 \mathrm{f}$ Chondrus crispus; $4 \mathrm{~g}$ Corallina officinalis

der oberen Fucus serratus-Zone fallen die hier behandelten großen Priele während der Ebbe nicht oder nur in ihren obersten Bereichen trocken. In unregelmäßigen Abständen liegen losgebrochene Buntsandsteinschollen flach auf dem Boden oder gegeneinandergelehnt. Außerdem ist die Prielsohle teilweise mit eingespülten Schillfeldern bedeckt. Der Schichtkopf bleibt am Fuß ständig vom Wasser umspült. Der obere freifallende Teil wird von den von der Schichtfläche herabhängenden Fucus-Thalli verdeckt.

Flor a : Der Algenbewuchs der Priele wird deutlich vom Sublitoral beeinflußt. Die bestimmenden Formen sind Cladophora rupestris, C. sericea, Chaetomorpha tortuosa, Ulva lactuca, Acrosiphonia arcta, Fucus serratus, Laminaria saccharina, L. digitata, Chondrus crispus, Polysiphonia sp., Ceramium rubrum, Dumontia incrassata, Corallina officinalis und krustenbildende Rotalgen (z. B. Hildenbrandia rubra, Phymatolithon spp.). Nicht alle Arten waren während des gesamten Untersuchungszeitraumes vertreten. Es bestand keine Dominanz einer einzelnen Art gegenüber allen anderen. Die aus dem Sublitoral eingespülten Algen (z. B. Laminaria digitata, L. hyperborea, Halidrys siliquosa und verschiedene Rhodophyceen) wurden während der Untersuchung nicht berücksichtigt.

Fa u na: In den Prielen wurden 110 verschiedene Makrofauna-Arten gefunden (Tab. 10). Die artenreichsten Gruppen waren die Polychaeta (17 Arten), Bryozoa (10), Prosobranchia (9) und Amphipoda (9). "Auffällige" Arten gehörten zu den Porifera, Hydrozoa, Bryozoa, Prosobranchia, Polychaeta, Amphipoda, Isopoda, Anomura, Bra- 
Tab. 10. Zeitliche und räumliche Verteilung der Makrofauna in den Prielen. Zur Numerierung der Kleinhabitate siehe Abbildung 13

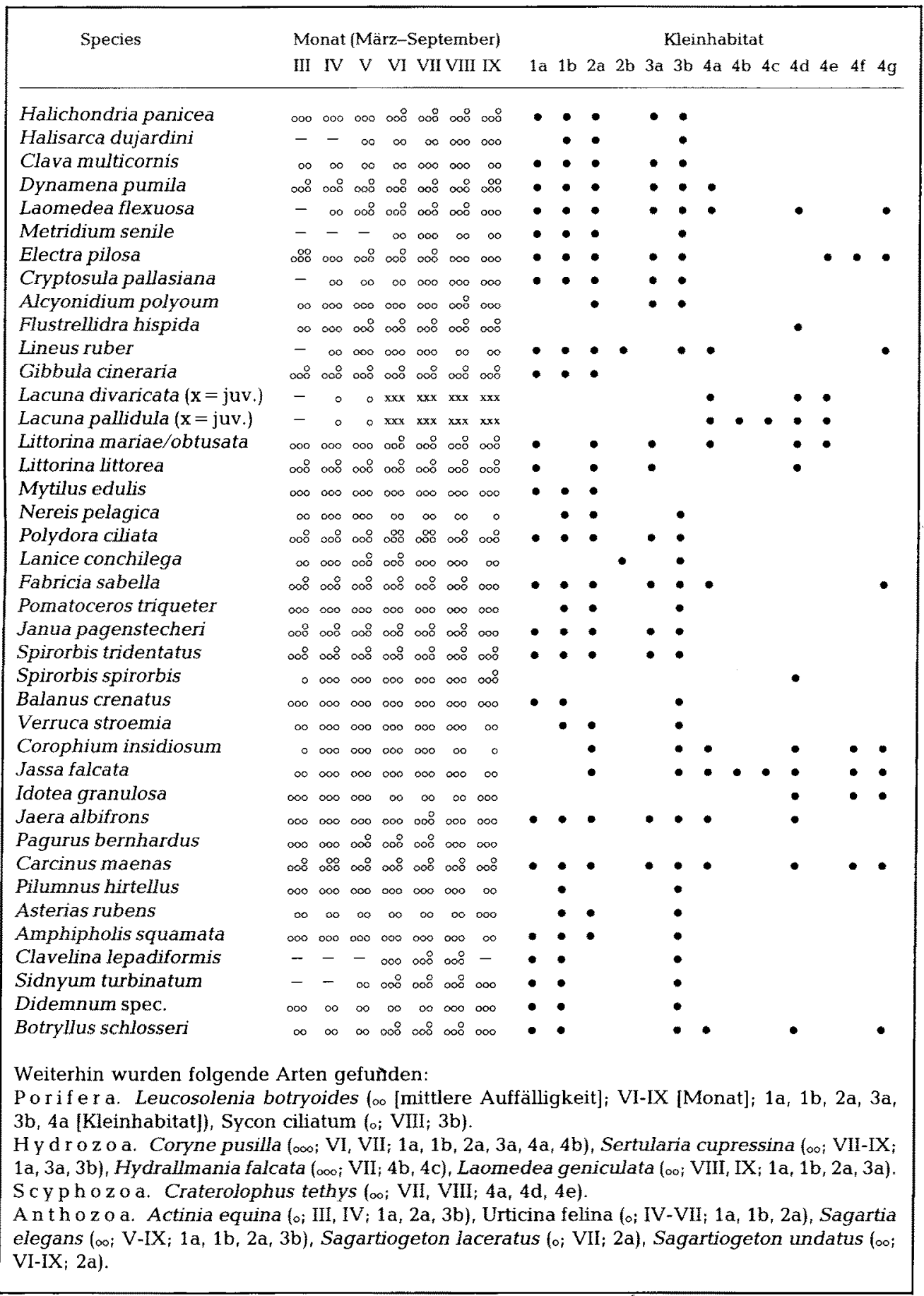


Tab. 10 (Fortsetzung). Verteilung der Makrofauna in den Prielen

B ry o z oa. Membranipora membranacea loo; VIII, IX; 4e), Conopeum reticulum (oo; IV-IX; 1b, 3b), Callopora lineata (oo; VII-IX; 2a, 3b, 4e), Bowerbankia imbricata (oo; VI-VIII; 4a), Bowerbankia pustulosa (oo; VI-VIII; 4a), Walkeria uva (ooo; VI-VIII; 4a).

Nem ertini. Lineus bilineatus (oo; IV-IX; 2a, 2b, 3b, 4a, 4g), Micrura fasciolata (oo; VI, VII; 4a, 4b), Amphiporus lactifloreus (o; IV; 3b), Oerstedia dorsalis (oo; V, VII-IX; 3b, 4a, 4b, 4d, 4g), Tetrastemma candidum (oo; VI; 2b, 3b, 4a), Tetrastemma vermiculus (o; VIII; 3b).

Ka m p tozoa. Pedicellina cernua (oo; VIII; 2a, 4a).

Polyplacophora. Lepidochiton cinereus (oo; III-IX; 1a, 1b, 2a, 3a, 3b), Lepidopleurus asellus (oo; III-VII; $1 \mathrm{~b}, 3 \mathrm{~b}$ ).

Prosobranchia. Onoba aculeus (oo; III-IX; 2a, 3b, 4a, 4b, 4f, 4g), Hydrobia ulvae (ooo; VI-IX; 3b, 4a, 4b, 4f, 4g), Skeneopsis planorbis (oo; VI-IX; 4a, 4d), Buccinum undatum (o; IV-IX; 1b, 2a). Op is thobra n chia. Acanthodoris pilosa (o; VI, VII; 1b, 2a, 3b), Onchidoris muricata (c; VIII; 2a, 3b), Polycera quadrilineata (o; III-VIII; 2a), Archidoris pseudoargus (oo; VI-VII; 1b, 2a, 3a, 3b), Coryphella verrucosa (oo; IV, V; 1b, 2a, 3b), Acolidia papillosa (oo; 1b, 2a, 3a, 3b).

B iv a lvia. Hiatella arctica (oo; III-IX; 1a, 1b, 3b), Hiatella rugosa (oo; III-IX; $1 \mathrm{a}, 1 \mathrm{~b})$.

$\mathrm{Pol}$ y $\mathrm{ch}$ a e ta. Lepidonotus squamatus (oo; III-V; 1a, 1b, 2a, 3a, 3b), Harmothoe impar (oo; V-IX; $1 \mathrm{a}, 1 \mathrm{~b}, 2 \mathrm{a}, 3 \mathrm{a}, 3 \mathrm{~b})$, Harmothoe imbricata (o; IV, VI; 2a, 3b), Anaitides maculata (oo; III-IX; 1b, 2a, 3a, 3b), Eulalia viridis (o; VIII; $1 \mathrm{~b}, 2 \mathrm{a}, 3 \mathrm{~b})$, Autolytus prolifer (o; VIII; $3 \mathrm{~b}, 4 \mathrm{a})$, Malacoceros fuliginosus (o; VII, VIII; 2b), Tharyx multibranchiss (oo; IV, V; 1a, 1b, 3b), Circeis spirillum (oo; VI-IX; 4a).

Pantopoda. Pycnogonum littorale (oo; III, V-VIII; $1 \mathrm{a}, 1 \mathrm{~b}, 3 \mathrm{~b})$.

Cir ripedia. Semibalanus balanoides (oo; III-IX; 1a, 2a), Elminius modestus (oo; III-IX; 1a, 2a). A m p hi p od a. Chaetogammarus marinus (1); III-IV, IX; 4d), Melita palmata (oo; IV, V, VII-IX; $2 \mathrm{a}, 4 \mathrm{a}, 4 \mathrm{~d}, 4 \mathrm{~g}$ ), Calliopius laeviusculus (ooo; VIII, IX, 2a, 4a, 4d, 4e, 4g), Apherusa bispinosa (oo: VIII, IX; 2a, 4a, 4d, 4g), Dexamine spinosa (oo; VII, VIII; 2a, 4a, 4d, 4e, 4g), Dexamine thea (oo; VIVIII; 2a, 4a, 4d, 4e, 4g), Caprella linearis (oo; IV, VI-VIII; $4 \mathrm{a}, 4 \mathrm{f}, 4 \mathrm{~g}$ ).

$\mathrm{Cu}$ a c e a. Bodotria scorpioides (oo; VII; 2 b).

$\mathrm{N}$ a t a $\mathrm{n}$ i a. Athanas nitescens (o; III; 2a), Eualus occultus (o; III; 2a), Pandalina brevirostris (o; IV; 2a), Crangon allmanni (o; IV, IX; 2a, 2b).

A n om u r a. Galathea squamifera (oo; III-VI; 1b, 3b).

B r a chy u ra. Liocarcinus holsatus (oo; IX; 1b, 2a), Cancer pagurus (oo; III-IX; 1b, 3b), Hyas araneus (o; III, IV, VII-IX; 2a, 4a).

E ch in od e r m a ta. Psammechinus miliaris (oo; V, VIII 1 b, 2a, 3b).

A s c id i e. Botrylloides leachi (oo; VII-IX; 1b, 3b), Molgula citrina (oo; IV-VIII; 1a, 1b, 3b).

chyura und Ascidiae. Charakteristisch für die Besiedlung war das benachbarte Vorkommen von rein sublitoralen und überwiegend eulitoralen Arten. Typisch für den sublitoralen Formenkreis waren die Bryozoa, Nemertini, Opisthobranchia, viele Polychaeta, Amphipoda und Ascidiae. Natantia wurden ebenfalls von See her eingespült. Dagegen wies die Besiedlung durch die Prosobranchia überwiegend eulitorale Arten (z. B. Littorina spp.) auf. Die einzige sonst nur im Sublitoral vorkommende Form war Buccinum undatum. Die ständige Überspülung wesentlicher Teile dieses Habitats ermöglichte auch eine Besiedlung durch Pagurus bernhardus und Cancer pagurus. Liocarcinus holsatus und Hyas araneus kamen dagegen nur "vereinzelt" vor.

Die am dichtesten besiedelten Flächen waren die Unterseiten der losgebrochenen Buntsandsteinschollen. Kolonien von Porifera, Bryozoa, Polychaeta und Ascidiae stießen hier direkt aneinander (Abb. 9),

Auch die Algen wurden in diesem Habitat z. T. dicht besiedelt. Besonders artenreich war die Fauna auf Cladophora rupestris, wo vor allem Bryozoa, Nemertini, juvenile Prosobranchia, Amphipoda und Isopoda vorkamen. Die Besiedlung von Fucus serratus 
wies gegenüber dem Thallusbewuchs auf den höher gelegenen Schichtflächen keine bedeutenden Unterschiede auf. Die Besiedlung von Laminaria saccharina und $L$. digitata war nur spärlich. Nur die sessilen Bryozoen Electra pilosa, Callopora lineata und Membranipora membranacea besiedelten die Thalli. M. membranacea, die als typischer Besiedler von Laminaria gilt (Ryland, 1962), kam nur in kleinen Kolonien im August und September vor. Im tieferen Sublitoral siedelte sie jedoch häufig auf $L$. hyperborea.

\section{Die Laminaria-Zone}

Der untersuchte Bereich der Laminaria-Zone liegt im obersten Bereich des Sublitorals (Abb. 14). Die morphologische Gliederung ist der in der Fucus serratus-Zone sehr ähnlich. Wegen der ständigen Wasserbedeckung fehlen die Gezeitentümpel und Prielpfützen. Bei günstigen Windverhältnissen und/oder bei Springniedrigwasser fallen lediglich die Phylloide und ein Teil der Cauloide der bestandsbildenden Großalgen frei.

Flora: Die Laminaria-Zone ist nach ihrer Hauptsiedlungsform benannt. Die weitaus überwiegende und dichte Algenwälder bildende Art ist Laminaria digitata. In kleineren Beständen eingestreut siedelt Laminaria saccharina. Im Schutz dieser Großalgen wächst eine artenreichere Algenflora als im Eulitoral. $\mathrm{Zu}$ den häufigen Arten gehören Cladophora rupestris, Ulva lactuca, Fucus serratus, Halidrys siliquosa, Chondrus crispus, Rhodomela converfoides, Corallina officinalis und krustenbildende Rotalgen. Häufige Epiphyten auf Fucus serratus und Laminaria spp. sind Polysiphonia

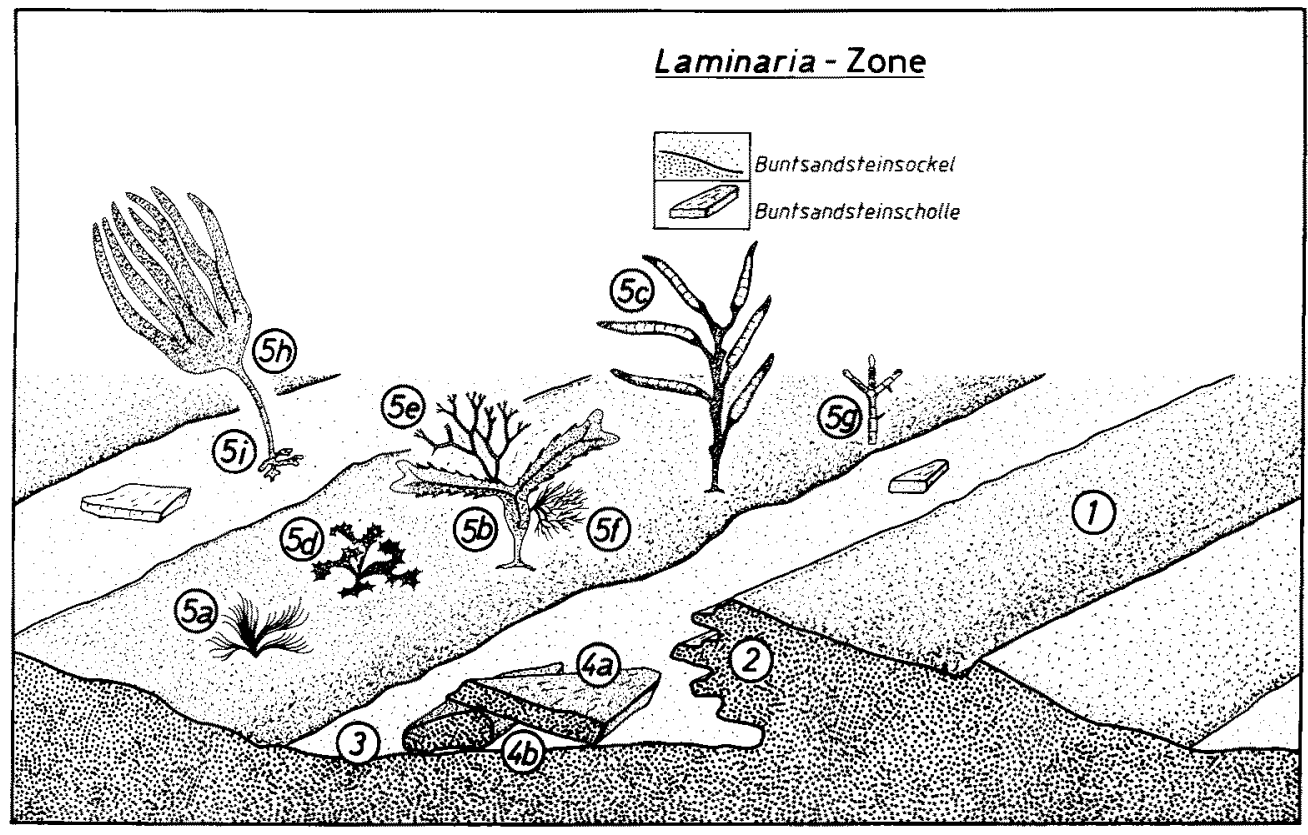

Abb. 14. Obere Laminaria-Zone im Helgoländer Felswatt (schematisch). 1 Schichtfläche; 2 Schichtkopf; 3 Prielsohle; 4a Buntsandsteinscholle (Aufseite); 4b Buntsandsteinscholle (Unterseite); 5a Cladophora rupestris; 5b Fucus serratus; 5c Halidrys siliquosa; 5d Chondrus crispus; 5e Ceramium rubrum; 5f Polysiphonia violacea; $5 \mathrm{~g}$ Corallina officinalis; $5 \mathrm{~h}$ Laminaria digitata (Phylloid, Cauloid); 5 i L. digitata (Rhizoid) 
Tab. 11. Zeitliche und räumliche Verteilung der Makrofauna in der oberen Laminaria-Zone. Zur Numerierung der Kleinhabitate siehe Abbildung 14

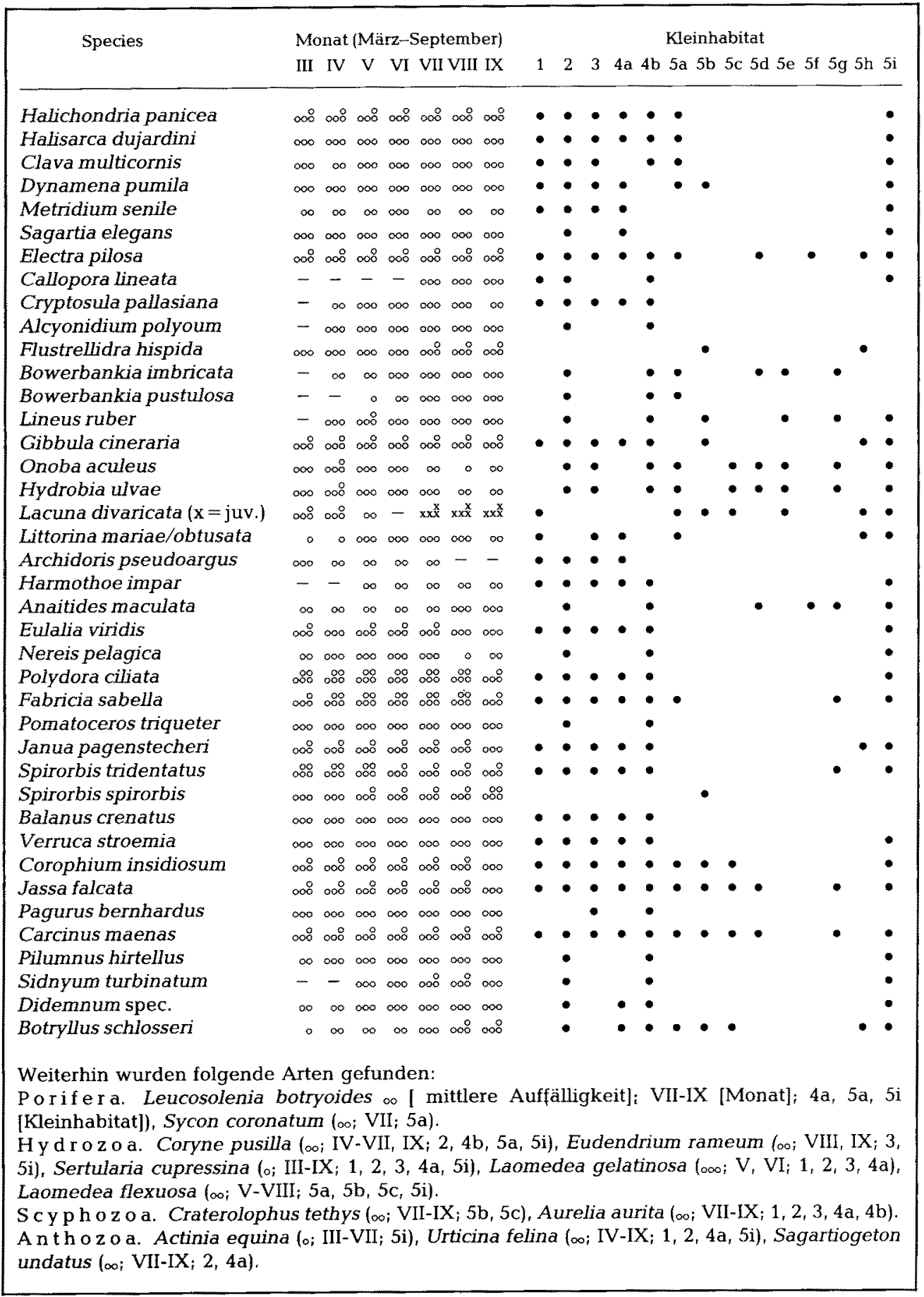


Tab. 11 (Fortsetzung). Verteilung der Makrofauna in der oberen Laminaria-Zone

B ry o zo a. Membranipora membranacea (oo; III-VIII; 5h, 5i), Conopeum reticulum (oo; IV-IX; 2 , 4a), Celleporella hyalina $1_{0}$; VII-IX, 5h, 5i), Cibrilina punctata (oo; VIII, IX; 2, 4a), Schizoporella errata (oo; VIII, IX; 1, 2, 3, 4b), Bowerbankia gracilis (o; VIII; 5g), Walkeria uva (oo; V-IX; $2,4 \mathrm{a}, 4 \mathrm{~b}, 5 \mathrm{a})$. Si p unculida. Golfingia minuta (oo: VIII; 5i).

Nem e rt in i. Cephalothrix rurifrons $\left(_{\infty} ; \mathrm{IV} ; 4 \mathrm{~b}, 5 \mathrm{i}\right)$, Procephalothrix filiformis (o; VIII; $\left.4 \mathrm{~b}, 5 \mathrm{i}\right)$, Lineus bilineatus (oo; IV-IX; 2, 4b, 5b, 5e, 5g, 5i), Lineus viridis (oo; VIII, IX; 4b, 5i), Emplectonema gracile (oo; V-VII, 5i), Oerstedia dorsalis (oo; V-IX, 2, 4b, 5a, 5b, 5e, 5g, 5i), Tetrastemma candidum (oo; IV-IX; 4b, 5i), Tetrastemma vermiculus (oo; V-IX; 2, 4b, 5i).

$\mathrm{K}$ a m p tozo a. Pedicellina cernua (oo; VII-IX; 4b, 5a, 5g, 5i).

Poly pla cophora. Lepidochiton cinereus (oo; III-IX; $1,2,3,4 \mathrm{a}, 4 \mathrm{~b})$, Lepidopleurus asellus (oo; III-IX; 1, 2, 3, 4a, 4b).

Prosobranchia. Acmaea virginea (o; IV-VII; 3), Calliostoma ziziphinum (o; VI; 3), Rissoa parva (oo; III-IX; 2, 5a, 5c,5d,5e), Rissoa inconspicua (o; VII, IX; 5i), Lacuna pallidula (juv.; VII-IX; $4 \mathrm{~b}, 5 \mathrm{a}, 5 \mathrm{~b}, 5 \mathrm{c}, 5 \mathrm{~h}, 5 \mathrm{i}$ ), Littorina littorea (oo; III; 1, 2, 3, 4b, 5a), Buccinum undatum ( $\infty$; VII, VIII; $1,2,3)$.

Op is th obranchia. Retusa truncatula (o; III, IV, VI; 5i), Dendronotus frondosus (o; V-IX 3 ), Doto coronata (o; IV-VII; 2, 5a, 5b), Acanthodoris pilosa (oo; IV-VII; 1, 2, 3, 4a, 4b), Onchidoris muricata (oo; VII, VIII; 2, 4b, 5i), Polycera quadrilineata (o; V-IX; $5 \mathrm{~d}, 5 \mathrm{e}, 5 \mathrm{f}$ ), Coryphella pedata (o; VII; 2), Coryphella verrucosa (o; V-VII; 5e, 5f), Facelina auriculata (o; V, VII; 2, 3), Aeolidia papillosa (o; IV-VI; $1,2,3,4 a$ ).

Bivalvia. Mytilus edulis (juv.; $\infty$; III-VII; $2,4 \mathrm{~b}, 5 \mathrm{a}, 5 \mathrm{i}$ ), Anomia ephippium (o; IV-VI; 2), Venerupis pullastra (juv.; $\infty$; VII, IX; 5a), Hiatella arctica $(\infty ;$ II-IX; $2,4 \mathrm{~b})$, Hiatella rugosa (o; III-IX; 2$)$. Poly ch a eta. Gattyana cirrosa (o; VIII; 2), Sthenelais boa (oo; V, VII, VIII, 5i), Typosyllis armillaris (oo; III-V, VIII; 5i), Syllides articulocirratus $\left(_{\infty} ; \mathrm{V}, \mathrm{VI}_{1}, 2,4 \mathrm{~b}\right)$, Autolytus prolifer $\left(0_{\infty} ; \mathrm{V}-\right.$ VIII; 2, 4a, 4b, 5a, 5i), Tharyx multibranchiis (o; III, V-VII; 5i), Amphitrite figulus (o; IV-VIII; $2,4 \mathrm{~b}$, 5i), Lanice conchilega (oo; IV-IX; 3, 4b); Sabellaria spinulosa (०; III-IX; 2, 4b, 5i), Circeis spirillum ${ }_{(\infty} ;$ VI-IX; $\left.5 \mathrm{a}, 5 \mathrm{~g}, 5 \mathrm{i}\right)$.

Pant op oda. Nymphon rubrum (os; VII-IX $;$ aa, 5e, 5f, 5i), Achelia hispida (o; VI-IX; 2, 4b, 5a, 5e, 5i), Phoxichilidium femoratum (o; V, VII, IX; 5i), Anoplodactylus angulatus (o; III-IX; 2, 4b, 5i) Pycnogonum littorale (oo; IV-IX; $2,4 \mathrm{~b}, 5 \mathrm{i})$.

Cirripedia. Balanus balanus $\left(0 ; \mathrm{V}, \mathrm{VI}_{;} 3\right)$.

A m p h i pod a. Gammarellus homari (oo; III; 4a, 5b, 5c, 5d), Cheirocratus sundevalli (oo; III-V; 2, 4a, 5a, 5b, 5c,5d,5g), Melita palmata (oi IV-VI; 1, 2, 4a, 5a, 5b, 5c,5d), Calliopius laeviusculus (oo; VII-IX; 1, 2, 3, 4a, 4b, 5a-i), Apherusa jurinei (oo; 1, 2, 3, 4a, 4b, 5a, 5b, 5c,5h, 5i), Apherusa bispinosa (oo; VIII; 4b, 5a, 5b, 5c,5h, 5i), Dexamine spinosa (ooo; VIII; 5b, 5e, 5f, 5g, 5h, 5i), Dexamine thea (o; VII-IX; 5a, 5d, 5e, 5f, 5h, 5i), Caprella linearis (oo; IV, V, VII, VIII; 2, 5e, 5f, 5i).

$\mathrm{Cu}$ a ce a. Bodotria scorpioides (oo; IX; $5 \mathrm{i}$ ).

I s o pod a. Idotea granulosa (o; III, VIII, IX; 5a, 5b,5c,5h,5i), Jaera albifrons (ooo; VI-IX; 2, 3 , $4 b, 5 a, 5 b, 5 i)$.

A n o m ura. Galathea squamifera (o; III-IX; $4 \mathrm{~b})$, Porcellana longicornis (o; IX; 2 ).

$\mathrm{Br}$ a chy u ra. Liocarcinus holsatus (o; VIII, IX; 4b, 5i), Cancer pagurus (oo; III-IV; $2,4 \mathrm{~b}, 5 \mathrm{i}$ ), Hyas araneus (o; III, IV, VIII, IX; 2, 3, 5a, 5b).

In se ct a. Clunio marinus $\left({ }_{\infty} ;\right.$ III, $V ;$ i) .

E chinodermata. Asterias rubens (oo; IV-IX, 1,2,3,4a, 4b), Amphipholis squamata (ooo; IIIIX; $2,4 \mathrm{~b}, 5 \mathrm{i}$ ), Psammechinus miliaris (o; III, VIII; $2,4 \mathrm{~b}$ ).

A sci di a e. Clavelina lepadiformis (oo; VII, VIII; 2, 5i), Botrylloides leachi (oo; V-IX; 2, 4b, 5i), Molgula citrina lo; $_{\text {iV }}$-IX; $\left.2,4 \mathrm{~b}, 5 \mathrm{i}\right)$.

violacea und Ceramium rubrum. Auf viele andere nicht bestandsbildende Formen soll an dieser Stelle nicht näher eingegangen werden. Kornmann \& Sahling (1977) und Lüning (1970) haben ihre Morphologie, örtliche Verbreitung und Vertikalverteilung beschrieben. 
Fa un a: In der oberen Laminaria-Zone wurden 133 Makrofauna-Arten gefunden (Tab. 11). Die artenreichsten Gruppen waren die Polychaeta (20 Arten), Bryozoa (14), Prosobranchia (12), Opisthobranchia (11), Amphipoda (11) und Nemertini (9). "Auffäl" lige" Arten gehörten zu den Porifera, Hydrozoa, Bryozoa, Nemertini, Prosobranchia, Polychaeta, Amphipoda, Isopoda, Brachyura, Echinodermata und Ascidiae. Charakteristisch für die obere Laminaria-Zone war die weitere Zunahme sublitoraler Formen. Die eulitoralen Prosobranchia und Cirripedia wurden dagegen seltener. Dafür nahm das Artenspektrum an Bryozoa, Nemertini, kleinen Prosobranchia-Formen (z. B. Rissoacea), Opisthobranchia, Pantopoda und Amphipoda gegenüber der Fucus serratus-Zone zu. Auch die für Helgoland selten nachgewiesenen Arten wie z. B. Acmaea virginea, Calliostoma ziziphinum, Anomia ephippium, Porcellana longicornis und einige Opisthobranchia konnten hier beobachtet werden.

Einen besonderen Lebensraum in dieser Zone bildeten die Rhizoide von Laminaria digitata (Kleinhabitat $5 \mathrm{i}$ in Tab. 11; Abb. 17). Hier wurden auf engstem Raum allein 82 Makrofauna-Arten nachgewiesen. Typische Besiedlungsmerkmale im Vergleich zu anderen Habitaten waren die relativ hohe Artenzahl von Nemertini, kleinen Prosobranchia und Pantopoda. Alle 5 im Felswatt nachgewiesenen Pantopoda-Arten kamen in diesem Kleinhabitat nebeneinander vor. In den Rhizoidhöhlen siedelte häufig Pilumnus hirtellus und/oder Nereis pelagica. Die von Gillandt (1979b) für Nereis pelagica erwähnte Besiedlungsdichte von 1 Individuum pro Rhizoid konnte bestätigt werden. Die Räume zwischen den Rhizoidkrallen wurden bevorzugt von röhrenbauenden Formen, die dichte Polster bildeten, besiedelt. Hier lebten Polydora ciliata, Fabricia sabella, Corophium insidiosum und Jassa falcata. An einigen Rhizoiden wurden die Polster von Halichondria panicea verdrängt. Die Phylloide und Cauloide wurden von vergleichsweise wenigen Arten besiedelt. Typische Vertreter waren Electra pilosa, Gibbula cineraria und Lacuna divaricata.

\section{Die Abrasionsterrasse: Beispiel für einen zonierten Lebensraum in der Gezeitenzone}

Aus der Zusammenfassung der Makrofauna und ihrer Verteilung auf der Abrasionsterrasse läßt sich eine deutliche Zonierung erkennen. Die obere eulitorale Zone ist durch die bis ins Supralitoral vordringenden Arten Littorina saxatilis und Petrobius brevistylis gekennzeichnet. Bis zur MTHWL siedeln auch Chaetogammarus marinus und Hyale nilssonii. Das mittlere Eulitoral ist charakterisiert durch Cirripedia (Semibalanus balanoides und Elminius modestus). Außerdem sind große Flächen von Mytilus edulis bedeckt. Die bestimmende Schnecke dieser Zone ist Littorina littorea. In den eingespülten Schill- und Sandflächen lebt Scolelepis squamata.

Das untere Eulitoral ist durch den dichten Fucus serratus-Bewuchs gekennzeichnet. Dieser Bereich unterscheidet sich gegenüber den höher gelegenen Bereichen schon durch seine deutlich erhöhte Artenzahl (Abb. 15). Hier treten vermehrt Porifera, Anthozoa, Bryozoa, Gastropoda, Polychaeta, Amphipoda und Ascidiae auf. Typische Leitformen am Buntsandsteinboden sind Halichondria panicea, Cryptosula pallasiana, Lepidochiton cinereus, Littorina littorea und Balanus crenatus. Die Schillfelder werden von Microphthalmus sczelkowii und Ophryotrocha gracilis besiedelt. Auf den Fucus-Thalli siedeln Flustrellidra hispida, Littorina mariae/obtusata, Lacuna pallidula, Spirorbis spirorbis und Idotea granulosa. Eine artenreiche Fauna lebt auf Cladophora rupestris. Neben den Kleinschnecken Rissoa parva, Onoba aculeus, Hydrobia ulvae und Skeneop- 


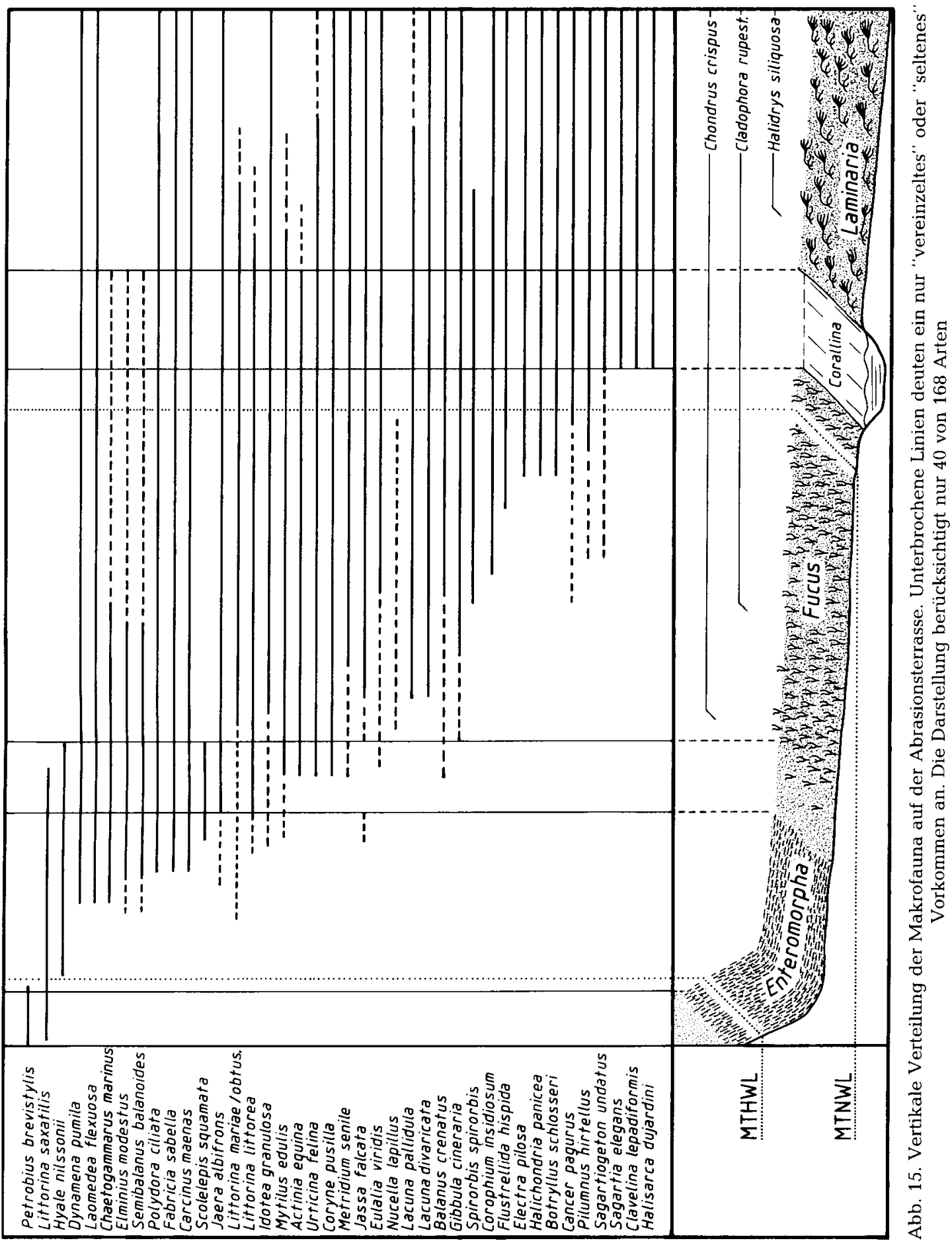




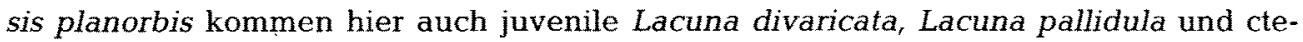
nostome Bryozoa (Bowerbankia spp., Walkeria uva) vor.

In der oberen sublitoralen Zone sind einige für das Eulitoral typische Formen (Littorina littorea, Semibalanus balanoides, Elminius modestus) fast vollständig verschwunden. Die Artenzahl der Porifera, Bryozoa, Polychaeta, Pantopoda und Ascidiae nimmt dagegen weiter zu. An geschützt gelegenen Standorten siedeln die Anthozoa Metridium senile, Sagartia elegans und Sagartiogeton undatus. Bestimmende Leitform für die Bryozoa ist Electra pilosa. Die typischen Prosobranchia sind Lacuna divaricata und Gibbula cineraria. In den Rhizoiden verkriechen sich Nemertini (z. B. Lineus spp., Oerstedia dorsalis). Typische Polychaeta dieses Kleinhabitats sind Eulalia viridis und Nereis pelagica. Außerdem siedeln hier in großer Individuendichte die Amphipoda Corophium insidiosum und Jassa falcata. In den Rhizoidhöhlen lebt Pilumnus hirtellus. Große Buntsandsteinflächen sind mit Ascidienkolonien wie z. B. Didemnum sp. und Botryllus schlosseri bedeckt. Hier kann man auch die nur in geringer Individuendichte vorkommenden Opisthobranchia beobachten. Littorina mariae/obtusata lebt nur noch vereinzelt auf den Fucus-Thalli.

Daneben ist das Felswatt auch von solchen Formen besiedelt, die im gesamten eulitoralen Bereich vorkommen. Zu solchen Arten gehören Dynamena pumila, Laomedea flexuosa, Polydora ciliata, Fabricia sabella, Spirorbis tridentatus, Jassa falcata, Jaera albifrons und Carcinus maenas.

\section{Die Nordostseite der Nordwestmole}

Die Nordwestmole, eine ca. $6 \mathrm{~m}$ hohe Betonmauer begrenzt das Untersuchungsgebiet nach Westen hin (Abb. 1). Bis in eine Höhe von ca. $3 \mathrm{~m}$ befinden sich in einem Abstand von etwa $60 \mathrm{~cm}$ konstruktionsbedingte waagerecht verlaufende Ritzen von ca. $5 \mathrm{~cm}$ Tiefe und $3 \mathrm{~cm}$ Breite. Im unteren Bereich sind an einigen Stellen kleinere Höhlen zu erkennen. Hier waren früher Holzbohlen eingelassen. Der Fuß der Mole ist teilweise unterspült. Die dort entstandenen kleinen Höhlen werden bis zu $10 \mathrm{~cm}$ hoch. Die höher gelegenen Bereiche des Molenfußes fallen bei Ebbe regelmäßig trocken. Die weiter seewärts liegenden Abschnitte bleiben ständig vom Wasser überspült.

Flor a: Die Algenbesiedlung an der Nordostseite der Mole weist eine deutliche vertikale Zonierung auf (Abb. 18). Der Saum oberhalb der MTHWL wird von Blidingia minima und Porphyra umbilicalis gebildet. In der mittleren Zone schließt sich ein dichter Fucus-Gürtel an. Im oberen Bereich überwiegt Fucus spiralis, im unteren Abschnitt $F$. serratus. Dazwischen siedelt in einem schmalen kaum ausgeprägten Saum F. vesiculosus. Im unteren Bereich der Mole wächst als bestandsbildende Art Cladophora rupestris. Ein in den Sommermonaten häufiger Epiphyt auf dieser Grünalge ist Ceramium rubrum. Im oberen Bereich wird Cladophora rupestris zudem von Ulva lactuca begleitet. Am häufig überspülten Molenfuß siedeln Chondrus crispus und Corallina officinalis. Zusammenfassend lassen sich 3 große Algensäume feststellen: die Blidingia/Porphyra-Zone, die Fucus-Zone und die Cladophora/Ulva/Ceramium-Zone.

Diese Verteilung ist an vielen Stellen nur unvollständig ausgebildet. Besonders die obere Zone kann vollständig fehlen. An ihrer Stelle dehnt sich dann ein breites Cirripedia-Band aus (Abb. 19).

Fauna: An der Nordostseite der Nordwestmole wurden 59 Makrofauna-Arten gefunden (Tab. 12). Die artenreichsten Gruppen bildeten die Prosobranchia (8 Arten) 


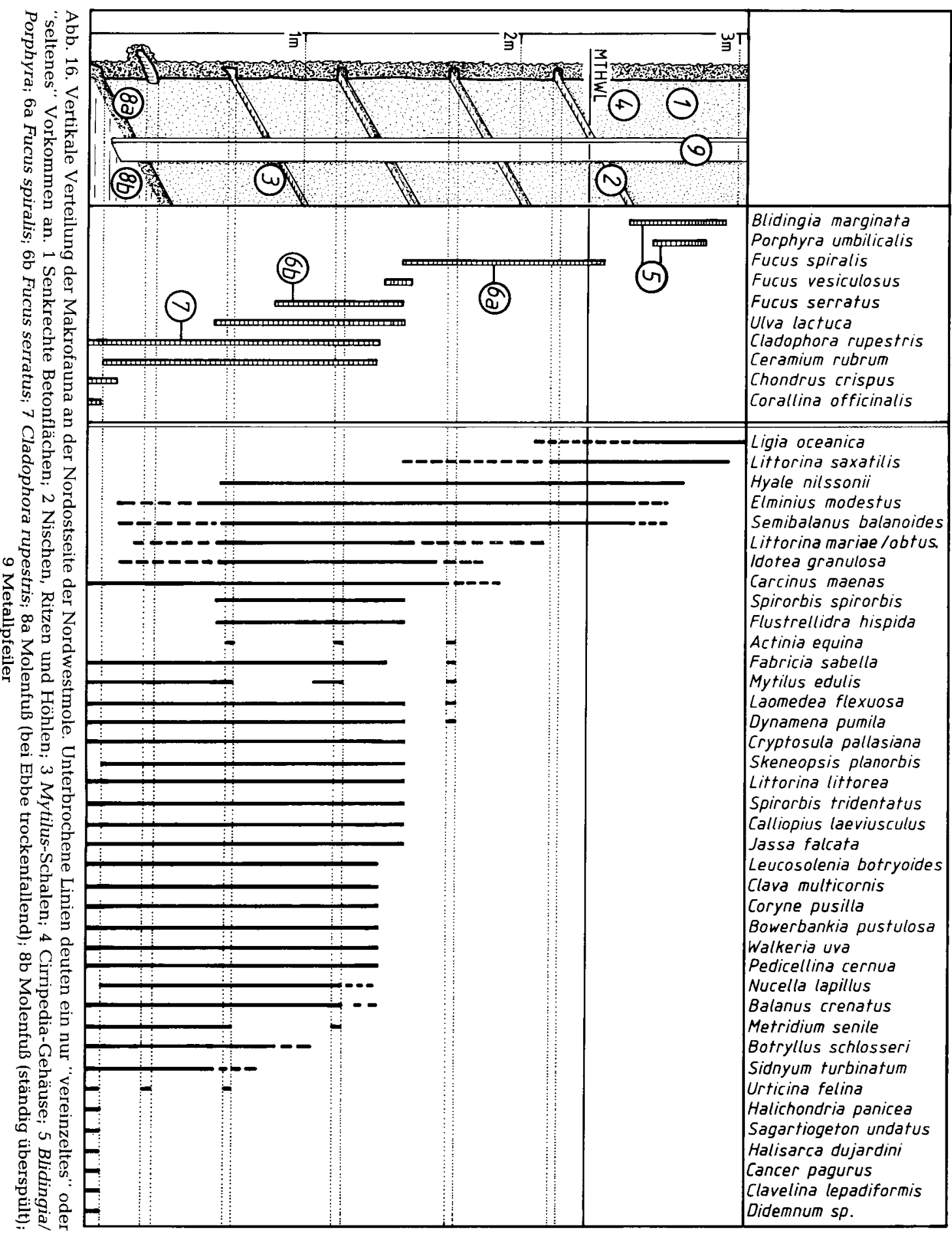


Tab, 12. Zeitliche und räumliche Verteilung der Makrofauna an der NE-Seite der NW-Mole. Zur Numerierung der Kleinhabitate siehe Abbildung 16

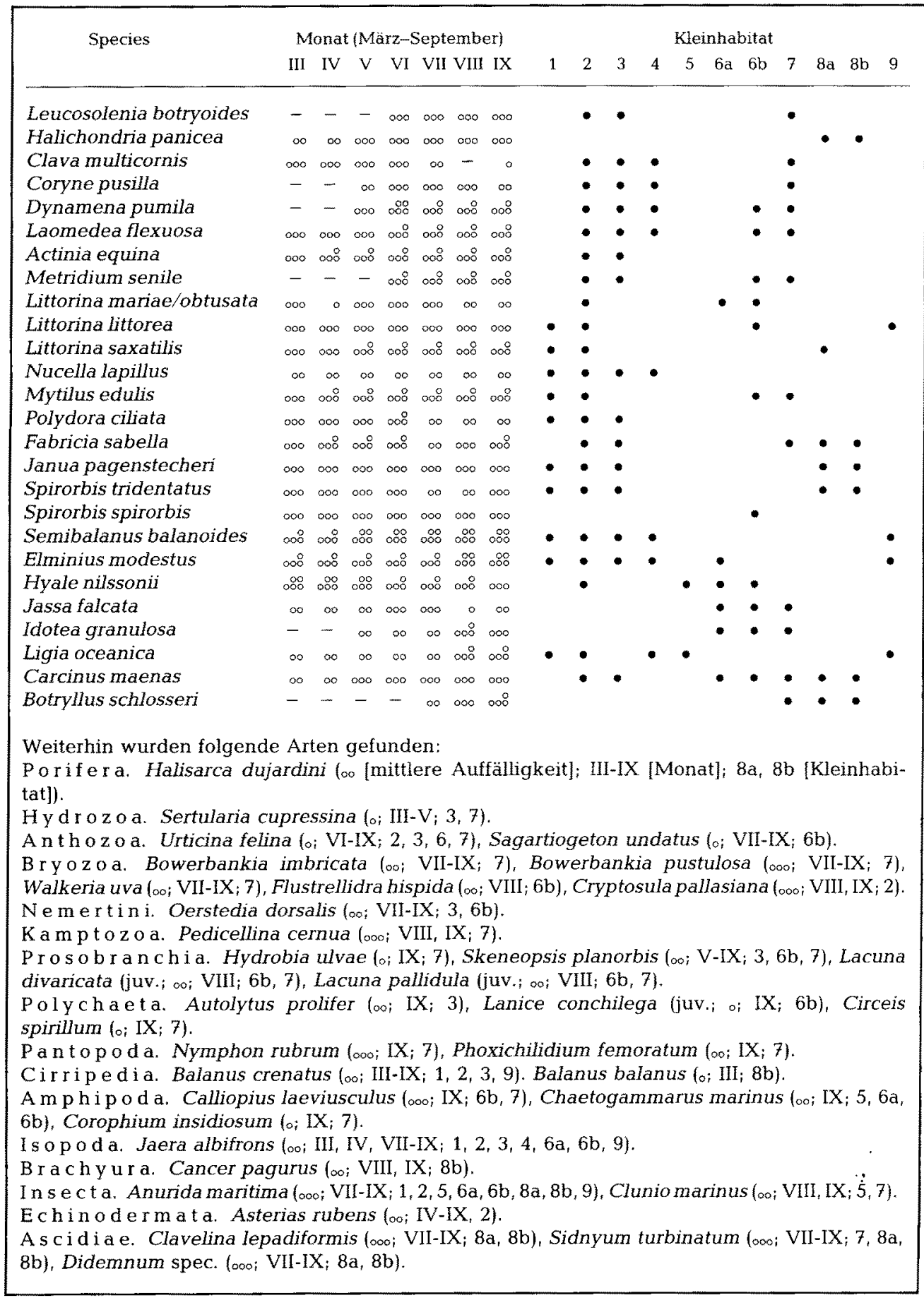


und die Polychaeta (8). "Auffällige" Arten gehörten zu den Hydrozoa, Anthozoa, Prosobranchia, Bivalvia, Polychaeta, Cirripedia, Amphipoda, Isopoda und Ascidiae.

Die Makrofauna weist eine deutliche vertikale Zonierung auf (Abb. 16). Dabei stimmten die oberen Verbreitungsgrenzen einiger Arten mit denen bestimmter Algen überein. Dies galt besonders für Fucus serratus und Cladophora rupestris (vgl. Abb. 16). Für einige Arten galt dies auch für die untere Besiedlungsgrenze bestimmter Algen (z. B. für Flustrellidra hispida und Spirorbis spirorbis auf Fucus serratus). Hier beeinflußte offensichtlich nicht nur der Wasserstand, sondern auch das Substratangebot die vertikale Verteilung. Eine ähnlich enge Substratbindung konnte auch für einige Arten auf Cladophora rupestris beobachtet werden. Diese buschig fädige Grünalge, die im Lichtund Windschatten von Fucus serratus und tiefer an der Mole siedelte, konnte während der Ebbe das Wasser zwischen den fädigen Ästen festhalten und erlaubte so kleinen sublitoralen Arten (z. B. Leucosolenia botryoides, Clava multicornis, Coryne pusilla, Bowerbankia spp., Walkeria uva, Pedicellina cernua, Skeneopsis planorbis, Phoxichilidium femoratum, Nymphon rubrum und Corophium insidiosum) das Vordringen in höhere Bereiche der Gezeitenzone. Typische Besiedler auf Fucus serratus waren die oben bereits erwähnten Arten Flustrellidra hispida und Spirorbis sprirorbis sowie Littorina mariae/obtusata, Skeneopsis planorbis und Idotea granulosa. L. mariae/obtusata und I. granulosa waren darüber hinaus auch auf Fucus spiralis verbreitet.

Nur wenige Arten besiedelten die ungeschützten Flächen oberhalb der Fucus-Zone. Lediglich Hyale nilssonii lebte auf dem Blidingia-Geflecht. Weitere typische Vertreter dieser Zone waren Littorina saxatilis und Ligia oceanica. Beide Arten blieben während der Ebbe zurückgezogen in kleinen Höhlen der porösen Oberflächen, in Ritzen und leeren Cirripedia-Gehäusen. In dieser Zone hatten Semibalanus balanoides und Elminius modestus ihre größte Besiedlungsdichte. Beide Arten hatten etwa die gleiche obere Verbreitungsgrenze. Eine deutlich vertikale Zonierung zeigten die Prosobranchia. Nach Littorina saxatilis erreichte L. mariae/obtusata als Fucus-Spezialist (Barkman, 1955; Bakker, 1959) die höchste Verbreitung bis in die mittlere Fucus spiralis-Zone. Littorina littorea und Nucella lapillus blieben in ihrer Verbreitung deutlich unter dieser Grenze und somit auf das mittlere und untere Eulitoral beschränkt.

Einige Arten konnten sich nicht an der senkrechten Wand, sondern nur in den geschützten Ritzen und Höhlen etablieren. Hierzu gehörten Actinia equina, Urticina felina, Mytilus edulis und Carcinus maenas. $M$. edulis konnte jedoch im unteren Bereich an wenigen Stellen in großen Trauben an der senkrechten Wand angeheftet beobachtet werden.

\section{Qualitative Ähnlichkeitsanalyse}

Zur Abschätzung der qualitativen Ahnlichkeit aller untersuchten Habitate untereinander eignet sich der Sørensen-Index (Braun-Blanquet, 1964). Dieser beschreibt den Prozentsatz der in zwei zu vergleichenden Proben gemeinsam verkommenden Arten: $I_{S}=\left(2 N_{A B} / N_{A}+N_{B}\right) 100$.

Es bedeuten: $N_{A}$ : Alle in Probe $A$ vorkommenden Arten, $N_{B}$ : alle in Probe $B$ vorkommenden Arten, $N_{A B}$ : alle sowohl in Probe $A$ als auch in Probe $B$ vorkommenden Arten.

Nach einem Vergleich aller Habitate untereinander wurde eine hierarchisch-agglo- 


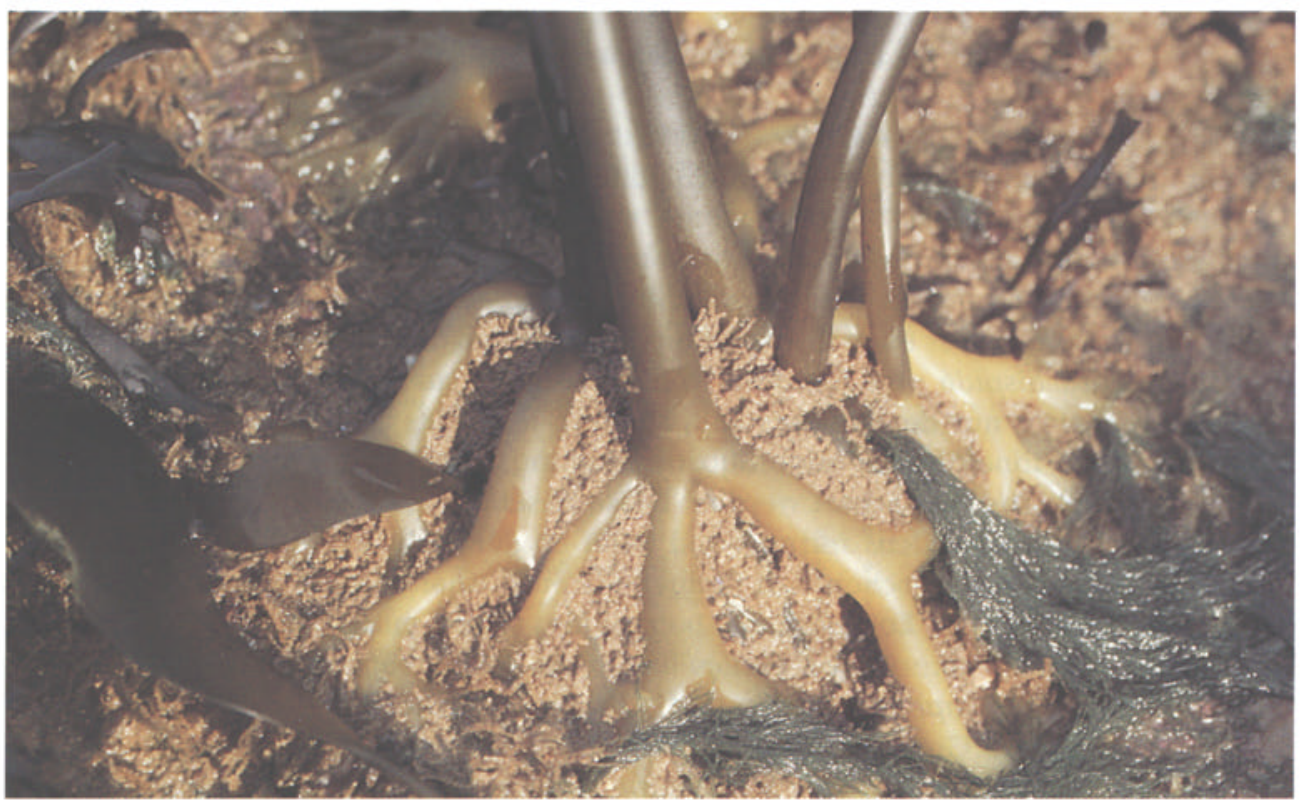

Abb. 17

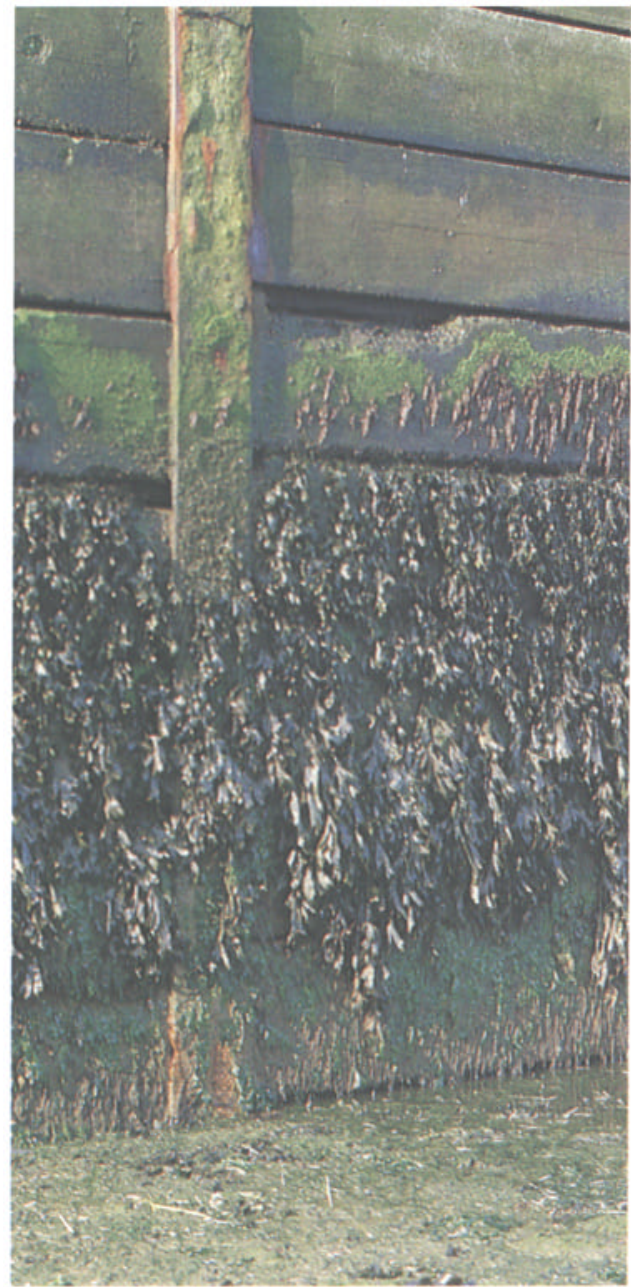

Abb. 18

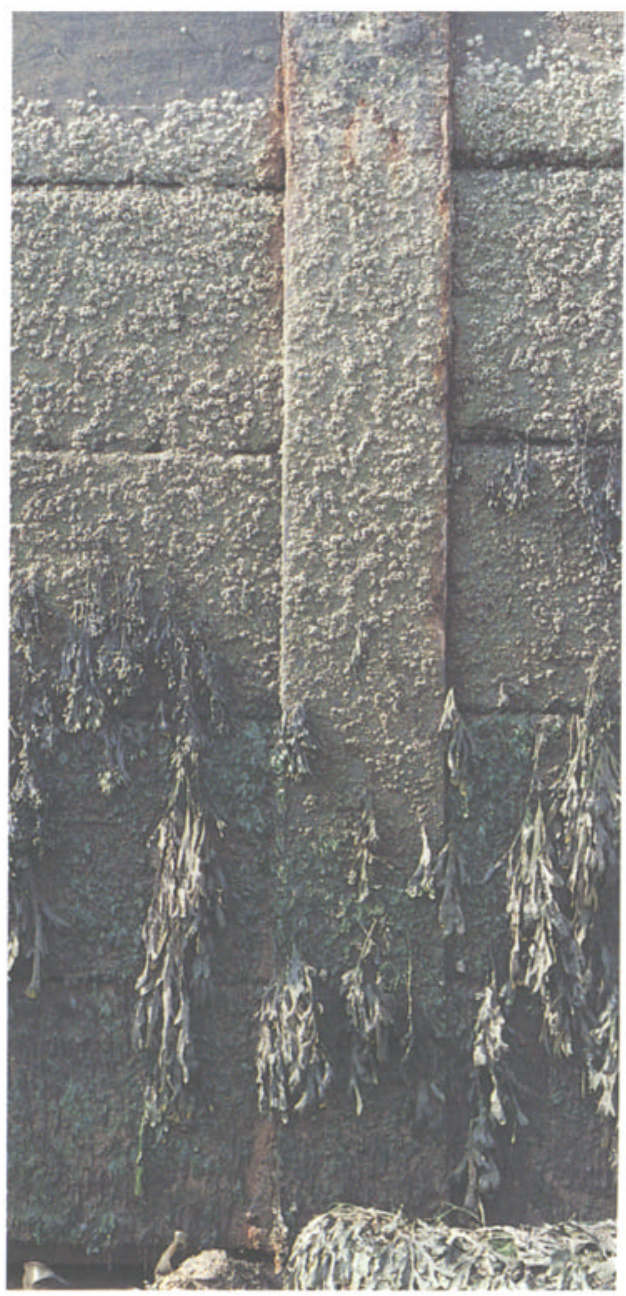

(Ab) 19 


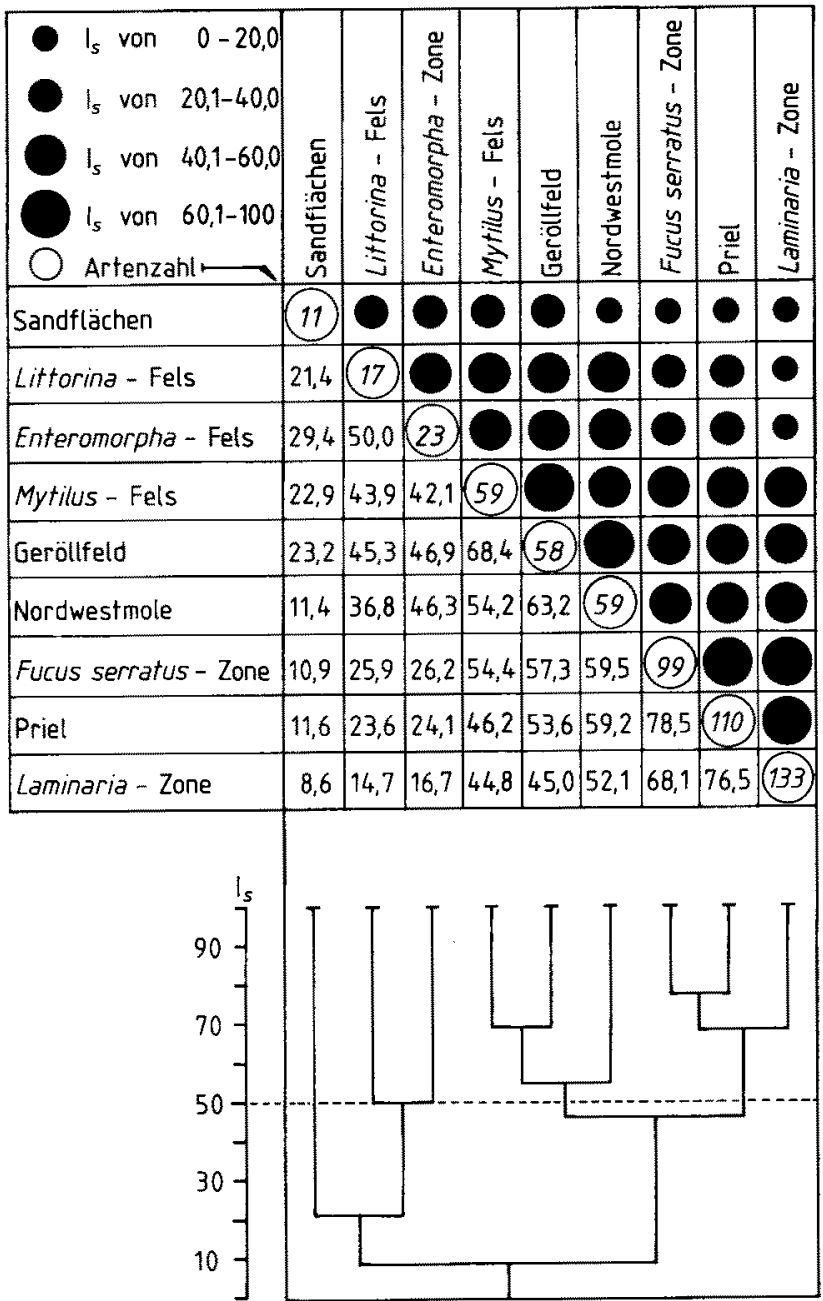

Abb. 20. Qualitative Ähnlichkeitsanalyse nach Sørensen mit angeschlossenem Linkage-Verfahren. (Nähere Erläuterungen siehe Text)

Abb. 17. Obere Laminaria-Zone. Rhizoid von Laminaria digitata. Zwischen den Wurzelkrallen erkennt man Röhrenpolster von Polydora ciliata, Fabricia sabella, Corophium insidiosum und Jassa falcata (August 1984)

Abb. 18. NO-Seite der NW-Mole. Zonierung der Makroalgen. Blidingia/Porphyra-Zone (oben); Fucus spiralis/F. serratus-Zone (Mitte); Cladophora/Ulva/Ceramium-Zone (unten; Juli 1984)

Abb. 19. NO-Seite der NW-Mole. Cirripedia-Gürtel von Semibalanus balanoides und Elminius modestus oberhalb der Fucus-Zone. Die Besiedlung durch Blidingia und Porphyra fehlt (Juli 1984) 
merative Klassifikation durchgeführt. Als Linkage-Verfahren wurde die "FurthestNeighbour"-Methode gewählt (Steinhausen \& Langer 1977). Unterhalb eines SørensenIndex von $50 \%$ erfolgte eine Gruppentrennung. Die vollständigen Ergebnisse sind in Abbildung 20 zusammengefaßt. Oberhalb des $50 \%$-Niveaus ergeben sich vier Gruppen.

Die geringste Ähnlichkeit gegenüber allen anderen Habitaten weisen die Sandflächen auf. Die gänzlich unterschiedlichen Substratverhältnisse können diesen Umstand leicht erklären. Die zweite Gruppe setzt sich aus der Enteromorpha-Zone und dem Littorina-Fels zusammen. Allerdings liegt ihre Ähnlichkeit genau auf der Gruppentrennungsgrenze.

Deutlich abgegrenzt ist die dritte Gruppe. Sie besteht aus den Geröllfeldern, dem Mytilus-Fels und der Nordostseite der Nordwestmole. Alle drei Probenorte zeichnen sich durch ihre stark anthropogen beeinflußte Morphologie aus.

Die vierte Gruppe wird von der Fucus serratus-Zone, den Prielen und der Laminaria-Zone gebildet. Der gemeinsame hohe Anteil der sublitoralen Fauna am Gesamtartenbestand beeinflußt die großen Ähnlichkeiten dieser Habitate untereinander (Abb. 21, 22).

\section{DISKUSSION}

Die vertikale Verteilung der Makrofauna im Nordost-Felswatt von Helgoland: Abrasionsterrasse und Nordostseite der Nordwestmole im Vergleich

Die dargestellten Ergebnisse (Abb. 15, 16) weisen sowohl die flach abfallende Abrasionsterrasse als auch die steile Nordostseite der Nordwestmole als biologisch zonierte Lebensräume im Eulitoral aus. Gemeinsame Merkmale und Unterschiede sollen im folgenden diskutiert werden.

Flora: Der Algenbewuchs weist in beiden Habitaten eine deutliche vertikale Zonierung auf. Der im oberen Eulitoral der Abrasionsterrasse angesiedelte Enteromorpha-Rasen fällt an der Mole aus. Statt dessen wächst hier Blidingia minima. In beiden Habitaten siedelt zudem Porphyra umbilicalis. Im mittleren Eulitoral fallen auf der Abrasionsterrasse die schmalen Gürtel von Fucus spiralis und $F$. vesiculosus kaum auf. Ihnen folgt zum unteren Eulitoral eine ausgeprägte $F$. serratus-Zone. An der Mole ist der Bewuchs durch $F$. spiralis dagegen erheblich stärker ausgeprägt. Die Bestände sind fast so groß wie die von $F$. serratus. In beiden Habitaten ist $F$. serratus von einem regelmäßigen Unterwuchs durch Cladophora rupestris begleitet. Dieser nimmt an der Mole den gesamten unteren Bereich ein. Es fehlen an der Mole dagegen Chondrus crispus, Corallina officinalis und die krustenbildenden Rotalgen in der Fucus-Zone. Sie sind erst unmittelbar am Molenfuß angesiedelt. Eine ausgeprägte Laminaria-Zone fehlt in dem höher gelegenen Bereich der Mole. Sie ist erst in den seewärts tiefer gelegenen Abschnitten ausgebildet.

Fauna: Auch die Fauna weist in beiden Habitaten eine deutliche vertikale Zonierung auf. Der Artenbestand der Mole (59 Arten) ist jedoch gegenüber dem auf der Abrasionsterrasse (168) stark reduziert. Für dieses Phänomen gibt es mehrere Gründe. Die Besiedlungsflächen und die Algenbestände der Abrasionsterrasse sind erheblich größer und differenzierter gestaltet. Sie bieten eine größere Anzahl von geschützten Kleinhabitaten. Auch eine Infauna scheint an der Mole mit Ausnahme von Polydora 
ciliata nicht zu existieren. Auf der Abrasionsterrasse bleiben bei Niedrigwasser Priele, Pfützen und Gezeitentümpel zurück, die es auch im Sublitoral verbreiteten Arten ermöglichen, in die Gezeitenzone vorzudringen. An der senkrechten Wand der Mole kann dagegen nur wenig Wasser während der Zeit des Trockenfallens zurückgehalten werden. Nicht zuletzt erschwert auch die hohe senkrechte Wand eine Besiedlung durch relativ große Arten. Diese können sich nur unzureichend dauerhaft festhalten. So besiedeln z. B. Mytilus edulis und Carcinus maenas vornehmlich die geschützten Ritzen. Unter den größeren vagilen Formen können lediglich Littorina littorea und Nucella

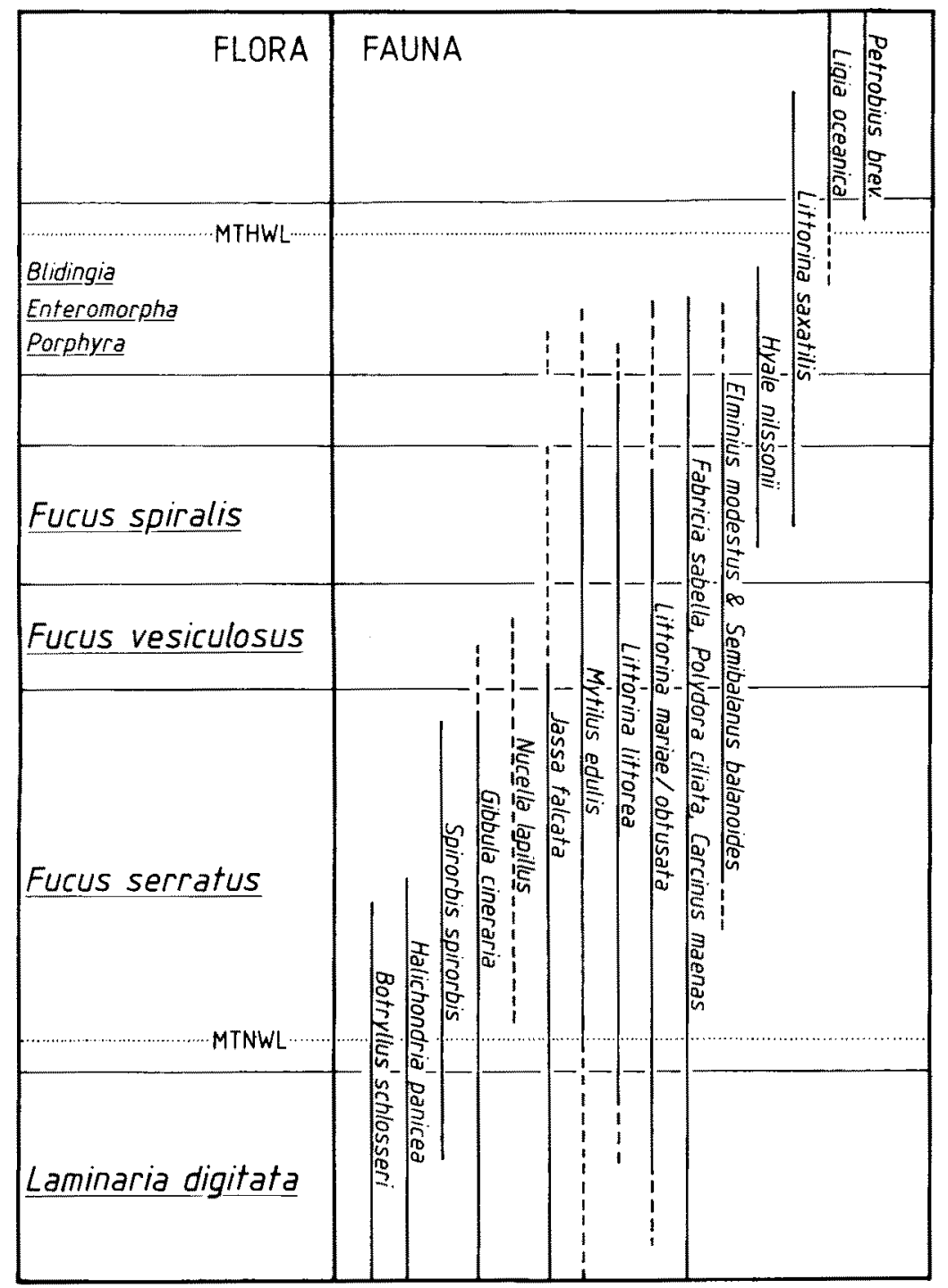

Abb. 21. Vertikale Zonierung der Makrofauna im Helgoländer Felslitoral. Unterbrochene Linien deuten ein nur "vereinzeltes" oder "seltenes" Vorkommen an 
lapillus die senkrechte Wand besiedeln. Für Ligia oceanica bietet nur die Mole mit ihren in der Spritzwasserzone gelegenen Ritzen innerhalb des Untersuchungsgebietes einen geeigneten Lebensraum. Dieser Isopode ist auch von Großbritannien (Crisp \& Southward, 1958; Evans, 1957; Lewis, 1964), den französischen Kanalküsten (Evans, 1957) und Norwegen (Brattegard, 1966) als den Helgoland nächstgelegenen Felsküsten bekannt. Dafür fehlt an der Mole Petrobius brevistylis. Dieser Felsenspringer ist nach Larink (1968) im oberen Bereich der Abrasionsterrasse und dort besonders in den Schutthängen anzutreffen. Einige von diesen sind jedoch mittlerweile von der See abgetragen worden. Abbildung 21 faßt die vertikale Verteilung zumeist "auffälliger" Arten auf der Abrasionsterrasse und/oder der Nordwestmole zusammen. Diese vereinfachte Darstellung bietet im folgenden die Grundlage für eine Expositionsanalyse und einen Vergleich mit der Besiedlungsstruktur an anderen Felsküsten.

\section{Exposition und Besiedlungsstruktur}

Die Exposition durch Wellenschlag hat große Bedeutung für die Makrofauna und den Algenbewuchs in der Gezeitenzone (Ballantine, 1961; Lewis, 1964; Dalby et al., 1978). Das Auftreten und die Anordnung bestimmter Besiedlungsstrukturen geben wichtige Hinweise auf den Grad der Exposition. Ballantine (1961) hat 8 verschiedene Expositionstypen vorgeschlagen, die von "extremely exposed" (extrem exponiert) bis "extremely sheltered" (extrem geschützt) reichen. Sie sind ursprünglich für sonnig gelegene und mit einer Neigung von 20 bis $50^{\circ}$ abfallende Felshänge der britischen Küsten definiert worden.

Das Helgoländer Nordost-Felswatt kann keiner dieser 8 aufgeführten Expositionstypen in allen aufgeführten Merkmalen zugeordnet werden. Einige in der Skala aufgeführte Leitformen der britischen Küsten fehlen auf Helgoland und können deshalb nicht berücksichtigt werden. Die für das Helgoländer Nordost-Felswatt typischen Merkmale sind den Kategorien 6 ("sheltered"), 7 ("very sheltered") und 8 ("extremely sheltered") zuzuordnen.

Charakteristisches Merkmal für Expositionsgrad 6 ist: (a) der große im oberen Sublitoral siedelnde Laminaria digitata-Bestand. Charakteristische Merkmale für den Expositionsgrad 7 sind: (b) die kleinen Bestände von Fucus spiralis und F. vesiculosus gegenüber F. serratus; (c) die regelmäßigen Corallina-Bestände in der unteren FucusZone; (d) das Fehlen von Littorina neritoides; (e) das häufige Auftreten von Gibbula cineraria; (f) die großen Mytilus-Bestände im mittleren Eulitoral. Charakteristische Merkmale für den Expositionsgrad 8 sind: (g) das seltene Auftreten von Nucella lapillus; (h) das reichliche Vorkommen von Littorina littorea und Littorina mariae/obtusata.

Das Auftreten der Merkmale (a), (g) und (h) kann bei näherer Kenntnis über das Untersuchungsgebiet erklärt werden. So liegen die Laminaria-Bestände nur teilweise im Schutz der Mole, da diese auf etwa $2 / 3$ der Länge eine große Lücke aufweist. Bei aufund ablaufendem Wasser entstehen an dieser Stelle starke Strömungen. Zudem fehlt der Schutz gegen eine starke Dünung von Nordwest. In dem weiter südöstlich gelegeneren Teil der Abrasionsterrasse überwiegt die an Küsten mit Expositionsgrad 7 typische Art Laminaria saccharina. Das seltene Auftreten von Nucella lapillus hat seine Ursache möglicherweise in dem ständigen Absammeln durch Studentenkurse. Die Reproduktionsrate dieser als Sammelobjekt beliebten Schnecke ist gering. Eine Rekrutierung von 
außen her ist aufgrund der direkten Entwicklung nicht möglich Im stärker exponiert gelegenen Westwatt (Abb. 1), das nur selten von Studentenkursen aufgesucht wird, ist die Schnecke häufiger anzutreffen. Das reichliche Vorkommen von Littorina littorea kann nicht nur durch die geringe Exposition, sondern möglicherweise auch durch das Fehlen wichtiger Nahrungskonkurrenten erklärt werden. So fehlen auf Helgoland Patella spp., Monodonta lineata und Gibbula umbilicalis.

Berücksichtigt man die o.g. Einwände, so weist die Besiedlungsstruktur das Nordost-Felswatt nach Ballantines Skala (1961) als "very sheltered" (sehr geschützt) aus. Zusätzliche Bestätigung findet dieser Befund durch die reichhaltigen Bestände von Enteromorpha spp., Cladophora rupestris und Chondrus crispus (Lewis, 1964).

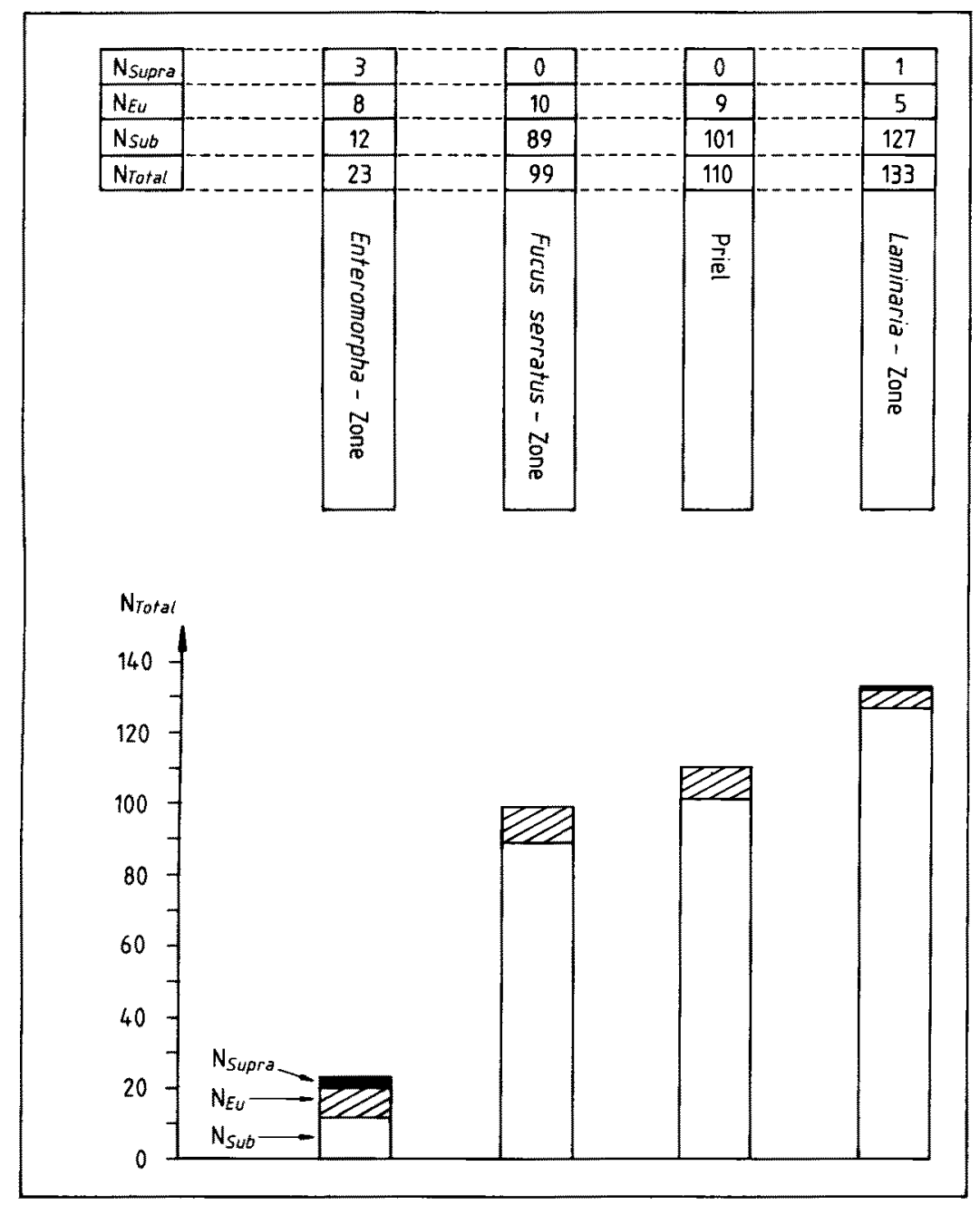

Abb. 22. Verteilung des Artenspektrums auf der Abrasionsterrasse. $\mathrm{N}_{\text {Supra }}$ : typische supralitorale Arten (max. 3), $N_{\mathrm{Eu}}$ : typische eulitorale Arten (16), $N_{\text {Sub }}$ : typische sublitorale Arten (153) 
Die geringe Exposition des Untersuchungsgebietes und der daraus resultierende dichte Algenbewuchs bewirken, daß viele überwiegend sublitorale Formen in die Gezeitenzone einwandern können. Die Fauna wird im mittleren und unteren Eulitoral durch eine verarmte sublitorale Lebensgemeinschaft geprägt (Abb. 21, 22). Überwiegend eulitoral verbreitete Arten spielen im Gesamtartenspektrum nur eine untergeordnete Rolle. Uberwiegend eulitorale Verbreitung finden Actinia equina, Flustrellidra hispida, Littorina mariae/obtusata, L. littorea, L. saxatilis, Nucella lapillus, Mytilus edulis, Microphthalmus sczelkowii, Scolelepis squamata, Ophryotrocha gracilis, Spirorbis spirorbis, Semibalanus balanoides, Elminius modestus, Chaetogammarus marinus, Hyale nilssonii und Ligia oceanica. Aus dem terrestrischen Bereich wandern zumindest zeitweise Petrobius brevistylis, Anurida maritima und Clunio marinus in die Gezeitenzone ein.

Die zum oberen Eulitoral weiter abnehmende Artenzahl dürfte sich auch in der darüberliegenden, auf Helgoland nur sehr schwach ausgebildeten, Flechtenzone ("black zone") nicht entscheidend verändern (Kronberg, 1983). Erst der mittlere und obere Bereich der Felswand dürfte von einem Formenkreis terrestrischer Arten besiedelt sein.

\section{Vergleich zwischen der Besiedlungsstruktur im Nordost-Felswatt von Helgoland und der an geschützt gelegenen britischen Felsküsten}

Die vertikale Zonierung der eulitoralen Fauna und Flora ist für die britischen Küsten bereits ausführlich beschrieben worden (Lewis, 1964; Little \& Smith, 1980). Lewis (1964) unterscheidet für Großbritannien 3 charakteristische Besiedlungsformen im Eulitoral borealer Felsküsten und zwar (1) von Seepocken, (2) von Muscheln und (3) von Fucaceen dominierte Küstenabschnitte. Das Helgoländer Nordost-Felswatt gehört der 3. Besiedlungsform an. Ein Vergleich mit der Zonierung bei Scullomie, Sutherland (vgl. Lewis, 1964; p. 118), zeigt sowohl im Artenspektrum als auch in der Verteilung große Ahnlichkeit mit den Helgoländern Verhältnissen. Es fehlen auf Helgoland lusitanische Formen wie z.B. Patella vulgata, Monodonta lineata, Gibbula umbilicalis und Littorina neritoides. Von $L$. neritoides und $P$. vulgata sind allerdings wenige Funde auch von Helgoland bekannt geworden (Ziegelmeier, 1966). Bemerkenswert ist bei Scullomie die im Vergleich zu Helgoland geringere Besiedlungsdichte von Littorina littorea. Das Besiedlungsmuster ist im wesentlichen jedoch vergleichbar. Das trifft z. B. auf die vertikale Verteilung von Gibbula cineraria, Nucella (= Thais) lapillus und Littorina obtusata zu.

An der Stelle von Enteromorpha spp. siedelt in Scullomie Pelvetia canaliculata. Auf Helgoland fehlen weiterhin Laurencia sp., Himanthalia elongata, Gigartina sp. und Palmaria palmata (= Rhodymenia $p$.).

Anders stellt sich die Besiedlungsstruktur an der flach abfallenden Küste von Bantham Bay, South Devon, dar (vgl. Lewis, 1964; p. 127). Hier verhindert die Abrasion im oberen Eulitoral die Ausbildung einer dichten Grünalgenzone (Lewis, 1964). Die typische Schnecke der oberen Gezeitenzone ist Littorina saxatilis. Darunter schließt sich ein schwach ausgebildeter Gürtel mit Fucus spiralis an. Er wird bevorzugt von Patella vulgata, Monodonta lineata, Littorina littorea und Chthamalus sp. besiedelt. Es folgt ein kräftig ausgebildeter Saum von Ascophyllum nodosum, in dessen Höhe Patella vulgata, 
Gibbula cineraria, Nucella lapillus und Littorina obtusata vorkommen. Unterhalb dieses Bereiches folgt ein breiter Gürtel von Fucus serratus. Hier siedeln überwiegend Patella vulgata, Littorina obtusata und Gibbula cineraria. Bemerkenswert ist der für viele britische Küstenabschnitte typische Gürtel von Ascophyllum nodosum. Auf Helgoland fehlt er in dieser bedeutenden Ausprägung. Lediglich einige Molenwände werden von kleineren Beständen besiedelt (Kornmann \& Sahling, 1977; Lüning, 1985).

Vergleichende Untersuchungen zur Besiedlung von geschützt gelegenen Felsküsten gestalten sich problematisch. Nach Lewis (1964) unterliegen gerade die von Fucaceen dominierten Küstenabschnitte einer großen Variationsbreite. Die Bearbeitung der Lebensgemeinschaften in solchen Gebieten ist deshalb so schwierig, weil schon kleinere Veränderungen des Untergrundes eine weitgehende Auflösung der Zonierung zur Folge haben können. Diese Beobachtung kann für das Helgoländer Nordost-Felswatt bestätigt werden. Im Bereich der unregelmäßig strukturierten Geröllfelder wird z. B. die Zonierung der Fucaceen und Littorinen völlig aufgehoben. Eine Kausalanalyse der beobachteten regionalen Unterschiede ist aus diesen Gründen bisher kaum möglich, zumal erst langjährige Untersuchungen ein Gebiet und seine "typische" Besiedlung wirklich charakterisieren können. Solche stehen für Helgoland bisher aus.

Danksagungen. Ich danke Herrn Prof. Dr. O. Kinne und Herm Prof. Dr. H.-P. Bulnheim für die Bereitstellung eines Arbeitsplatzes an der Biologischen Anstalt Helgoland (Meeresstation). Für die herzliche Gastfreundschaft und die unermüdliche Hilfe bei den vielen kleinen und großen Problemen danke ich den Mitarbeitern der "Arbeitsgruppe Gastforschung" S. Mielke, K. Boysen und G. Tadday. Herrn K. Treutner und Herrn. P. Mangelsdorf verdanke ich unveröffentlichte ozeanographische Daten. Bei der Bestimmung einzelner Algen und Tierarten halfen mir freundlicherweise Herr Dr. H.-J. Andres, Frau Dr. habil. Hartmann-Schröder, Herr Dr. habil. D. Jebram, Herr A. Krüß, Herr Prof. Dr. O. Larink, Frau Dr. K. Riemann-Zürneck, Herr P.-H. Sahling, Herr M. Schweimanns und Herr Dr. E. Ziegelmeier. Herr Dr. M. Meyer stellte für die Cluster-Analyse bereitwillig Programm und Rechensystem zur Verfügung. Mein besonderer Dank aber gilt Herm Dr. K. Anger und Herrn Prof. Dr. W. Noodt für die Anregung zum Thema, das stetige Interesse am Fortgang der Arbeit und die konstruktive Kritik.

\section{LITERATUR}

Allen, J. A, 1960. On the biology of CIangon allmanni Kinahan in the Northumberland waters. J. mar. biol. Ass. U.K. 39, 481-508.

Anger, K., 1978. Development of a subtidal epifaunal community at the island of Helgoland. Helgoländer wiss. Meeresunters. 31, 457-470.

Attems, C., 1896. Beiträge zur Meeresfauna von Helgoland. VI. Beitrag zur Kenntnis der rhabdocoelen Turbellarien Helgolands. - Wiss. Meeresunters. (Helgoland) 2, 219-232.

Bakker, K., 1959. Feeding habits and zonation of some intertidal snails. - Archs néerl. Zool. 13, $230-257$.

Ballantine, W. J., 1961. A biologically defined exposure scale for the comparative description of rocky shores. - Fld Stud. 1 (3), 1-19.

Barkman, J, J, 1955. On the distribution and ecology of Littorina obtusata and its subspecific units. - Archs néerl. Zool. 11, 22-86.

Boaden, P. J. S., O'Connor, R. J. \& Seed, R., 1975. The composition and zonation of a Fucus serratus community in Strangford Lough, Co. Down. - J. exp. mar. Biol. Ecol. 17, 111-136.

Brattegard, T., 1966. The natural history of the Hardangerfjord. 7. Horizontal distribution of the fauna of rocky shores. - Sarsia $22,1-54$.

Braun-Blanquet, J., 1964. Pflanzensoziologie. Springer, Wien, $865 \mathrm{pp}$.

Caspers, H., 1938. Die Bodenfauna der Helgoländer Tiefen Rinne. - Helgoländer wiss. Meeresunters. 2, 1-112. 
Caspers, H., 1950. Die Lebensgemeinschaft der Helgoländer Austernbank. - Helgoländer wiss. Meeresunters. 3, 120-169.

Caspers, H., 1952. Der tierische Bewuchs an Helgoländer Seetonnen. - Helgoländer wiss. Meeresunters. 4, 138-160.

Colman, J., 1933. The nature of the intertidal zonation of plants and animals. - J. mar. biol. Ass. U.K. $18,435-476$.

Colman, J, 1940. On the fauna inhabiting intertidal seaweeds. - J. mar. biol. Ass. U.K. 24, 129-183.

Connell, J. H., 1961. Effects of competition, predation by Thais lapillus, and other factors on natural populations of the barnacle Balanus balanoides. - Ecol. Monogr. 31, 61-104.

Connell, J. H., 1972. Community interactions on marine rocky intertidal shores. - A. Rev. Ecol. Syst. $3,169-192$.

Crisp, D. J. \& Southward, A. J., 1958. The distribution of intertidal organisms along the coasts of the English Channel. - J. mar. biol. Ass. U.K. 37, 157-208.

Cubit, J. D., 1984. Herbivory and seasonal abundance of algae on a high intertidal rocky shore. Ecology 65, 1904-1917.

Dalby, D. H., Cowell, E. B., Syratt, W. J. \& Crothers, J. H., 1978. An exposure scale for marine shores in western Norway. - J. mar. biol. Ass. U.K. 58, 975-996.

Dalla-Torre, K. W. von, 1889. Die Fauna von Helgoland, - Zool. Jb. (Syst. Ókol. Geogr. Tiere) 4 (Suppl.), 1-99.

Dörjes, J., 1968. Zur Ókologie der Acoela (Turbellaria) in der Deutschen Bucht. - Helgoländer wiss. Meeresunters. 18, 78-115.

Ehrenbaum, E., 1896. Beiträge zur Meeresfauna von Helgoland. VIII. Die Cumaceen und Schizopoden von Helgoland nebst neueren Beoabachtungen über Vorkommen in der Deutschen Bucht und in der Nordsee. - Wiss. Meeresunters. (Helgoland) 2, 403-435.

Evans, R. G., 1947a. The intertidal ecology of Cardigan Bay. - J. Ecol. 34, 273-309.

Evans, R. G, 1947b. The intertidal ecology of selected localities in the Plymouth neighbourhood.J. mar. biol. Ass. U.K. 27, 173-219.

Evans, R. G., 1949. The intertidal ecology of rocky shores in South Pembrokeshire. - J. Ecol. 37, 120-139.

Evans, R. G., 1957. The intertidal ecology of some localities on the Atlantic coast of France. - J. Ecol. $45,245-271$.

Fretter, $V_{.}$1980. Observations of the gross anatomy of the female genital duct of British Littorina spp. - J. moll. Stud. 46, 148-153.

Fretter, V. \& Graham, A., 1978. The prosobranch molluscs of Britain and Denmark. Part 4. Marine Rissoacea. - J. moll. Stud. (Suppl) 6, 152-241.

Gallardo, C. S. \& Götting, K. J., 1985. Reproduktionsbiologische Untersuchungen an drei LittorinaArten der südlichen Nordsee. - Helgoländer Meeresunters, 39, 165-186.

Gillandt, L., 1979a. Zur Ókologie der Polychaeten des Helgoländer Felslitorals. - Helgoländer wiss. Meeresunters. 32, 1-35.

Gillandt, L., 1979b. Zur Systematik, Biologie und Autökologie der Polychaeten des Helgoländer Felslitorals. - Mitt. hamb. zool. Mus. Inst. 76, 19-73.

Goodwin, B. J. \& Fish, J. D., 1977. Inter- and intraspecific variation in Littorina obtusata and $L$. mariae (Gastropoda). - J. moll. Stud. 43, 241-254.

Gruner, H. E., 1965. Krebstiere oder Crustacea. 5. Isopoda. - Tierw. Dtl. 51, 1-380.

Hagerman, L., 1966. The macro- and microfauna associated with Fucus serratus L. with some ecological remarks. - Ophelia 3, 1-42.

Hagmeier, A., 1930. Die Besiedlung des Felsstrandes und der Klippen von Helgoland. Teil 1. Der Lebensraum. - Wiss. Meeresunters. (Helgoland) 15 (18a), 1-35.

Hannaford-Ellis, C., 1979. Morphology of the oviparous rough winkle Littorina arcana (HannafordEllis, 1978) with notes on the taxonomy of the Littorina saxatilis species complex. - J. Conch. 30 , $43-56$.

Harms, J. \& Anger, K. 1983. Seasonal, annual, and spatial variation in the development of hard bottom communities. - Helgoländer Meeresunters. 36, 137-150.

Hartlaub, C., 1896. Beiträge zur Meeresfauna von Helgoland. IV. Die Coelenteraten Helgolands. Wiss. Meeresunters. (Helgoland) 2, 161-206. 
Hartmeyer, R., 1908. Beiträge zur Meeresfauna von Helgoland. XIV. Die Ascidien von Helgoland. Wiss. Meeresunters. (Helgoland) 8, 117-127.

Hawkins, S. J. \& Hartnoll, R. G., 1983. Grazing of intertidal algae by marine invertebrates. Oceanogr. mar. Biol, 21, 195-282.

Heincke, F., 1894a. Beiträge zur Meeresfauna von Helgoland. I. Die Fische Helgolands. - Wiss. Meeresunters. (Helgoland) 1, 99-120.

Heincke, F., 1894b. Beiträge zur Meeresfauna von Helgoland. II. Die Mollusken Helgolands. Wiss. Meeresunters. (Helgoland) 1, 121-153.

Heincke, F., 1896. Beiträge zur Meeresfauna von Helgoland. VIl. Nachträge zur Fisch- und Molluskenfauna Helgolands. I. - Wiss. Meeresunters. (Helgoland) 2, 233-252.

Heller, J., 1975. The taxonomy of some British Littorina species with notes on their reproduction (Mollusca: Prosobranchia). - Zool. J. Linn. Soc. 56, 131-151.

Hillmer, G., Spaeth, Chr. \& Weitschat, W., 1979. Helgoland - Portrait einer Felseninsel. (Führer zur Helgoland-Ausstellung des Geol.-Paläont. Inst. der Univ. Hamburg). Rasch, Bramsche, 40 pp.

Jackson, J. B. C., 1977 a. Habitat area, colonization, and development of epibenthic community structure. In: Biology of benthic organisms. Ed. by B. F. Keegan, P.O. Ceidigh \& J. P. S. Boaden. Pergamon Press, Oxford, 349-358.

Jackson, J. B. C., 1977b. Competition on hard marine substrata: the adaptive significance of solitary and colonial strategies. - Am. Nat. 111, 743-767.

Kornmann, P. \& Sahling, P.-H., 1977. Meeresalgen von Helgoland. - Helgoländer wiss. Meeresunters. 29, 1-289.

Kronberg, I., 1983. Ókologie der schwarzen Zone im marinen Felslitoral. Diss., Univ. Kiel, 238 pp.

Krumbein, W. E., 1975. Verwitterung, Abtragung und Küstenschutz auf der Insel Helgoland. - Abh. Verh. naturwiss. Ver. Hamburg 18-19, 5-31.

Krumbein, W. E., 1977. Zur Frage der Verwitterung der Felsmasse der Insel Helgoland. - Abh. Verh. naturwiss. Ver. Hamburg 20, 5-11.

Larink, O., 1968. Zur Ókologie des küstenbewohnenden Machiliden Petrobius brevistylis (Thysanura, Insecta), - Helgoländer wiss. Meeresunters. 18, 124-129.

Lauterborn, R., 1894. Beiträge zur Meeresfauna von Helgoland. V. Die pelagischen Protozoen und Rotatorien Helgolands. - Wiss. Meeresunters. (Helgoland) 1, 207-213.

Lein, T. E., 1980. The effects of Littorina littorea (Gastropoda) on littoral green algae in the inner Oslofjord, Norway. - Sarsia 65, 87-92.

Lein, T. E., 1984. A method for experimental exclusion of Littorina littorea (L.) (Gastropoda) and the establishment of fucoid germlings in the field. - Sarsia 69, 83-85.

Lewis, J. R., 1964. The ecology of rocky shores. English Univ. Press, London, $323 \mathrm{pp}$.

Little, C. \& Smith, L. P., 1980. Vertical zonation on rocky shores in the Severn estuary. - Estuar. coast. mar. Sci. 11, 651-669.

Lubchenco, J., 1980. Algae zonation in the New England rocky intertidal community: an experimental analysis. - Ecology 61, 333-344.

Lubchenco, J., 1982. Effects of grazers and algal competition on fucoid colonization in tidepools. $-J$. Phycol. 18, 544-550.

Lubchenco, J. \& Menge, B. A., 1978. Community development and persistance in a low rocky intertidal zone. - Ecol. Monogr. 48, 67-94.

Lüning, K., 1970. Tauchuntersuchungen zur Vertikalverteilung der sublitoralen Helgoländer Algenvegetation. - Helgoländer wiss. Meeresunters. 21, 271-291.

Lüning, K., 1985. Meeresbotanik. Thieme, Stuttgart, 375 pp.

Luther, G., 1976a. Bewuchsuntersuchungen auf Natursteinsubstraten im Gezeitenbereich des Nordsylter Wattenmeeres. - Helgoländer wiss. Meeresunters. 28, 145-166.

Luther, G., 1976b. Bewuchsuntersuchungen auf Natursteinsubstraten im Gezeitenbereich des Nordsylter Wattenmeeres: Algen. - Helgoländer wiss. Meeresunters, 28, 318-351.

Luther, G., 1977. Bewuchsuntersuchungen auf Natursteinsubstraten im Gezeitenbereich des Nordsylter Wattenmeeres: sessile und hemisessile Tiere. - Helgoländer wiss. Meeresunters. 29, 375-403.

Markham, J. W. \& Munda, I. M., 1980. Algal recolonization in the rocky eulittoral of Helgoland. Aquat. Bot. 9, 33-71. 
Menge, B. A., 1976. Organisation of the New England rocky intertidal community: role of predation, competition, and environmental heterogeneity. - Ecol. Monogr. 46, 355-393.

Menge, B. A., 1978a. Predation intensity in a rocky intertidal community. Relation between predator foraging activity and environmental harshness. - Oecologia 34, 1-16.

Menge, B. A., 1978b. Predation intensity in a rocky intertidal community. Effect of an algae canopy, wave action, and desiccation on predator feeding rates. - Oecologia 34, 17-35.

Moritz, D., 1975. Die epilithischen Populationen von Jaera albifrons und Jaera ischiosetosa (Isopoda, Asellota) aus dem Eulitoral der Deutschen Bucht und aus Brackgewässern der schleswig-holsteinischen Ostküste. Diss., Univ. Hamburg, 267 pp.

Moyse, J. \& Nelson-Smith, A., 1963. Zonation of animals and plants on rocky shores around Dale, Pembrokeshire. - Fld Stud. 1 (5), 1-31.

Munda, M. \& Markham, J. W., 1982. Seasonal variation of vegetation pattern and biomass constituents in the rocky eulittoral of Helgoland. - Helgoländer Meeresunters. 35, 131-151.

Newell, R. C., 1979. Biology of intertidal animals. Marine Ecological Surveys Ltd, Faversham, 781 pp.

Nielsen, C., 1980. On the occurrence of the prosobranchs Littorina neritoides, $L$ mariae and $L$. obtusata in Denmark. - J. moll. Stud. 46, 312-316.

Nienburg, W., 1930. Die Besiedlung des Felsstrandes und der Klippen von Helgoland. Teil 2. Die Algen. - Wiss. Meeresunters. (Helgoland) 15 (19), 1-19.

Osman, R. W., 1977. The establishment and development of a marine epifaunal community. - Ecol. Monogr. 47, 37-63.

Paine, R. T., 1974. Intertidal community structure. Experimental studies on the relationship between a dominant competitor and its principal predator. - Oecologia 15, 93-120.

Pratje, O., 1948. Die Stadien in der Entwicklung der Insel Helgoland. - Z. Erdkunde 2, 322-330.

Price, J. H., Irvine, D. E. G. \& Farnham, W. F., 1980. The shore environment. Acad. Press, London, 1, $1-321$.

Raffaelli, D., 1982. Recent ecological research of some European species of Littorina. - J. moll. Stud. $48,342-354$.

Rasmussen, E., 1973. Systematics and ecology of the Isefjord marine fauna (Denmark), - Ophelia 11, $1-495$.

Reise, K., 1977. Predator experiments in an intertidal mud flat. - Helgoländer wiss. Meeresunters. 30, 263-271.

Reise, K., 1978. Experiments on epibenthic predation in the Wadden Sea. - Helgoländer wiss. Meeresunters. 31, 55-101.

Ryland, J. S., 1962. The association between Polyzoa and algal substrata. - J. Anim. Ecol. 31, $331-338$.

Sacchi, C. F. \& Rastelli, M., 1966. Littorina mariae, nov. sp.: les différences morphologiques et écologiques entre "nains et normaux" chez l'espèce $L$. obtusata (L.) et leur signification adaptive et évolutive. - Atti Soc. ital. Sci. nat. 105, 351-369.

Schmidt-Thomé, P., 1937. Der tektonische Bau und die morphologische Gestaltung von Helgoland. - Abh. Verh. naturwiss. Ver. Hamburg 1-2, 215-249.

Seed, R. \& Boaden, P. J. S., 1977. Epifaunal ecology of intertidal algae. In: Biology of benthic organisms. Ed. by B. F. Keegan, P.O. Ceidigh \& P. J. S. Boaden. Pergamon Press, Oxford, $541-548$.

Seed, R., Elliott, M. N., Boaden, P. J. S. \& O'Connor, R. J., 1981. The composition and seasonal changes amongst the epifauna associated with Fucus serratus (L.) in Strangford Lough, Northern Ireland. - Cah. Biol. mar. 22, 243-266.

Skolowsky, A., 1900. Beiträge zur Meeresfauna von Helgoland. XI. Die Amphipoden Helgolands. Wiss. Meeresunters. (Helgoland) 4, 141-166.

Smith, J. E., 1981. The natural history and taxonomy of shell variation in the periwinkle Littorina saxatilis and Littorina rudis. - J. mar. biol. Ass. U.K. 61, 215-241.

Southward, A. J., 1958. The zonation of plants and animals on rocky sea shores. - Biol. Rev. 33, 137-177.

Steinhausen, D. \& Langer, K., 1977. Clusteranalyse. De Gruyter, Berlin, 206 pp.

Stephenson, T. A. \& Stephenson, A., 1949. The universal features of zonation between tidemarks on rocky coasts. - J. Ecol. 37, 209-305. 
Stephenson, T. A. \& Stephenson, A., 1972. Life between tidemarks on rocky shores. Freeman, San Francisco, $425 \mathrm{pp}$.

Stripp, K., 1969. Jahreszeitliche Fluktuationen von Makrofauna und Meiofauna in der Helgoländer Bucht. - Veröff. Inst. Meeresforsch. Bremerhaven 12, 65-94.

Timm, R., 1894. Beiträge zur Meeresfauna von Helgoland. III. Die Copepoden und Cladoceren Helgolands. - Wiss. Meeresunters. (Helgoland) 1, 155-159.

Weltner, W., 1896. Beiträge zur Meeresfauna von Helgoland. IX. Die Cirripedien Helgolands. Wiss. Meeresunters. (Helgoland) 2,437-447.

Wood, V. \& Seed, R., 1980. The effects of shore level on the epifaunal communities associated with Fucus serratus (L.) in the Menai Strait, North Wales. - Cah. Biol. mar. 21, 135-154.

Wurster, P., 1962. Geologisches Portrait Helgolands. - Die Natur 70, 1-56.

Ziegelmeier, E., 1957. Die Muscheln (Bivalvia) der deutschen Meeresgebiete. - Helgoländer wiss. Meeresunters. 6, 1-64.

Ziegelmeier, E., 1966. Die Schnecken (Gastropoda, Prosobranchia) der deutschen Meeresgebiete und der brackigen Küstengewässer. - Helgoländer wiss. Meeresunters. 13, 1-61. 